\title{
(Patho)physiology of the renin-angiotensin system: relationships with sodium balance
}

Citation for published version (APA):

Krekels, M. M. E. (1996). (Patho)physiology of the renin-angiotensin system: relationships with sodium balance. [Doctoral Thesis, Maastricht University]. Universiteit Maastricht. https://doi.org/10.26481/dis.19961220mk

Document status and date:

Published: 01/01/1996

DOI:

10.26481/dis.19961220mk

Document Version:

Publisher's PDF, also known as Version of record

\section{Please check the document version of this publication:}

- A submitted manuscript is the version of the article upon submission and before peer-review. There can be important differences between the submitted version and the official published version of record.

People interested in the research are advised to contact the author for the final version of the publication, or visit the DOI to the publisher's website.

- The final author version and the galley proof are versions of the publication after peer review.

- The final published version features the final layout of the paper including the volume, issue and page numbers.

Link to publication

\footnotetext{
General rights rights.

- You may freely distribute the URL identifying the publication in the public portal. please follow below link for the End User Agreement:

www.umlib.nl/taverne-license

Take down policy

If you believe that this document breaches copyright please contact us at:

repository@maastrichtuniversity.nl

providing details and we will investigate your claim.
}

Copyright and moral rights for the publications made accessible in the public portal are retained by the authors and/or other copyright owners and it is a condition of accessing publications that users recognise and abide by the legal requirements associated with these

- Users may download and print one copy of any publication from the public portal for the purpose of private study or research.

- You may not further distribute the material or use it for any profit-making activity or commercial gain

If the publication is distributed under the terms of Article $25 \mathrm{fa}$ of the Dutch Copyright Act, indicated by the "Taverne" license above, 


\section{(PATHO)PHYSIOLOGY OF THE RENIN-ANGIOTENSIN SYSTEM:}

RELATIONSHIPS WITH SODIUM BALANCE 
- Krekels, Marielle Martine Elisabeth ISBN 90-9010027-x

Printing of this thesis was made possible by financial support of Servier, AHP Pharma, Ciba and Parke Davis. 


\section{(Patho)physiology of the renin-angiotensin system: relationships with sodium balance}

\section{PROEFSCHRIFT}

ter verkrijging van de graad van doctor aan de Universiteit Maastricht, op gezag van de Rector Magnificus, Prof. Mr. M.J. Cohen, volgens het besluit van het College van Decanen, in het openbaar te verdedigen. op vrijdag 20 december 1996 om 16.00 uur

door

\section{M E Krekels}

geboren op 20 december 1967 te Den Haag 


\section{Promotores:}

Prof, dr H.F.P. Hillen

Prof. dr P.W. de Leeuw

\section{Beoordelingscommissie:}

1. Prof. dr H.A.J. Struijker Boudier, voorzitter

2. Prof. dr H.R. Brunner (Université de Lausanne, Suisse)

3. Prof. dr M.P. van Dieijen-Visser

4. Prof. dr N.K. Hollenberg (Harvard Medical School, Boston, USA)

5. Prof. dr H.H.J. Wellens 
'Gelukkig is de man wiens kennis afkomstig is wan onderzoek'

Euripides

Voor mijn ouders 


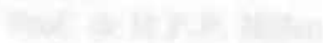

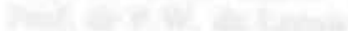

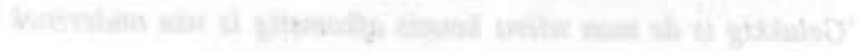

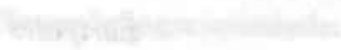

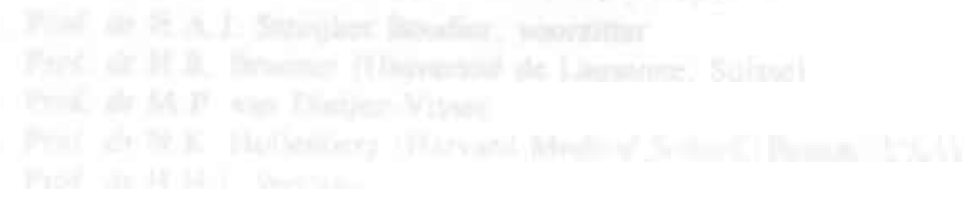




\section{Contents}

Chapter 1: General introduction 9

Chapter 2: Study 1: Heterogeneous patterns of sodium excretion during sodium restriction in essential hypertensive patients $\mathbf{1 5}$

Chapter 3: Study 2: Sodium sensitivity of blood pressure in hypertensives is not related to sodium, but rather to renin $\mathbf{2 5}$

Chapter 4: Study 3: Sodium sensitivity of blood pressure during sodium restriction is related to inadequate activation of renin during the early phase of sodium loss 35

Chapter 5: Study 4: Dissociation between the renal effects of angiotensin 1 and II in sodium-restricted normal subjects $\mathbf{5 1}$

Chapter 6: Study 5: Possible discrimination between the effects of plasmatic versus tissue angiotensin II in man 67

Chapter 7: Study 6: The role of sodium intake on the effects of plasma and tissue angiotensin II in men 87

Chapter 8: General discussion 105

Chapter 9: Summary and concluding remarks 123

Chapter 10: Samenvatting 129

Dankwoord 135 
ajmino?

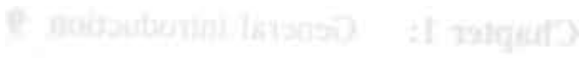

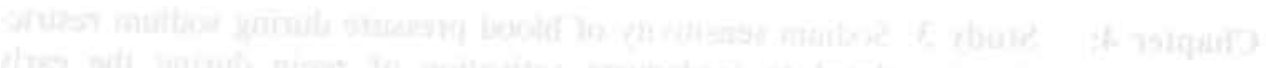

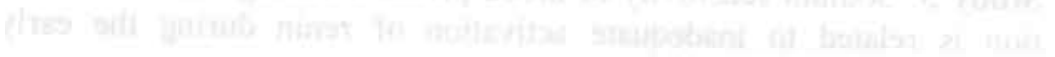

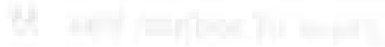




\section{Chapter 1}

\section{General introduction}




\section{General introduction}

In industrialized countries hypertension is a major risk factor for cardiovascular complications. Although the prevalence of this disorder in The Netherlands is not exactly known, it is estimated to be approximately 15 to $20 \%$. We are dealing, therefore, with a serious health problem. Over the last twenty years many largescale therapeutic trials have been performed which have clearly shown that antihypertensive treatment confers substantial benefit. The number of strokes may be reduced by as much as $40 \%$, and although the effect of treatment on cardiac sequelae is less pronounced, one may still expect a $20 \%$ reduction in coronary events $^{2}$. In absolute terms the greatest benefit of treatment may be expected in elderly patients and in those with more severe or complicated hypertension ${ }^{3}$.

In the second half of this century many antihypertensive drugs have been developed but, so far, none has proved to be the ideal agent. With any antihypertensive drug the response rate, that is the number of patients in whom blood pressure adequately falls, is somewhat in the order of 30 to $60 \%{ }^{4}$. All agents which are available today have been fairly well characterized in terms of their pharmacological properties, but the mechanisms whereby they lower pressure in the intact individual are only poorly understood, if at all. Surely, diuretics lower extracellular volume (at least initially), most beta-adrenoceptor blocking drugs lower cardiac output and renin and angiotensin converting enzyme inhibitors reduce the formation of angiotensin II. Those features, however, still provide insufficient explanation as to why they lower blood pressure. When one meticulously studies the effects of antihypertensive agents on various aspects of blood pressure control, it soon becomes clear that many of these agents act through multiple pathways. But even then it remains difficult to explain why blood pressure falls, not the least because short-term and long-term effects may differ considerably. Part of this problem may be related to uncertainty about the actions of a particular drug, but a large part may also be due to our incomplete understanding of the regulation of blood pressure. Precisely the latter was the impetus for the studies described in this thesis.

Hemodynamically speaking, blood pressure is determined by cardiac output and total peripheral vascular resistance. From a theoretical point of view, therefore, both cardiac and vascular factors could be involved in the pathogenesis of essential hypertension. However, it is now generally accepted that the prime abnormality in essential hypertension is a rise in vascular resistances. In its early phase the vasoconstriction of hypertension is to a large extent related to functional abnormalities but with time structural alterations in the vessel wall (media hypertrophy) contribute progressively to the rise in resistance ${ }^{6}$.

Which are the abnormalities that promote vasoconstriction in hypertension-prone individuals? In this respect enhanced sympathetic activity and/or activation of the 
renin-angiotensin system are likely candidates. Although multiple lines of evidence support the notion that these systems play at least some role in the pathophysiology of essential hypertension, definite proof for their primacy is still lacking. Numerous other systems have also been studied but so far the origin of high blood pressure has not been elucidated. Whatever the primary cause of hypertension may be, according to Guyton the kidney must be involved as well $7^{7}$. In his theory any rise in pressure will eventually be offset by increased natriuresis. Only when the kidney is not able to augment sodium output, blood pressure will rise by virtue of a relatively expanded volume. It is not surprising, therefore, that many investigators have directed their research efforts towards the kidney. The work described in this thesis also bears testimony of such an approach.

When it comes to the study of the kidney in hypertension, a few aspects need particular attention. These are renal hemodynamics, sodium homeostasis and regulation of the renin-angiotensin system. All three factors are involved in blood pressure control and derangements in any of these systems could, either alone or in concert, contribute to the development or maintenance of high blood pressure. Interestingly, both renal hemodynamics and renin are affected by (changes in) sodium intake. It has also long been known that a high sodium intake may lead to a rise in blood pressure. It is totally unclear, however, through which pathways this occurs. First of all, not everybody responds to a higher sodium consumption with an increase in pressure. This observation has led to the concept that there are sodium-sensitive and sodium-resistant individuals ${ }^{8}$. Secondly, hemodynamic and neurohumoral responses to alterations in sodium intake may vary widely from one individual to the other ${ }^{9,10}$. One has to bear in mind, however, that the kidney is the ultimate organ regulating sodium balance. If, for instance, sodium intake is suddenly lowered, the kidney needs to reduce sodium output in order to maintain sodium balance and to achieve a new steady state where output matches intake. Several renal and extrarenal mechanisms contribute to this adaptation of the kidney. However, if for some reason the renal response is inadequate (too slow, too fast, or otherwise inappropriate) one could imagine that extracellular volume suddenly changes to such an extent that it affects blood pressure.

Although there are many studies in the literature which suggest that, notably in sodium-sensitive subjects, changes in sodium intake are associated with alterations in weight there is very limited information on the actual changes in cumulative sodium balance. This is surprising, because one really cannot interpret modulations in renal hemodynamics or renin activation without some appreciation of the amount of sodium that is lost or gained by the body during manipulation of dietary salt intake. This prompted us to set up a series of studies aimed at characterizing the respective roles of sodium balance and renin in determining the final changes in blood pressure in hypertensive patients who were faced with a sudden drop in 
sodium intake. Since the initial studies pointed to renin as the major determinant of the changes in blood pressure we then proceeded with a number of additional experiments to better define the pathophysiological actions of the renin-angiotensin system. In particular, we were interested in the role of angiotensin II in the regulation of renal hemodynamics and renin release. Moreover, we wanted to explore whether tissues respond differently to circulating and to tissue angiotensins. The following questions are addressed in this thesis:

1) How does the hypertensive kidney respond to a sudden reduction in sodium intake? What are the time course and the pattern by which sodium excretion is matched to the new intake (Chapter 2)?

2) Can inter-individual variations in blood pressure changes during a sudden reduction in sodium intake be explained by differences in cumulative sodium Ioss (Chapter 3)?

3) To what extent do changes in cumulative sodium loss and activation of the renin system interact during a sudden reduction in sodium intake? Does the degree of renin activation predict final changes in blood pressure (Chapter 4)?

4) Given the importance of the renin-angiotensin system in both sodium homeostasis and blood pressure control, what are the effects of circulating angiotensin I and II on the kidney? Can the effects of angiotensin I on the kidney be explained by intravascular conversion of this peptide or to angiotensin II that is formed intrarenally (Chapter 5)?

5) Is it possible to discriminate in man between the effects of circulating angiotensin II and those of tissue angiotensin II (Chapter 6) ?

6) What is the effect of sodium intake on the responses to circulating and tissue angiotensin II (Chapter 7)?

The data that have been generated by the various studies are discussed in more detail and in the light of information from current literature in Chapter $\mathbf{8}$. 


\section{References}

1 De Smit JEH, De Leeuw PW, Thien ThA. Hypertensie in Nederland, Een vergelijking van zeventien bevolkingsonderzoeken. Nederlandse Hartstichting, 1996;33-51.

2 Collins R, Peto R, MacMahon S, Hebert P. Fiebach NH, Eberlein KA, Godwin J, Qizilbash N, Taylor JO, Hennekens $\mathrm{CH}$. Blood pressure, stroke, and coronary heart disease. Part 2, short-term reductions in blood pressure: overview of randomised drug trials in their epidemiological context. Lancet 1990;335:827-838.

3 Collins R, Peto R. Antihypertensive drug therapy: effects on stroke and coronary heart disease. In: Swales JD, eds. Textbook of Hypertension. Oxford: Blackwell Scientific Publications, 1994;1156-1164.

4 Brunner HR, Ménard J, Waeber B, Burnier M, Biollaz J, Nussberger J, Bellet M. Treating the individual hypertensive patient: considerations on dose, sequential monotherapy and drug combinations. J Hypertens 1990;8:3-11.

5 Birkenhäger WH, De Leeuw PW. Schalekamp MADH. Control mechanisms in essential hypertension. Amsterdam: Elsevier Biomedical Press, 1982.

6 Folkow B. 'Structural factor' in primary and secondary hypertension. Hypertension 1990;16:89-101.

7 Guyton AC. Arterial pressure and hypertension. Circulatory Physiology III. Philadelphia: WB Saunders Company, 1980.

8 Weinberger MH. Salt sensitivity of blood pressure in humans. Hypertension 1996;27:481-490.

9 Sullivan JM, Ratts TE. Sodium sensitivity in human subjects. Hemodynamic and hormonal correlates. Hypertension 1988;11:717-723.

10 Overlack A, Ruppert M, Kolloch R, Gobel B. Kraft K, Diehl I, Schmilt W, Stumpe KO. Divergent hemodynamic and hormonal responses to varying salı imake in normotensive subjects. Hypertension 1993;22:331-338. 


\section{Chapter 2}

\section{Heterogeneous patterns of sodium excretion during sodium restriction in essential hypertensive patients}

MME Krekels, AJHM Houben, ATJ Lavrijssen, PN van Es, PW De Leeuw

J Hum Hypertens 1996; 10 (suppl 3): S123-S126 


\section{Abstract}

\section{Objective}

The present study was performed to assess the sodium excretory pattern by which sodium balance is reached.

\section{Methods}

Ninety untreated essential hypertensives with a median age of 47 (range:18-70 yrs) were admitted to a metabolic ward for seven days and put on a sodium diet of $55 \mathrm{mmol} /$ day. During these seven days urinary excretions of sodium, potassium and creatinine were determined daily along with mean arterial pressure (MAP) and weight.

\section{Results}

Changes in urinary sodium excretion were not uniform, but according to the pattern of attaining sodium balance, subjects could be divided into four groups. Group $1 \quad(n=31)$ gradually reached sodium balance, whereas group $2(n=10)$ showed an abrupt fall in sodium excretion on the third day and an extremely fluctuating sodium excretion thereafter. Group $3(n=32)$ reached sodium balance on day four, but displayed a rise in sodium excretion during the following days and group $4(\mathrm{n}=17)$ attained sodium balance only very slowly or not at all. Compared to the other groups, group 4 lost more sodium and at the same time displayed a greater fall in blood pressure.

\section{Conclusion}

Our data suggest that there may be at least four different patterns by which sodium balance can be reached following a reduction in sodium intake. The determinants of these responses remain, however, elusive. 


\section{Introduction}

The kidney quickly responds to alterations in dietary sodium intake by increasing or decreasing renal sodium excretion. Several studies, both in man and in animals, have reported that changes in renal sodium output during salt restriction are compatible with a first order exponential process $^{1.7}$. In some of these studies, however, subjects were not admitted to hospital, but rather followed up on a outpatient basis. Thus, the data obtained under such circumstances may have been subject to error. In some other studies we are not informed about the localization of the study. In our own laboratory sodium balances which were determined in hypertensive subjects during sodium restriction for the sake of other experimental protocols, showed great variability and certainly not in all patients changes in sodium excretion mimicked a first order exponential process. The present study, therefore, was undertaken to study the renal adaptation to a sudden change in dietary sodium intake in more detail.

\section{Subjects and methods}

\section{Subjects}

Only patients with uncomplicated essential hypertension and normal renal function (serum creatinine less than $120 \mu \mathrm{mol} / \mathrm{l}$ ) were included in the present study. In addition, to be eligible, 24 hour urinary sodium excretion had to be at least 70 mmol on multiple occasions prior to admission. Antihypertensive treatment, if any, was stopped at least three weeks prior to the study (six weeks in case of diuretics). The study was approved by the Ethics Committee of the hospital and written informed consent was obtained from all patients after an explanation of the protocol.

\section{Protocol}

Patients were admitted to a metabolic ward for the duration of 8 days. They received a sodium-restricted diet which contained $55 \mathrm{mmol}$ of sodium and $70 \mathrm{mmol}$ potassium per day. Caloric intake remained constant during the study period and was calculated on an individual basis. Patients were allowed to walk around, but they had to be in the supine position for at least 20 minutes prior to blood pressure measurements. Twenty-four hour urine collections for determination of sodium, potassium and creatinine were started immediately after admission and continued for the remainder of the hospital period.

Mean arterial pressure (MAP) was measured every hour by Dinamap (Tampa, 
Florida) and averaged for each day. In addition, weight was determined daily.

\section{Statistical methods}

Differences between groups were analyzed by the nonparametric Kruskall-Wallis test. As data were not normally distributed, they are expressed as medians and ranges.

\section{Results}

Ninety patients with uncomplicated essential hypertension and a median age of 47 yrs (range 18-70) were enrolled in this study. Initial urinary sodium excretion was 140 (70-328) mmol/24 hour for the whole group. Urinary creatinine excretion during the entire study period averaged $13.5 \mathrm{mmol} / 24$ hours (range $5-28.5$ ) When changes in sodium excretion following initiation of sodium restriction were analyzed for all patients together, the observed pattern was consistent with a first order exponential process (figure 1). On average, however, sodium excretion varied greatly between subjects, even after seven days (figure 1). Obviously, at a time where patients were supposed to be in sodium balance and sodium output should be around $50.60 \mathrm{mmol} / \mathrm{day}$ in all patients, the variability in sodium excretion was as great as prior to sodium restriction. In fact, 24 hour sodium excretion ranged from 69 to 273 (median:96) mmol on day 2 and from 1 to 115 (median:57) $\mathrm{mmol}$ on the last day.

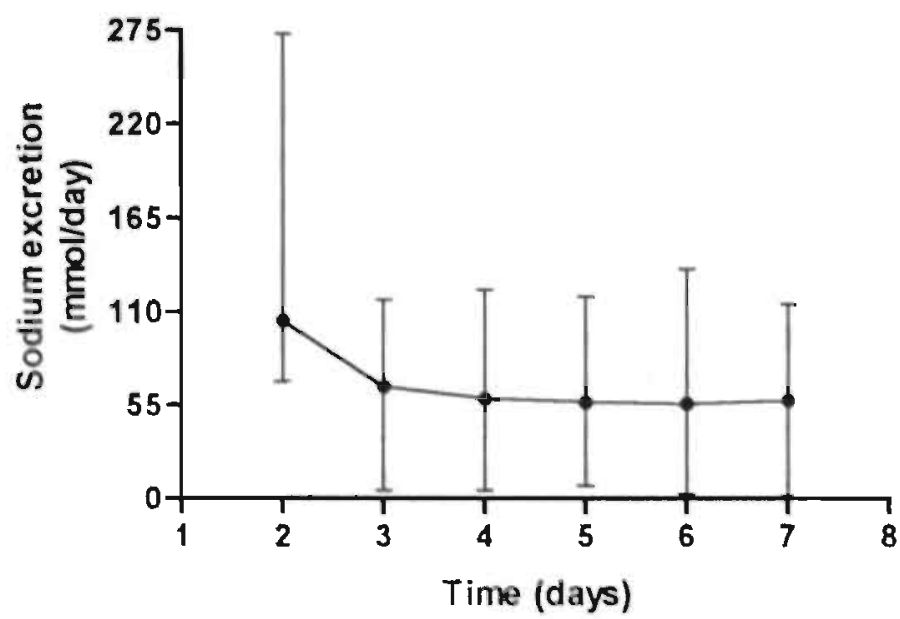

Figure 1. Time course of sodium excretion in the whole group $(n=90)$ during seven days of sodium restriction 
A closer look at the data revealed that patients could respond in at least four different ways to the sudden decrease in sodium intake (figure 2). In group 1 $(n=31)$ the fall in sodium excretion was consistent with a first order exponential process, reflected by the fact that sodium excretion fell by approximately $50 \%$ on each consecutive day until the new staedy state level had been reached. In group 2 $(n=10)$ sodium excretion showed an oscillatory pattern before reaching a steady state around $55 \mathrm{mmol}$. In group $3(\mathrm{n}=32)$ sodium excretion fell gradually to approximately $55 \mathrm{mmol} /$ day within three days, but displayed a rise (above 55 mmol) during the following days. Finally, in group $4(n=17)$ sodium excretion remained high during several days of sodium restriction; in this group sodium balance was attained only after day 5 or not at all.
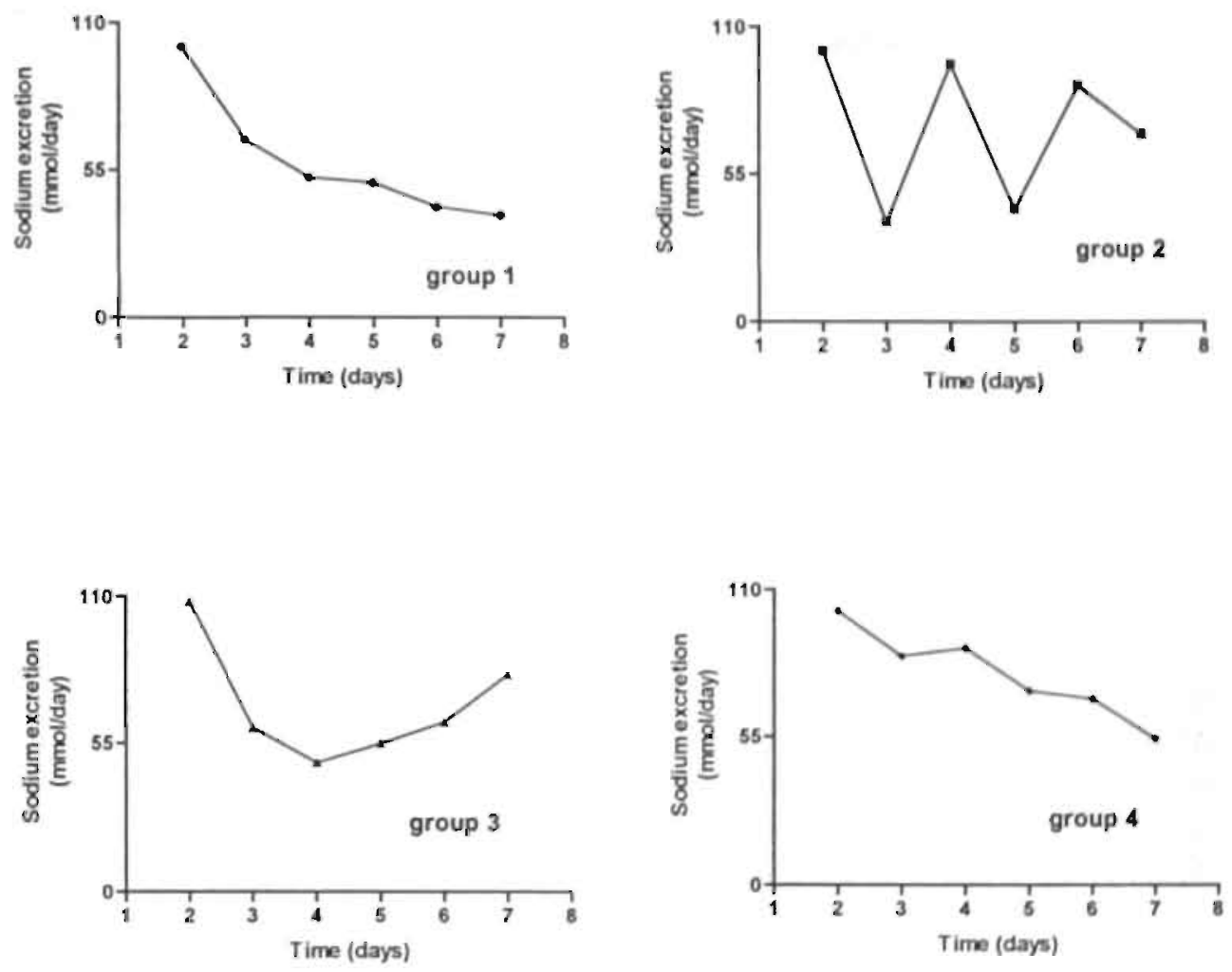

Figure 2. Examples of the sodrum excretory patterns in the four groups 
Age and data for sodium and potassium excretion, mean arterial pressure (MAP) and weight on the second hospital day (first day of sodium restriction) in these four groups are shown in table 1. To account for possible stress reactions related to hospital admission blood pressure data gathered on the first day were ignored. Blood pressure was slightly different between the four groups, but this was not statistically significant. As shown in table 2 the observed decline in blood pressure after seven days of sodium restriction was largest in group 4 , whereas it was least in group $1(\mathrm{p}<0.05)$. Group 2 and 3 took intermediate positions. The magnitude of the blood pressure fall after seven days of sodium restriction was not correlated to initial blood pressure.

Table 1. Baseline characteristics after hospital admission in the four groups.

\begin{tabular}{|c|c|c|c|c|}
\hline & Group 1 & Group 2 & Group 3 & Group 4 \\
\hline $\begin{array}{l}\text { Age } \\
\text { (yrs)! }\end{array}$ & $\begin{array}{c}37 \\
(18-59)\end{array}$ & $\begin{array}{c}40 \\
(30-56)\end{array}$ & $\begin{array}{c}52 \\
(28-67)\end{array}$ & $\begin{array}{c}48 \\
(21-70)\end{array}$ \\
\hline $\begin{array}{c}\text { UnaV } \\
\text { (mmol) }\end{array}$ & $\begin{array}{c}91 \\
(69-156)\end{array}$ & $\begin{array}{c}97 \\
(77-185)\end{array}$ & $\begin{array}{c}94 \\
(69-273)\end{array}$ & $\begin{array}{c}100 \\
(70-130)\end{array}$ \\
\hline $\begin{array}{c}\text { UkV } \\
\text { (mmol) }\end{array}$ & $\begin{array}{c}61 \\
(31-109)\end{array}$ & $\begin{array}{c}74 \\
(56-106)\end{array}$ & $\begin{array}{c}65 \\
(40-156)\end{array}$ & $\begin{array}{c}66 \\
(36-133)\end{array}$ \\
\hline $\begin{array}{c}\text { MAP } \\
(\mathrm{mm} \mathrm{Hg})\end{array}$ & $\begin{array}{c}116 \\
(94-146)\end{array}$ & $\begin{array}{c}124 \\
(109-160)\end{array}$ & $\begin{array}{c}124 \\
(98-179)\end{array}$ & $\begin{array}{c}114 \\
(97-141)\end{array}$ \\
\hline $\begin{array}{c}\text { Weight } \\
(\mathrm{kg})\end{array}$ & $\begin{array}{c}77 \\
(59-99)\end{array}$ & $\begin{array}{c}80 \\
(53-101)\end{array}$ & $\begin{array}{c}85 i \\
(58-106)\end{array}$ & $\begin{array}{c}79 \\
(54-93)\end{array}$ \\
\hline
\end{tabular}

UnaV =urinary sodium excretion; UkV =urinary potassium excretion; MAP = mean arterial pressure

In all four groups the greatest fall in blood pressure was seen during the first three days of sodium restriction.

Along with the different sodium excretory patterns, cumulative sodium balances also tended to be different between the groups. Group 1 displayed al sodium loss of $36(-131$ to +152$) \mathrm{mmol}$, whereas group 4 lost $109(-270$ to -48$) \mathrm{mmol}$ of sodium. Again group 2 and 3 took intermediate positions with sodium losses of 64 (-208 to $+81)$ and $84(-253$ to +109$) \mathrm{mmol}$ respectively. The difference in cumulative sodium loss between group 1 and group 4 was statistically significant $(p<0.05)$. Time course of potassium excretion was comparable in all four groups and potassium balances after seven days were not different either. In all four groups weight loss during the study week was approximately $1.5 \mathrm{~kg}$. 
Table 2. Changes in variables in the four groups after seven days of sodium restriction* $p<0.05$ as compared to group 1

\begin{tabular}{|c|c|c|c|c|}
\hline & Group I & Group 2 & Group 3 & Group 4 \\
\hline $\begin{array}{c}\mathrm{Na}^{+} \\
\text {balance } \\
\text { (mmol) }\end{array}$ & $\begin{array}{c}-36 \\
(-131 \text { to }+151)\end{array}$ & $\begin{array}{c}-64 \\
(-208 \text { to }+81)\end{array}$ & $\begin{array}{c}-84 \\
(-253 \text { to }+109)\end{array}$ & $\begin{array}{c}-109^{*} \\
(-270 \text { to }-48)\end{array}$ \\
\hline $\begin{array}{c}\mathrm{K}^{+} \\
\text {balance } \\
\text { (mmol) }\end{array}$ & $\stackrel{-1}{-1}(-197$ to 292$)$ & $(-161$ to +76$)$ & $\begin{array}{c}-21 \\
(-254 \text { to }+140)\end{array}$ & $(-392$ to +154$)$ \\
\hline $\begin{array}{l}\text { Change } \\
\text { in MAP } \\
(\mathrm{mm} \mathrm{Hg})\end{array}$ & $(-16$ to +6$)$ & $\left(-211^{-6}\right.$ to +2$)$ & $(-25$ to +10$)$ & $\begin{array}{c}-10^{*} \\
(-42 \text { to }+7)\end{array}$ \\
\hline $\begin{array}{l}\text { Weight } \\
\text { loss } \\
(\mathrm{kg})\end{array}$ & $\begin{array}{c}-1.5 \\
(-3.7 \text { to }+1.2)\end{array}$ & $\begin{array}{c}-1.3 \\
(-4.2 \text { to } 0.0)\end{array}$ & $\begin{array}{c}-1.5 \\
(-3.9 \text { to }+0.4)\end{array}$ & $\begin{array}{c}-1.6 \\
(-4 \text { to }-0.5)\end{array}$ \\
\hline
\end{tabular}

\section{Discussion}

Until now, all studies on sodium excretion during modifications of dietary sodium intake have reported that changes in sodium excretion during restriction mimick a first-order exponential process ${ }^{8}$. Moreover, it is generally held that sodium output matches the new intake within, approximately, four days. If we would have analyzed our data on sodium excretion for the whole group, we also would have found a pattern that is consistent with a first order exponential process (figure 1). However, instead of looking at mean or median values of sodium excretion in the whole group, we studied the sodium excretory pattern of each patient individually. In fact, our data suggest that there are at least four different sodium excretory patterns by which subjects attain sodium balance during sodium restriction.

As patients were admitted to a metabolic ward and since both sodium intake and urine collections were carefully monitored in each patient we think it is uniikely that the results can be explained by insufficient compliance of patients. We are not informed, however, about the reproducibility of the various excretory patterns and, hence, we cannot ascertain whether a particular pattern has to be considered as an intrinsic property or as a variable that may change over time. Also, the (patho)physiological meaning of the different excretory patterns is unclear. Nevertheless, the differences between the groups suggest that the balance between sodium-retaining and sodium excretory mechanisms may be affected differently between subjects, when dietary salt intake changes.

A shift towards continued excretion of sodium, despite restriction, may be 
related to a higher initial body sodium content (as observed in group 4). Indeed, according to the Strauss-concept, there is a critical level of body sodium, below which the kidney starts retaining sodium and above which the excess of sodium is rapidly excreted ${ }^{8}$. If this is true, we have to assume that patients in group 4 must have had difficulty in excreting an excess of sodium prior to this study. Perhaps, these patients resemble the non-modulating or salt-sensitive hypertensive subgroup that has been described by Hollenberg and coworkers'. Whereas the data from group 1 suggest that the body, at least in these patients, is able to sense actual sodium intake and to adapt to that intake gradually, the patterns in group 2 and 3 indicate that sometimes the body has to "seek" the proper sodium output.

Clearly, further research is necessary to elucidate the possible determinants of these patterns. 


\section{References}

1 Strauss MB, Lamdin A, Smith WP, Bleifer DJ. Surfeit and deficit of sodium. A kinetic concept of sodium excretion. Arch. Intern. Med. 1958;102:527-536.

2 Hollenberg NK. Set-point for sodium homeostasis: surfeit, deficit, and their complications. Kidney Int. 1980;17:423-429.

3 Simpson FO. Sodium handling in hypertension: speculations based on the setpoint concept. NZ Med. J. 1983;96:907-910.

4 Simpson FO. A set-point for sodium? A new analysis. In: Puschett JE, Greenberg A, eds. Diuretics II:chemistry, pharmacology, and clinical applications. New York: Elsevier 1987:569-576.

5 Simpson FO. Sodium intake, body sodium, and sodium excretion. Lancet 1988;2:2529.

6 Sagnella GA. Markandu ND, Singer DR, MacGregor GA. Kinetics of sodium excretion during changes in dietary sodium intake in man- an exponential process? Clin and Exp Hyper-theory and practice 1990;A(12):171-178.

7 Walser M. Phenomenological analysis of renal regulation of sodium and potassium balance. Kidney Int 1985;27;837-841.

8 Simpson FO. The control of body sodium in relation to hypertension: exploring the Strauss Concept. J. Cardiovasc. Pharmacol. 1990;16 (Suppl 7):S27-30.

9 Hollenberg NK, Williams GH. Abnormal renal function, sodium volume homeostasis and renin-system behavior in normal renin essential hypertension: the evolution of the non-modulation concept. In: Laragh $\mathrm{H}$, Brenner BM, eds. Hypertension: pathophysiology, diagnosis, and management. New York: Raven Press Ltd, 1995;1837-1856. 


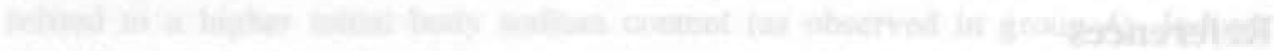

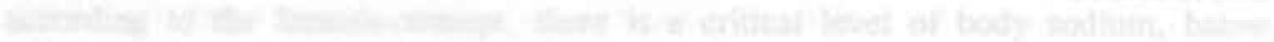

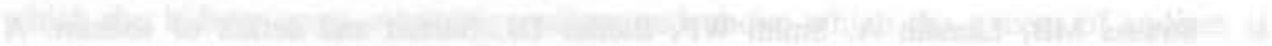

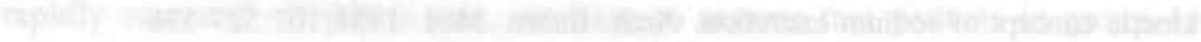

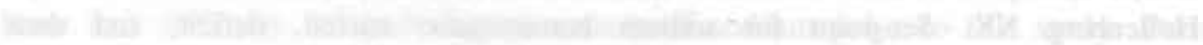

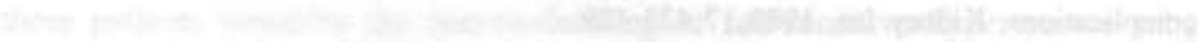
Whath

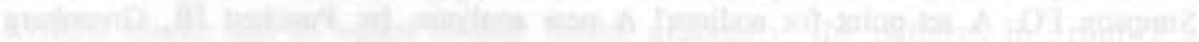

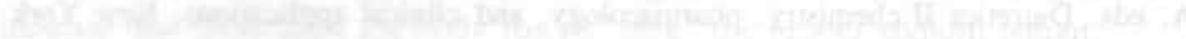

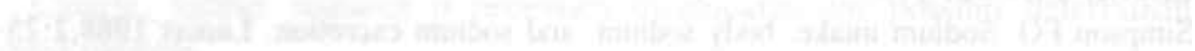

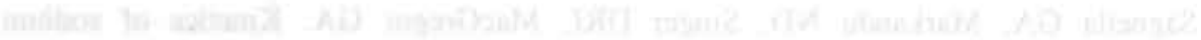

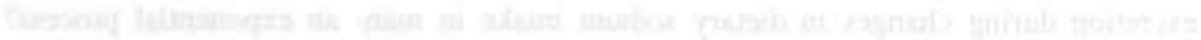

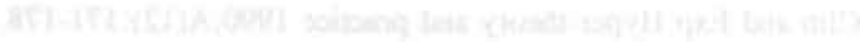

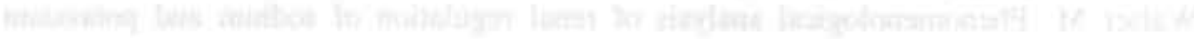

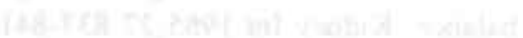




\section{Chapter 3}

Sodium sensitivity of blood pressure in hypertensives is not related to sodium, but rather to renin

MME Krekels, PN van Es, KML Leunissen, PW De Leeuw

J Hum Hypertens 1996; 10 (suppl 3): \$127-S130 


\section{Abstract}

\section{Objective}

The purpose of this study was to investigate whether a certain degree of sodiumsensitivity of blood pressure in essential hypertensives during sodium restriction is related to cumulative sodium loss.

\section{Methods}

One-hundred and seventeen untreated essential hypertensives were admitted to a metabolic ward for seven days and put on a sodium restricted diet of $55 \mathrm{mmol} / \mathrm{day}$. During seven days urinary excretions of sodium, potassium and creatinine were determined daily along with mean arterial pressure (MAP) and weight. Active plasma renin concentration (APRC), aldosterone (ALDO), renal plasma flow (RPF) and plasma volume (PV) were assessed after seven days under steady state condition. The population was divided into tertiles based on the final changes in blood pressure after seven days.

\section{Results}

Tertile 1 displayed a median fall in MAP of $13(-42$ to -9$) \mathrm{mm} \mathrm{Hg}$, whereas in tertile 2 and 3 a fall of $6(-9$ to -4$) \mathrm{mm} \mathrm{Hg}$ and a rise of $1(-3$ to +11$) \mathrm{mm} \mathrm{Hg}$ respectively, was encolintered. Baseline characteristics were comparable between the tertiles. When tertile 1 was compared to tertile 3 no significant differences between these tertiles were found with respect to cumulative sodium and potassium balances and weight losses. On the other hand, APRC levels were significantly higher in tertile 3 as compared to tertile 1 ( 22 and $27 \mathrm{mU} / 1$, respectively). RVR tended to be higher in tertile 3 , although this was not statistically significant. Aldo, $\mathrm{RPF}$ and PV were comparable between the tertiles.

\section{Conclusions}

In contrast with tertile 1, MAP in tertile 3 is maintained at its original level, despite comparable sodium losses. In tertile 3 , however, levels of renin are higher compared to the group that is more sodium-sensitive. Therefore, our data suggest that the degree of sodium-sensitivity of blood pressure in essential hypertensive subjects is not determined by sodium status, but rather by renin. 


\section{Introduction}

Many studies have addressed the association between blood pressure and sodium intake. For instance, data from the Intersalt study showed that for every $10 \mathrm{mmol}$ rise in a population's sodium intake there was an average increase of $0.9 \mathrm{~mm} \mathrm{Hg}$ systolic and $0.45 \mathrm{~mm} \mathrm{Hg}$ diastolic in the population's blood pressure'. However, it is known that people differ in their susceptibility to alterations in dietary salt intake and that they may respond with widely varying changes in blood pressure. Hence, the salt-sensitivity concept was developed ${ }^{2}$, though its pathophysiological significance has been disputed ${ }^{3}$.

A defect in renal sodium excretion, possibly due to sympathetic overactivity and/or involvement of the renin-angiotensin-aldosterone system has been suggested as a potential mechanism of salt-sensitivity ${ }^{4.5}$. Still, inferences about the determinants of salt sensitivity remain troublesome, not the least because most authors have dichotomized their study subjects into a salt-sensitive and salt-resistant group and have used different and arbitrary working definitions of salt sensitivity ${ }^{6}$. However, as changes in blood pressure during dietary salt manipulation follow a Gaussian distribution?, it would be more appropriate to deal with salt-sensitivity as a gradual phenomenon.

In the present study, therefore, characteristics of salt sensitivity were studied in relation to the degree of blood pressure changes during sodium restriction.

\section{Patients and methods}

\section{Patients}

Only patients with uncomplicated essential hypertension and an urinary sodium excretion of more than $70 \mathrm{mmol} /$ day were selected for the present study. Secondary hypertension had had to be ruled out by routine laboratory examination and besides essential hypertension no concomitant disease had to be present. Patients who regularly used non-steroidal anti-inflammatory drugs were excluded. Antihypertensive treatment, if any, was withdrawn at least three weeks prior to the study (six weeks in case of diuretics).

The study was approved by the Ethics Committee of the University Hospital and written informed consent was obtained from all patients.

\section{Study protocol}

Patients were admitted to a metabolic ward for 8 days and put on a sodiumrestricted diet containing $55 \mathrm{mmol}$ of sodium and $70 \mathrm{mmol}$ of potassium per day. 
The amount of calories remained constant during the entire study period and was calculated on an individual basis. Physical exercise was kept constant during the admission period and smoking was forbidden. Twenty-four hour urine collections for determination of sodium, potassium and creatinine excretion were started immediately after admission and continued until discharge. Accuracy of the urine collections was assessed by creatinine excretion.

Mean arterial pressure (MAP) was measured every hour by Dinamap (Tampa, Florida) and averaged for each day. In addition, weight was determined daily. After seven days, when a steady state had been reached, plasma volume (PV; ${ }^{131} \mathrm{I}-$ labeled albumin), renal plasma flow (RPF; ${ }^{125}$ I-labeled hippuran), active plasma renin concentration (APRC; IRMA-method) and aldosterone (ALDO; Coat-a-Count methodi) were determined. Blood volume (BV) and renal vascular resistance (RVR) were calculated.

Based on their blood pressure fall from day 2 until day 7, patients were divided into tertiles. Because of possible stress reactions related to hospital admission, blood pressures on day 1 were ignored. Differences in characteristics between tertiles were analyzed by the non-parametric Kruskall-Wallis test. A statistical value of $p<0.05$ was considered significant. Because data were not normally distributed they are expressed as medians and ranges.

\section{Results}

One-hundred and seventeen essential hypertensive subjects with a median age of 47 (18-70) years were studied. Urinary creatinine excretion during the entire study period averaged $13.8 \mathrm{mmol} / 24$ hour (range 5.0-29.0). After seven days of sodium restriction changes in blood pressure varied from -42 to $+11 \mathrm{~mm} \mathrm{Hg}$ (median fall: $7 \mathrm{~mm} \mathrm{Hg}$ ). Based on the changes in blood pressure patients were divided into tertiles: tertile 1 displayed a fall in blood pressure of $13(-42$ to -9$) \mathrm{mm} \mathrm{Hg}$, whereas in tertile 2 and 3 a fall and rise in blood pressure of $6(-9$ to -4$)$ and $1(-3$ to +11$) \mathrm{mm} \mathrm{Hg}$ respectively, were encountered.

\section{Baseline characteristics}

Initial levels of blood pressure, sodium excretion and weight were comparable in the three tertiles and showed the same distribution (table 1). Age was also similar in the three groups. 
Table 1. Patient characteristics at baseline.

\begin{tabular}{cccc}
\hline & Tertile 1 & Tertile 2 & Tertile 3 \\
\hline $\begin{array}{c}\text { Age } \\
\text { (yrs) }\end{array}$ & 47 & 43 & 52 \\
MAP & $(20-67)$ & $(20-70)$ & $(18-64)$ \\
$($ mm Hg) & 127 & 128 & 121 \\
Weight & $(98-173)$ & $(96-156)$ & $(102-163)$ \\
(kg) & 81.4 & 80.0 & 77,9 \\
UnaV & $(54.4-105.9)$ & $(52.3-104)$ & $(52-114,2)$ \\
$($ mmol/day) & 130 & 137 & 158 \\
\end{tabular}

MAP=mean arterial pressure: Una V =urinary sodium excretion

\section{Sodium, potassium and weight losses during sodium restriction}

Despite the restriction in dietary sodium, cumulative sodium balance became positive in several patients who responded to the intervention by an extreme drop in urinary sodium output. The number of such patients, however, was equal in the three tertiles. Also, no differences in time-course of sodium excretion between the tertiles were apparent. Cumulative sodium losses amounted to $72(-253$ to +131$)$ mmol in tertile $1,74(-355$ to +132$) \mathrm{mmol}$ in tertile 2 and $53(-307$ to +145$)$ mmol in tertile 3 (figure 1). There were no statistically significant differences in sodium loss between the tertiles. Weight losses were also comparabie between the tertiles: $1.5(0$ to -3.2$) \mathrm{kg}$ in tertile $1,1.5(+0.5$ to -4.5$) \mathrm{kg}$ in tertile 2 and 1.7 $(+0.5$ to -4.5$) \mathrm{kg}$ in tertile 3. Finally, there were no differences between the tertiles with respect to changes in potassium balance. As shown in figure 2, there was no correlation between changes in sodium balance and changes in blood pressure at the end of the study period.

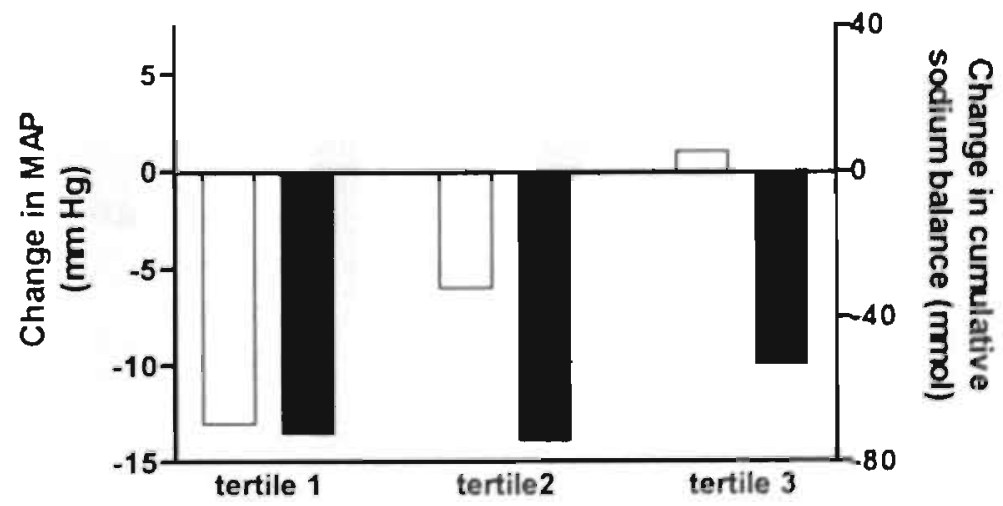

Figure 1. Changes in cumulative sodium balance and blood pressure in tertiles 1.2 and 3 after seven days of sodium restriction (steady state condition) 


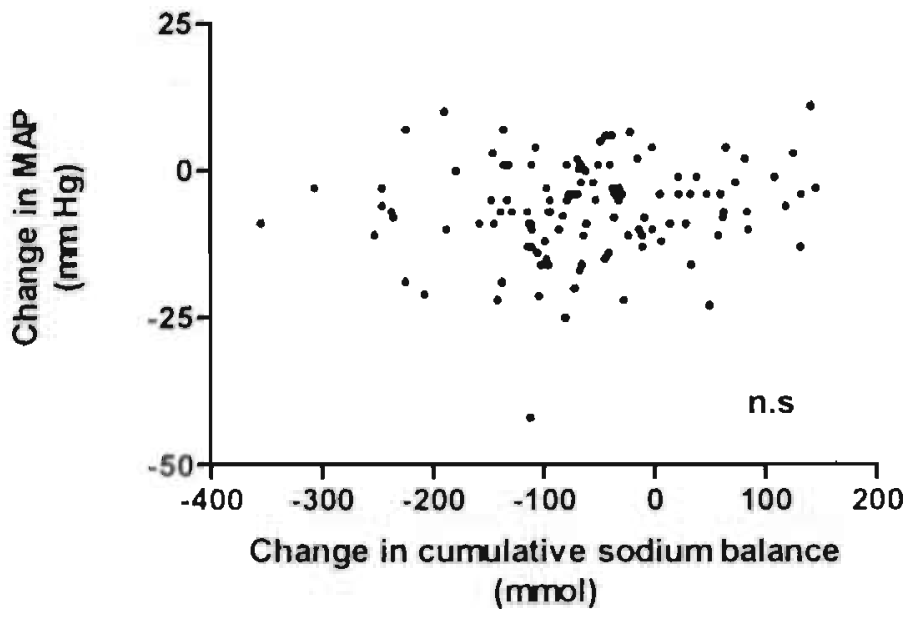

Figure 2. Changes in blood pressure plotted against changes in cumulative sodium loss after seven days of sodium restriction

Hemodynamic and hormonal data at steady state (day 7)

Levels of APRC after seven days of sodium restriction were higher in tertile 2 and 3 as compared to tertile 1 . The difference between tertile 1 and 3 was significant (figure 3). On the other hand, aldosterone levels were not different between the tertiles after seven days of sodium restriction (figure 3 ).

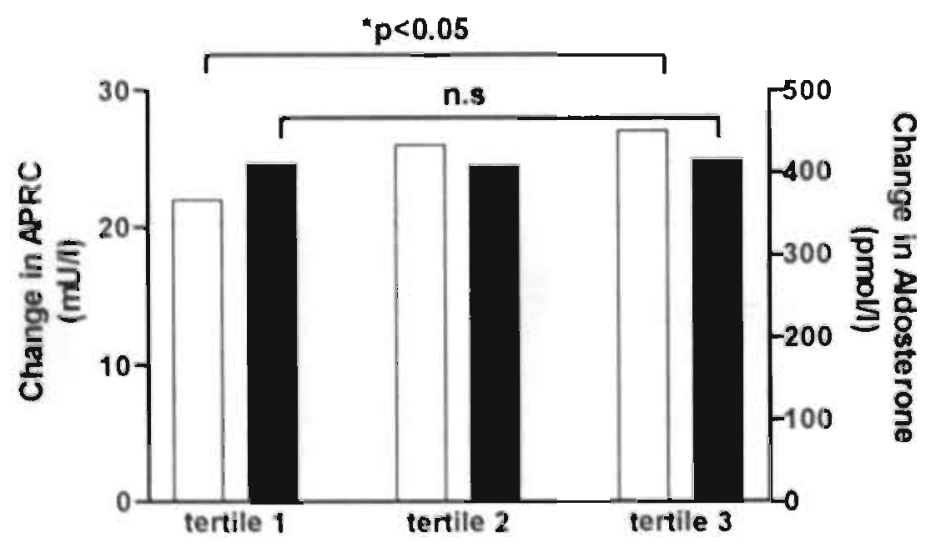

Figure 3. Levels. of renin and aldosterone in tertiles 1,2 and 3 after seven days of sodium restriction (steady state condition) 
Data for renal hemodynamics and volume measurements on day 7 of hospital admission are given in table 2 . Renal plasma flow, renal blood flow, blood volume and plasma volume did not differ between the tertiles. There was a trend for renal vascular resistance to increase from tertile 1 to tertile 3 , but this was not statistically significant.

Table 2. Renal haemodynamics and blood/plasma volume after 7 days of sodium restriction (steady state) volume

\begin{tabular}{cccc}
\hline & Tertile 1 & Tertile 2 & Tertile 3 \\
\hline $\begin{array}{c}\text { RPF } \\
(\mathrm{ml} / \mathrm{min})\end{array}$ & 561 & 563 & 546 \\
RBF & $(295-962)$ & $(317-815)$ & $(585-905)$ \\
$(\mathrm{ml} / \mathrm{min})$ & 1010 & 943 & 956 \\
RVR & $(543-1850)$ & $(572-1455)$ & $(585-1551)$ \\
$($ units $)$ & 8421 & 8752 & 9655 \\
PV & $(1082-15896)$ & $(5168-15316)$ & $(5030-19155)$ \\
$(\mathrm{ml})$ & 2976 & 2990 & 2873 \\
BV & $(1990-4006)$ & $(1764-4325)$ & $(2011-4314)$ \\
$(\mathrm{ml})$ & 5257 & 5090 & 5241 \\
\hline
\end{tabular}

$R P F=$ renal plasma flow; $R B F=$ renal blood flow; $R V R=$ renal vascular resistance; $P V=$ plasma volume; $\mathrm{BV}=$ blood volume

\section{Discussion}

In the present study we divided our patients into tertiles according to the magnitude of their blood pressure responses to sodium restriction. Whereas tertile 1 displayed a clear fall in pressure, blood pressure hardly changed in tertile 3 . According to current thinking, therefore, tertile 1 would be classified as salt-sensitive and tertile 3 as salt-resistant. Nevertheless, by carefully monitoring sodium balance we found that tertile 1 lost the same amount of sodium during restriction as tertile 3 . Moreover, we did not observe a relationship between changes in cumulative sodium balance and changes in blood pressure.

Our results, therefore, suggest that the degree of blood pressure fall during sodium restriction is independent from the cumulative sodium loss. Not only was there no exaggerated sodium loss in tertile 1, also weight loss was comparable between the tertiles. This further strengthens the idea that the degree of extracellular volume depletion was similar in the three tertiles. Thus, our data could not substantiate the idea that salt-sensitivity is associated with defective renal sodium handling and a disturbed pressure-natriuresis relationship $p^{2.8 .9}$. On the other 
hand, our results are in keeping with the data of Campese et al., who also were unable to demonstrate differences in sodium balance between salt-sensitive and saltresistant subjects ${ }^{10}$. In point of fact, most studies failed to demonstrate a significant relationship between the amount of sodium lost during sodium depletion or retained during sodium loading and the accompanying changes in arterial pressure ${ }^{\Perp}$.

To determine whether differences in sodium sensitivity across the tertiles were associated with differences in renal hemodynamics or circulating volume we also measured plasma volume and renal plasma flow in all patients after seven days of sodium restriction. Since it was not the purpose of the present study to evaluate changes in these variables during changes in sodium balance, we deliberately performed our measurements in steady state. By doing so, we would allow for a meaningful comparison of the tertiles.

Plasma or blood volume did not differ between the tertiles. Although data on plasma and blood volume during sodium restriction are scarce, our results are in accordance with those of Oshima et al., who also found that plasma volume was not different in salt-sensitive subjects when compared to salt-resistant ones ${ }^{12}$. Therefore, we think that salt-sensitivity is not determined by volume status. Our data on renal hemodynamics are at variance with those of Fujita et al. ${ }^{4}$ who reported a higher renal vascular resistance in salt-sensitive subjects, whereas our data, if anything, suggest that renal vascular resistance tends to be higher in saltresistant subjects.

The present study was not designed to investigate the dynamic response of the renin-angiotensin-aldosterone system to sodium restriction. We cannot exclude, therefore, that the rises in renin and aldosterone were inadequate in patients who are most salt sensitive.

Our observations on steady state levels of renin, however, are in accordance with other data, which demonstrated that salt-sensitive subjects have lower renin levels. However, despite the fact that renin levels were lower in tertile 1 than in tertile 3 , they were certainly not suppressed. Ishii et al. found that sensitivity of blood pressure to increased dietary salt intake in hypertensive patients could be related to altered aldosterone dynamics ${ }^{13}$. Also, other studies reported that patients with the greatest fall in blood pressure displayed the least rise in renin and aldosterone. In our hands, however, aldosterone was not related to the degree of sodium sensitivity. This discrepancy (in aldosterone results) may be explained by the fact that in the latter studies patients were more sodium depleted, as sodium. diets of $20 \mathrm{mmol}$ and $10 \mathrm{mmol}$ in addition to $40 \mathrm{mg}$ of furosemide were used. By contrast, our patients consumed a diet of $55 \mathrm{mmol}$ of sodium. It could well be that differences in aldosterone levels become more marked as sodium depletion is more severe. We further found that subjects with a higher degree of sodium sensitivity were of similar age as those who were least sensitive and certainly not older as has 
been suggested in other studies?

In conclusion, our data indicate that a greater degree of sodium sensitivity of blood pressure in hypertensives is associated with lower, but not necessarily suppressed levels of renin and a tendency towards a lower renal vascular resistance. Whilst these findings again point to the kidney as the major determinant of sodium sensitivity, our results do not favor the hypothesis that disturbances in sodium handling or volume regulation are involved. 


\section{References}

1 Intersalt Cooperative Research Group. Findings of the International Cooperative Intersalt study. Br Med J 1988;297:319-328.

2 Kawasaki T, Delea CS, Bartter FC, Smith H. The effect of high-sodium and lowsodium intakes on blood pressure and other related variables in human subjects with idiopathic hypertension. Am J Med 1978;64:193-198.

3 Watt GCM. Does salt sensitivity exists? Klin Wochenschr 1991;699 (Suppl 25):3035 .

4 Fujita T, Ando K, Ogata E. Systemic and regional hemodynamics in patients with salt sensitive hypertension. Hypertension 1990;16:235-244.

5 Overlack A et al. Divergent hemodynamic and hormonal responses to varying salt intake in normotensive subjects. Hypertension 1993;22:331-338.

6 Dimsdale JE, Ziegler M, Mills P. Berry C. Prediction of salt sensitivity. Am J Hypertens 1990;3:429-435.

7 Weinberger $\mathrm{MH}$ et al. Definitions and characteristics of sodium sensitivity and blood pressure resistance. Hypertension 1986;8(Suppl II):S127-134.

8 Kimura $\mathrm{G}$ et al. Sodium sensitive and sodium retaining hypertension. Am J. Hypertens 1990;3:854-858.

9 Kimura G, Brenner BM. A novel method for distinguishing between salt sensitive from non-salt sensitive forms of human and experimental hypertension. Curr Opin Nephrol Hyperiens 1993;2:341-349.

10) Campese VM et al. Abnormal relationship between $\mathrm{Na}^{*}$ intake and sympathetic nervous system activity in salt-sensitive patients with essential hypertension. Kidney Int 1982;21:371-378.

11 Dustan HP. Kirk KA. Corcoran Lecture: the case for and against salt in hypertension. Hypertension 1989;13:696-705.

12 Oshima $T$ et al. Factors determining sodium chloride sensitivity of patients with essential hypertension: evaluation by multivariate analysis. J Hypertens 1989;7:223227.

13 Ishii $\mathrm{M}$ et ai. Role of the aldosterone system in the salt-sensitivity of patients with benign essential hypertension. Jpn Heart J 1983:24:79-90. 


\section{Chapter 4}

Sodium sensitivity of blood pressure during sodium restriction is related to inadequate activation of renin during the early phase of sodium loss

MME Krekels, NC Schaper, PW de Leeuw

(submitted for publication) 


\section{Abstract}

\section{Objective}

The objective of the present study was to explore the interrelationships between cumulative sodium loss, renin activation and blood pressure changes during sodium restriction in essential hypertensives. Specifically, we wanted to know whether the degree of sodium sensitivity of blood pressure depends upon renin activation during steady state or upon initial renin activation during the first days of sodium restriction.

\section{Methods}

Sixty-seven untreated essential hypertensive patients were admitted to a metabolic ward for eight days and put on a sodium restricted diet of $55 \mathrm{mmol} / \mathrm{day}$ from the second to the last day. Urinary excretions of sodium, potassium and creatinine were determined along with mean arterial pressure and weight during seven days. Besides measurements in steady state condition (after seven days) active plasma renin concentration, aldosterone and catecholamines were also assessed during the first three days of sodium restriction.

\section{Results}

Analyzabie data are available for 55 patients. Both baseline sodium excretion and the activation of renin during the first three days appeared to be predictors of total sodium loss after seven days. Changes in blood pressure were not related to changes in sodium balance, but they were to baseline blood pressure, baseline norepinephrine and renin activation during the early phase of sodium restriction. In addition, blood pressure appeared to fall more when the normal relationship between sodium loss and early (but not late) activation of renin was disturbed.

\section{Conclusion}

We conclude that sodium sensitivity of blood pressure during sodium restriction is linked to a relative unresponsiveness of the renin system during the early phase of sodium loss rather than to absolute renin levels during steady state. 


\section{Introduction}

Although sodium sensitivity of blood pressure has been the subject of many investigations, the mechanisms underlying this condition have not yet been elucidated. Among the potential pathophysiological mechanisms involved are sympathetic overactivity ${ }^{13}$, possibly in conjunction with an increased ratio of alpha2 over beta- 2 adrenoceptors ${ }^{4}$ and altered sodium handling by the kidney ${ }^{5.7}$. Sodium sensitivity appears to be related to older age, black race and low levels of renin and prorenin $^{8-11}$. In addition, it has been linked to a blunted rise in renin with sodium restriction $^{2.11-14}$. However, interpretation of available data is difficult, because in many of the studies dealing with sodium sensitivity no information is given regarding changes in body fluid. volumes or cumulative sodium balance. Moreover, little is known about the time course of changes in sodium balance and renin that determine the final change in blood pressure. This prompted us to study the interrelationships between changes in cumulative sodium balance, renin and blood pressure during a period of sodium restriction in more detail. As sodium sensitivity should be considered as a gradual phenomenon ${ }^{8}$, we analyzed the data in relation to the degree of blood pressure changes rather than on the basis of an arbitrary cut-off point.

\section{Methods}

\section{Patients}

Sixty-seven patients with essential hypertension were included in this study after having given written informed consent. Secondary hypertension had been ruled out by routine clinical and laboratory investigations and antihypertensive medication, if any, was stopped at least 3 weeks prior to the study. None of the patients had been treated with diuretics within twelve months before the start of the study. To be eligible, supine diastolic blood pressure had to be above $95 \mathrm{~mm} \mathrm{Hg}$ and 24-hour urinary sodium excretion had to be at least $70 \mathrm{mmol}$ on multiple occasions. In addition, serum creatinine concentration had to be below $120 \mu \mathrm{mol} / \mathrm{l}$.

\section{Protocol}

All patients were admitted to a metabolic ward for 8 days and kept on a diet containing $55 \mathrm{mmol}$ of sodium per day; potassium intake was fixed at $70 \mathrm{mmol}$ per day. The diet was designed by the hospital dietitian and adjusted to the subjects' caloric intake. Meals were prepared by the metabolic kitchen. Since blood pressure may show a non-specific fall on the day of admission, the study proper was started 
on the second hospital day.

Twenty-four hour urine collections for determination of sodium, potassium and creatinine were started immediately after admission and continued throughout the study period. Cumulative sodium balances were calculated from the first day of dietary restriction onwards. Completeness of urine collections was verified from creatinine excretions. For each patient, data from a 24-hour urinary collection were accepted for analysis only when creatinine excretion in that collection deviated by no more than $5 \%$ from the average creatinine excretion during the entire study period in that patient. During daytime mean arterial pressure (MAP) was measured every hour by Dinamap (Tampa, Florida) and averaged for each day. In addition, weight was determined daily. During the first three days of sodium restriction blood was drawn at $8.00 \mathrm{a} . \mathrm{m}$. for the measurement of active plasma renin concentration (APRC), angiotensin II (AngII), aldosterone (ALDO) and catecholamines. After seven days, when a steady state condition had been reached, these variables were assessed once more. APRC was determined by the IRMA method $^{15}$, whereas ALDO was measured by radioimmunoassay ${ }^{16}$. AngII was also measured by radioimmunoassay after extraction of plasma ${ }^{17}$. Catecholamines (norepinephrine and epinephrine) were assessed by a radioenzymatic (COMT) method using HPLC for separation of radioactive products ${ }^{18}$.

\section{Statistical analysis}

Results are expressed as means and standard deviation. Regression analysis was applied to detect associations between variables. Associations that were found to be significant in univariate analysis were grouped together and tested again in a multivariate analysis. A sliding mean analysis technique was used to explore the relationship between changes in blood pressure and certain aspects of volume control. A p-value $<0.05$ was considered to denote statistical significance.

\section{Results}

in twelve of the sixty-seven patients at least one of the seven urine collections was incomplete, making it impossible to calculate in these subjects cumulative sodium losses after the dietary intervention. These patients were therefore excluded from analysis. Urinary creatinine excretion averaged $14 \pm 4 \mathrm{mmol} / 24$ hour for the entire study period. Baseline characteristics of the remaining 55 patients are presented in table 1. The study population consisted of 36 men and 19 women who were all of European descent. Mean age was 41 years with a range from 20 to 67 years. At the start of the study blood pressure was, on average, in the hypertensive range but 
three patients proved to have normal blood pressure at that time. Mean 24-hour urinary sodium excretion on admission was $121 \mathrm{mmol}$, but varied over a wide range. In six subjects initial sodium excretion was below $70 \mathrm{mmol}$ per 24 hour. In the whole group baseline concentrations of catecholamines, renin, angiotensin II and aldosterone in plasma were normal, but in eleven of the 55 patients (20\%) renin levels were low. These low-renin patients did not differ from the others with respect to age, weight, initial blood pressure and baseline sodium excretion.

Table I. Patient characteristics at baseline

\begin{tabular}{lcc}
\hline & Mean \pm SD & Range \\
\hline Age (years) & $43 \pm 11$ & $22-67$ \\
Male/fernale & & \\
Weight (kg) & $80 \pm 14$ & $52-114$ \\
Systolic pressure (mmHg) & $161 \pm 22$ & $106-212$ \\
Diastolic pressure (mmHg) & $107 \pm 11$ & $85-130$ \\
Heart rate (bpm) & $79 \pm 9$ & $61-97$ \\
UnaV (mmol/day) & $121 \pm 56$ & $49-274$ \\
UkV (mmol/day) & $56 \pm 21$ & $14-105$ \\
UcreatV (mmol/day) & $14.1 \pm 4.2$ & $7.0-27.0$ \\
Norepinephrine (nmol/l) & $1.65 \pm 0.80$ & $0.15-3.59$ \\
Epinephrine (nmol/l) & $0.25 \pm 0.18$ & $0.02-1.03$ \\
APRC (mU/l) & $17.9 \pm 9.1$ & nd-41.0 \\
AngII (pmol/l) & $5.7 \pm 5.2$ & nd-15.0 \\
Aldo (pmol/l) & $304 \pm 169$ & $120-875$ \\
\hline
\end{tabular}

UnaV $=$ Urinary sodium excretion; $U k V=$ Urinary potassium excretion; UcrearV $=$ Urinary creatinine excretion; APRC $=$ Active plasma renin concentration; Ang $\Pi=$ Plasma angiotensin II; Aldo $=$ Plasma aldosterone; nd $=$ not detectable

\section{Cumulative sodium balance}

Twenty-four hour urinary sodium output amounted $121 \pm 56 \mathrm{mmol}$ at the start of the study, but fell gradually, as expected, during the first. few days of dietary restriction. A new steady state where sodium output again matched intake generally was reached by the fourth day, but time courses varied from three to six days. While cumulative sodium balance became negative in the majority of patients, in 10 of them (18\%) actually a positive balance was found at steady state. The latter 
was due to an extreme fall in urinary sodium output upon institution of the diet.

In the whole group cumulative sodium balance fell by an average of $112 \mathrm{mmol}$ (range -455 to $+155 \mathrm{mmol}$ ), which was associated with a mean weight loss of $1.8 \mathrm{~kg}$ (range -4 to $0 \mathrm{~kg}$ ). The total amount of sodium excreted over seven days was not related to age nor to initial weight or blood pressure. However, as shown in figure 1 cumulative sodium loss was positively related to sodium excretion on the first day of salt restriction $(y=1.6 x-77 ; r=0.68 ; p<0.001)$. In addition, an inverse correlation was found between renin concentration on the first day of the intervention and cumulative sodium loss $(y=203-5.1 x ; r=-0.36 ; p<0.01)$. In the multivariate analysis, however, only initial sodium excretion remained as a significant determinant of total sodium loss.

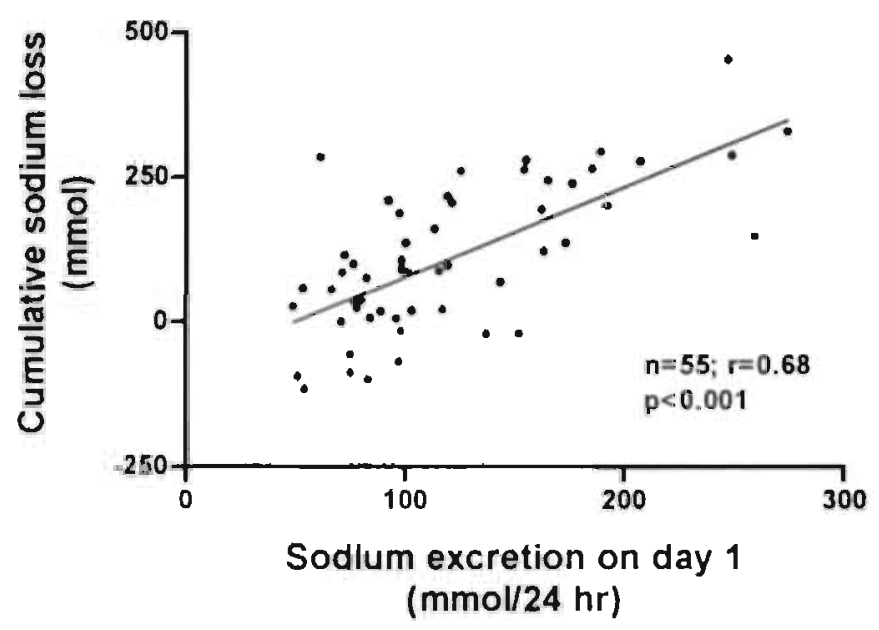

Figure 1. Scatterplor showing the relationship between sodium excretion on the first day of dietary restriction and cumulative sodium loss after one week

\section{Neurohumoral responses}

Renin concentrations rose appropriately dụring sodium restriction but individual renin responses varied widely: from a fall of $17 \mathrm{mU} / 1$ to a rise of $47 \mathrm{mU} / 1$ after three days and from a fall of $12 \mathrm{mU} / \mathrm{l}$ to a rise of $62 \mathrm{mU} / \mathrm{l}$ after one week. Changes in renin proved to be independent from baseline levels. The early renin response (i.e. the change in renin from the first to the third day) appeared to be inversely related to age $(y=19.7-0.35 x ; r=-0.36 ; p<0.01)$, whereas the final response (the change in renin after one week) was not. When patients were classified according to their renin response on the third day, those with the least 
response had the greatest increase in renin from day 3 to day 7 , while a slight fall in renin was seen in those patients with the largest increment in renin during the first three days.

Both on the third and on the seventh day renin responsiveness was inversely related to the pre-intervention mean arterial pressure $(y=36-0.26 x ; r=-0.45$; $p<0.001$ and $y=65-0.45 x ; r=-0.39 ; p<0.05$ respectively). Although the early renin response was not related to initial sodium excretion, a positive relationship was found between sodium excretion on the first day and renin levels on the last $(y=0.11 x-5.8 ; r=0.44 ; p<0.05)$. When the various factors were tested in a multivariate analysis model, age and pre-intervention MAP remained as the only independent determinants of the early and final renin response respectively. In other words, a higher age and a higher blood pressure blunted the changes in renin.

By and large, AngII and ALDO followed the same patterns as those observed for renin. There were, indeed, very close relationships between changes in renin and in AngII on the one hand and between changes in AngII and in ALDO on the other. In contrast to the alterations in the renin-angiotensin-aldosterone system, catecholamine concentrations remained stable throughout the study period.

\section{Blood pressure responses}

After seven days of sodium restriction changes in MAP varied from -49 to $+6 \mathrm{~mm}$ $\mathrm{Hg}$ (mean fall $16 \mathrm{~mm} \mathrm{Hg}$ ). Blood pressure fell by more than $10 \mathrm{~mm} \mathrm{Hg}$ in 36 of the 55 patients $(65 \%)$. Changes in blood pressure were not related to age, initial sodium excretion or renin on day 1. However, significant inverse relationships were observed between the final change in MAP and MAP on the first day ( $y=31$ $0.37 x ; r=-0.53 ; p<0.0001$ ) and between the change in mean arterial pressure and norepinephrine levels on day $1(y=-5.5-5.9 x ; r=-0.46 ; p<0.001)$. Both factors remained also significant in the multivariate analysis, indicating that a higher blood pressure and a higher level of norepinephrine before the intervention were associated with a greater fall in pressure.

\section{Interrelationships between changes in sodium balance, renin and blood pressure}

When patients in whom renin was unchanged or had fallen on the third day of sodium restriction were compared to those in whom renin had risen by that time, the former group displayed a significantly greater sodium output on the third and fourth day of the dietary restriction but not on any of the other days (figure 2). 


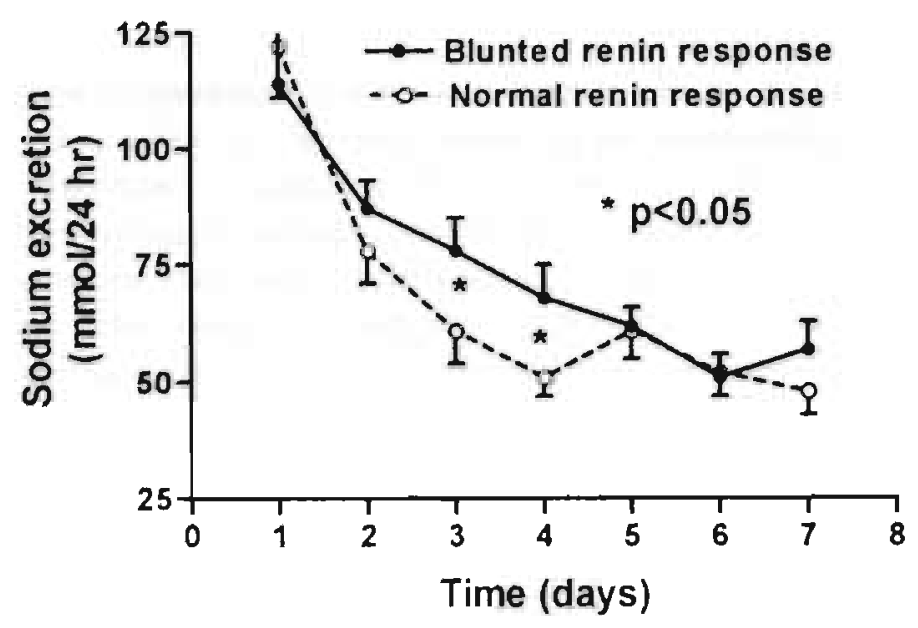

Figure 2. Line graph showing the change in urinary sodium output with time in patients, with. a normal (open circles) or a blunted (closed circles) early renin response

Moreover, the early renin response appeared to be a important predictor of total sodium loss as a significant inverse relationship was found between the degree of renin activation on the third day on the one hand and cumulative sodium loss after seven days on the other $(y=131-3.5 x ; r=-0.30 p<0.05$; figure $3 a)$. With respect to the final renin response after seven days, however, this relationship had reversed $(y=3.6 x+65 ; r=0.40 ; p<0.05)$. Multivariate analysis proved sodium excretion on the first day $(p<0.001)$ and both the initial $(p<0.001)$ and the final $(p<0.01)$ renin response to be independently related to total sodium lass with an overall explanatory power of $70 \%$. Also in this multivariate analysis absolute renin levels on the first day were not independently related to cumulative sodium loss.

As illustrated in figure $3 \mathrm{~b}$ the change in mean arterial pressure that had occurred at the end of the study period appeared to be significantly related to the early rise in renin $(y=0.4 x-17.4 ; r=0.40 ; p<0.005)$. No such relationship, however, was found with the final change in renin. Since changes in blood pressure were also related to blood pressure and norepinephrine levels on the first day (see above), we performed multivariate regression analysis to evaluate the relative importance of these factors. In fact, all three factors turned out to be significant and independent predictors of the final change in pressure with an explained variance of $46 \%$. 


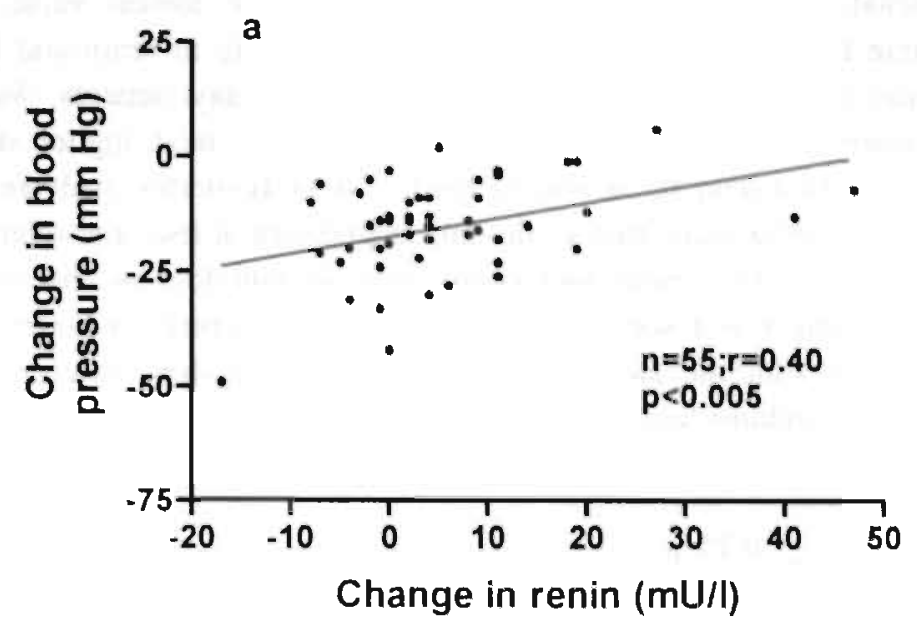

b

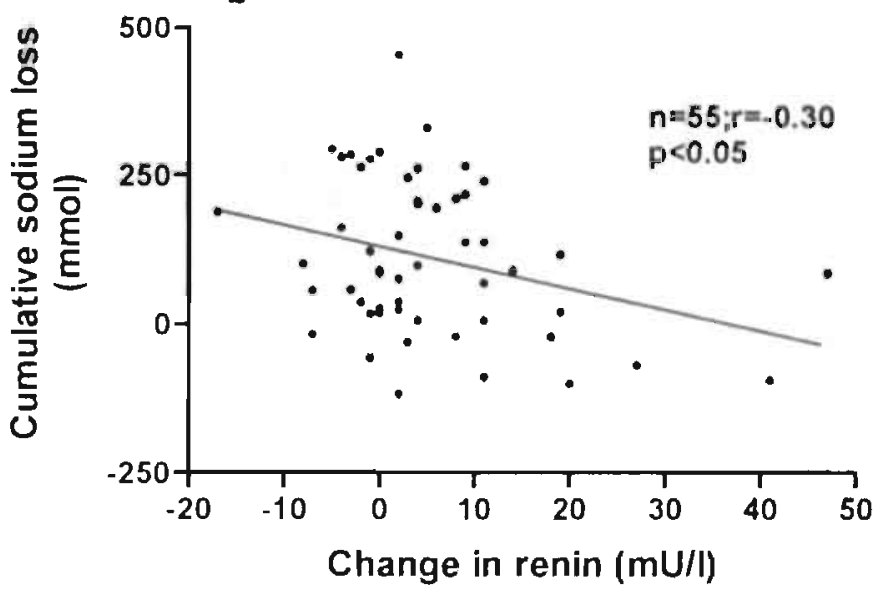

Figure 3. Scatterplots showing the relationship between the change in renin during the first three days of sodium excretion on the one hand and cumulative sodium loss (a: upper panel) or the final change in blood pressure (b: lower panel) after one week on the other hand

Although both cumulative sodium loss and the final change in blood pressure were reiated to the early rise in renin sodium losses and blood pressure after one week were not related to each other. Therefore, we tested whether the ultimate change in blood pressure was correlated with the 'strength' of the relationship between early renin activation and sodium loss. To this end we applied the technique of moving averages. Patients were ranked according to the magnitude of 
their blood pressure change and starting with the lowest value the correlation coefficient for the relationship between the early rise in renin and the final change in sodium balance was calculated for the first twenty patients. Subsequently, the same relationship was calculated after adding the next higher data point while deleting the first data point and so forth ${ }^{19}$. Results of this analysis are depicted in figure 4 . The data show that as the fall in pressure is less, the relationship between early renin responsiveness and cumulative sodium loss at the end of the study becomes stronger and statistically significant. Conversely, a larger fall in pressure is associated with the lack of a significant relationship between the early renin response and sodium loss.

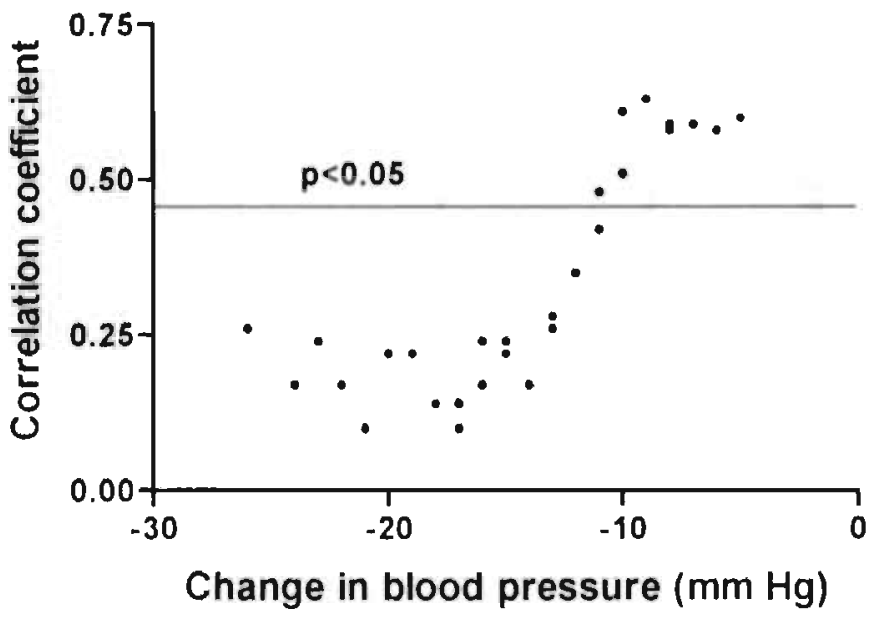

Figure 4. Scatterplot showing the relationship between the change in blood pressure after one week of sodium restriction and the correlation coefficient (sign omitting) that describes the strength of the relationship between early renin activation and final sodium loss. Each point represents the average of twenty patients and differs from the preceding or succeeding point by only one observation

\section{Discussion}

The mechanisms whereby sodium restriction lowers blood pressure in salt-sensitive individuals are still poorly understood. Although some investigators have suggested that salt-sensitive subjects differ from salt-resistant ones in their ability to achieve sodium balance on a low salt diet, others have failed to demonstrate consistent differences in sodium balance between salt-sensitive and salt-resistant patients ${ }^{20,21}$. 
Moreover, at least two groups have shown that alterations in blood pressure during dietary salt restriction are independent from changes in cumulative sodium loss ${ }^{22,23}$. However, in these studies a rather rigorous protocol to achieve sodium depletion was followed, including the administration of furosemide. Thus, while these results may be indicative for a state of true volume depletion, they do not necessarily reflect the relationship between volume and pressure under less extreme conditions. In the present study we adopted a more liberal approach. After admission to hospital all patients were put on a mildly sodium restricted diet $(55 \mathrm{mmol} / \mathrm{day})$ which probably better reflects real life situations. Ail patients had continued their habitual diet until the intervention, because we deliberately wanted to achieve a wide variation in cumulative sodium losses at the end of the dietary period. Not unexpectedly, we found that the total amount of sodium lost during the dietary period correlated with urinary sodium excretion on the first day of the study. In other words, changes in cumulative sodium balance following institution of a sodium restricted diet are to a large extent determined by the level of salt intake in the preceding period. Nevertheless, despite the large splay in cumulative sodium losses, we failed to find a relationship between changes in sodium balance and changes in blood pressure. In this respect our data corroborate and extent those from the earlier studies ${ }^{22,23}$.

When changes in blood pressure during sodium restriction are not determined by the degree of volume loss, other factors must be responsible. Since the reninangiotensin-aldosterone system is involved in both hemodynamic regulation and in volume homeostasis, we took multiple blood samples during the study to assess the responsiveness of this system. Contrary to others ${ }^{8}$ we could not find a relationship between baseline renin and final changes in blood pressure. However, our data do show some linkage between the degree of renin responsiveness and the magnitude of blood pressure changes. Although not very impressive, a positive relationship was observed between the early renin response (i.e. during the first three days of sodium restriction) and the difference between final and initial blood pressure, indicating that a greater renin response during the first few days of sodium restriction was associated with a lesser fall in pressure (figure $3 \mathrm{~b}$ ). In principle this confirms the data from others who have also shown that salt sensitivity is linked to a blunted responsiveness of the renin system ${ }^{1.20-22.24-26}$. Interestingly, though, our data also demonstrate that final changes in renin (i.e. after one week) do not correlate anymore with changes in blood pressure. Given the fact that salt sensitivity is not limited to subjects with suppressed renin, but also occurs among people with normal renin levels, our findings seem to suggest that an abnormal dynamic behavior of renin during the early phase of sodium loss rather than steady state levels of renin is linked to the phenomenon of salt sensitivity. Since an abnormal renin response is more likely to occur in patients with low renin levels or 
elderly patients, it is not surprising, therefore, that salt sensitivity is more prevalent in these groups.

The question now arises why hormonal responses that occur early during sodium restriction have such an impact on blood pressure a few days later. Although we can only speculate about the answer, it is noteworthy that the early renin response more or less coincides with the period that the organism is 'seeking' a new steady state to match urinary sodium excretion to sodium intake. Interestingly, we found an inverse relationship between early changes in renin and total sodium loss after one week. Thus, the more renin rises during the first few days of sodium restriction, the less sodium is lost. On the other hand, a positive association was found for final changes in renin and total sodium loss. Our explanation for these findings is as follows: when sodium intake is suddenly decreased, cumulative sodium balance falls in proportion to initial sodium intake. The greater the decrement in sodium balance, the more renin eventually rises. Thus, renin levels at the end of the dietary period seem to be dependent on the amount of sodium loss rather than the other way around. However, there appears to be a profound interindividual variation in the speediness of the renin response. As our data show (figure 2), a brisk renin response during the early days apparently limits the final sodium loss. As a consequence further stimulation of renin will be slowed down which, indeed, is exactly what we found. In patients with a more sluggish early response, on the other hand, we found a more pronounced rise in renin from day 3 to day 7 suggesting that the ongoing sodium loss finally enhanced renin release. As a corollary of these observations one would be inclined to conclude that a greater initial stimulation of renin is associated with both lesser volume depletion and a lesser fall in pressure and that, therefore, volume and pressure changes ought to be correlated. However, as stated above, such a correlation could not be detected in our data.

In an attempt to put these observations into better perspective we stretched the analysis of our data a little further by exploring the dynamic relationship between the fall in pressure on the one hand and the volume-renin connection on the other. To this end we plotted the correlation coefficient that described. the relation between the early renin response and the final change in cumulative sodium balance as a function of the fall in blood pressure using a sliding mean analysis technique. As the plot in figure 4 clearly shows, there is a tight and statistically significant relationship between initial renin stimulation and sodium loss in the patients in whom blood pressure falls only slightly. However, a progressively greater drop in pressure is associated with uncoupling of this renin-sodium relationship. These observations may now provide an explanation for the lack of a relationship between changes in cumulative sodium balance and changes in blood pressure. For the same decline in cumulative sodium balance the change in blood pressure may not depend 
so much upon whether renin rises or not but upon whether renin rises fast enough as a function of sodium loss. Perhaps renin activation during salt restriction serves a dual purpose: in the first place it is needed to conserve sodium and maintain body sodium stores within acceptable limits. At the same time, however, the rise in renin causes the pressure-natriuresis curve to be shifted to the right in order to keep the equilibrium point at the same pressure level $22.27,28$. Once a new steady state has been attained, the role of circulating renin may become less important as compared to other mechanisms, e.g. intrarenal renin. This would also explain why some investigators failed to find an association between renin and salt sensitivity ${ }^{29.30}$.

The data from the present study do not allow to make inferences about the causes of a disturbed renin-volume relationship. According to our analyses, higher age, a higher initial blood pressure and higher norepinephrine levels may all play a part but further studies are needed to explore this. Volume expansion at the start of the study could also be involved but is less likely as in an earlier study we did not find a relationship between the degree of sodium sensitivity and plasma volume ${ }^{31}$.

In conclusion, we have shown that the degree of sodium sensitivity during sodium restriction is not solely determined by changes in cumulative sodium balance, but rather by a complex interplay between sodium loss and early (but not late) renin activation. In our view, it is not a suppressed renin system that is related to salt sensitivity, but rather the fact that the system is relatively fixed. Accordingly, it is our opinion that studies on the pathophysiology of sodium sensitivity of blood pressure should focus more on dynamic processes taking place early during dietary intervention rather than on differences at steady state. 


\section{References}

1 Fujita T, Henry WL, Bartter FC, Lake CR, Delea CS. Factors influencing blood pressure in salt-sensitive patients with hypertension. Am J Med 1980;69:334-344.

2 Koolen M1, Van Brummelen P. Adrenergic activity and peripheral hemodynamics in relation to sodium sensitivity in patients with essential hypertension. Hypertension $1984 ; 6: 820-825$

3 Campese VM, Romoff MS, Levitan D, Saglikes Y, Friedler RM, Massry SG. Abnormal relationship between sodium intake and sympathetic nervous system activity in salt-sensitive patients with essential hypertension. Kidney Int $1982 ; 21: 371-378$

4 Skrabal F, Kotanko P, Meister B, Doll P, Gruber G. Up-regulation of alpha adrenoreceptors and down-reguiation of beta ${ }_{2}$ adrenoreceptors by high-salt diet in normotensive men: enhanced up-regulation of operative (alpha ${ }_{2}: \mathrm{beta}_{2}$ ) adrenoreceplor ratic predicts salt sensitivity. J Hypertens 1986;4(suppl 6):S196S199.

5 Kawasaki T, Delea CS, Bartter FC, Smith H. The effect of high-sodium and lowsodium intakes on blood pressure and other related variables in human subjects with idiopathic hypertension. Am J Med 1978;64:193-198.

6 Kimura G, Ashida T, Abe H. Kawano Y, Yoshimi H, Sanai T, Imanishi M, Yoshida K, Kawamura M, Kojima S, Kuramochi M, Omae T. Sodium sensitive and sodium retaining hypertension. Am J Hypertens 1990;3:854-858.

7 Williams GH, Hollenberg NK. 'Sodium-sensitive' essential hypertension: emerging insights into pathogenesis and therapeutic implications. Contemp Nephrol 1985:3:303-331.

8 Weinberger MH, Miller JZ, Luft FC, Grim CE, Fineberg NS. Definitions and characteristics of sodium sensitivity and blood pressure resistance. Hypertension 1986;8 (Suppl II):III127-II134.

9 Stamler J, Rose G, Elliott P, Dyer A, Marmot M, Kesteloot H, Stamler R. Findings of the international cooperative INTERSALT study. Hypertension 1991;17 (suppl 1):I9-I15.

10 Dustan HP, Kirk KA. Relationship of sodium balance to arterial pressure in black hypertensive patients. Am J Med Sci 1988;31:378-383.

11 Pecker MS, James GD, Laragh JH, Sealy JE. Plasma prorenin is inversely related to the salt sensitivity in borderline to mild hypertension. J Am Soc Nephrol $1993 ; 4: 537$ (abstract).

12 Longworth DL, Drayer JIM, Weber MA, Laragh JH. Divergent blood pressure responses during short term sodium restriction in hypertension. Clin Pharmacol Ther 1980;27:544-546.

13 Parfrey PS, Markandu ND Roulston JE, Jones BE, Jones JC, MacGregor GA. Relation between arterial pressure, dietary sodium intake and renin system in essential hypertension. Br Med J 1981;283:94-97. 
14 Koolen MI, Van Brummelen P. Sodium sensitivity in essential hypertension: role of the renin-angiotensin-aldosterone system and predictive value of an intravenous frusemide test. J Hypertens 1984;2:55-59.

15 Simon D, Hartmann BJ, Badouaille G, Caillot G, Guyenne TT, Corvol P, Pau B, Marchand J. Two-site direct immunoassay specific for active renin. Clin Chem 1991:38:1959-1962.

16 Kubasik NP, Warren K, Sine HE. Evaluation of a new commercial radioassay kit for aldosterone using an iodinated tracer. Clin Biochem 1978:12:59-61.

17 Nussberger J, Brunner DB, Waeber B, Brunner HR. True versus immunoreactive angiotensin II in human plasma. Hypertension 1985;7 (Suppl 1):I1-17.

18 Endert E. Determination of epinephrine and norepinephrine in plasma by a radioenzymatic assay using high pressure liquid chromatography for the separation of the radiochemical products. Clin Chim Acta 1979;96:233-239.

19 Chau NP, Safar ME, Weiss YA, London GM, Simon ACh, Milliez PL. Relationships between cardiac output, heart rate and blood volume in essential hypertension. Clin Sci Mol Med 1978;54:175-180.

20 Campese VM. Salt sensitivity in hypertension. Renal and cardiovascular implications. Hypertension 1994;23:531-550.

21 Weinberger MH. Salt sensitivity of blood pressure in humans. Hypertension 1996;27:481-490.

22 Fraser R, Davies DL, Zoccali C, Usherwood T, Beretta-Piccoli C, Brown J, Cumming AMM, Lever AF, Robertson JIS, Watt R. Relation of blood pressure and body sodium content during sodium depletion in normal and hypertensive subjects. J Cardiovasc Pharmacol 1984;6 (suppi 1):S107-S114.

23 Dustan HP, Kirk KA. Corcoran Lecture: the case for and against salt in hypertension. Hypertension 1989;13:696-705.

24 Overlack A, Ruppert M, Kolioch R, Göbel B, Kraft K, Diehl J, Schmitt W, Stumpe KO. Divergent hemodynamic and hormonal responses to varying salit intake in normotensive subjects. Hypertension 1993;22:331-338.

25 Sullivan JM, Ratts TE. Sodium sensitivity in human subjects. Hemodynamic and hormonal correlates. Hypertension 1988;11:717-723.

26 Van Paassen P, De Zeeuw D, Navis G, De Jong PE. Does the renin-angiotensin system determine the rena! and systemic hemodynamic responses to sodium in patients with essential hypertension? Hypertension 1996;27:202-208.

27 Girardin E, Caverzasio J, Iwai J, Bonjour JP, Muller AF, Grandchamp A. Pressure natriuresis in isolated kidneys from hypertension-prone and hypertension-resistant rats. Kidney Int 1980;18:10-19.

28 Guyton AC. Arterial pressure and hypertension. Philadelphia: WB Saunders, 1980.

29 Gerdts E, Myking OL, Omvik: P. Salt sensitive essential hypertension evaluated by 24 hour ambulatory blood pressure. Blood Press 1994;3:375-380.

30 Draaijer P, De Leeuw P, Maessen J, Van Hooff J, Leunissen K. Salt-sensitivity testing in patients with borderline hypertension: reproducibility and potential mechanisms. J Hum Hypertens 1995;9:263-269. 
31 Krekels MME, Van Es PN, Leunissen KML, De Leeuw PW. Sodium sensitivity of blood pressure in hypertensives is not related to sodium, but rather to renin. J Hum Hypertens 1996;10 (suppl 3):S127-S130. 


\section{Chapter 5}

\section{Dissociation between the renal effects of angiotensin I and II in sodium-restricted normal subjects}

MME Krekels, W Spiering, NC Schaper, AJHM Houben, PW de Leeuw 


\section{Abstract}

\section{Objective}

In the present study we compared the systemic and renal effects of equimolar doses of Angiotensin I (AngI) and Angiotensin II (AngII), in order to determine whether the effects of Angl can be fully explained by conversion of AngI into AngII in the plasma compartment.

\section{Methods}

Ten healthy volunteers whom were in balance on a sodium-restricted diet were studied on two separate occasions during which, in random order, infusions of human Angl or Angll were given in stepwise increasing doses of $0.3,1$ or 3 $\mathrm{pmol} / \mathrm{kg} \cdot \mathrm{min}$. Mean arterial pressure (MAP), heart rate, effective renal plasma flow (ERPF), glomerular filtration rate (GFR), renin (APRC), AngI, AngII, aldosterone (Aldo) and catecholamines were assessed at baseline, after each dose of AngI or AngII and thirty and sixty minutes after discontinuation of the AngI/AngII infusion.

\section{Results}

The rise in AngII was significantly lower during the AngI infusion than during the AngII infusion $(p<0.05)$. The increments in MAP and Aldo and the decrease in GFR, however, were comparable during both the infusion regimens. In the kidney, on the other hand, the fall in APRC and ERPF during the AngII infusion exceeded those during Angl $(\mathrm{p}<0.05)$. After cessation of the AngI/AngII infusion, the AngII concentrations returned to baseline as did MAP, ERPF and Aldo. Only renin remained significantly inhibited $(p<0.05)$. Catecholamines did not change during any of the experiments.

\section{Conclusions}

Our data suggest that the effects of Angl on blood pressure and aldosterone release may be brought about by AnglI, formed, at least partly, from the AngI at tissue sites. However, due to a low capacity of the kidney to convert AngI, the renal effects of Angl are less prominent than those of AngII. The longer-lasting inhibition of renin after cessation of the AngI/AngII infusion points towards accumulation of AngII in the kidney. 


\section{Introduction}

Conversion of angiotensin I (AngI) into angiotensin II (AngII) by angiotensinconverting enzyme (ACE) in tissues other than the lung may contribute to circulating levels of $\mathrm{AngI}^{1-3}$. Recently, Admiraal and coworkers demonstrated conversion of arterially derived AngI into AngII in the vascular bed of the forearm and leg, while they found only little evidence for conversion in the renal vascular $b^{4}$. The latter is in keeping with observations in the isolated perfused rat kidney showing that the AngI dose had to be 50 times higher than that of Angll to obtain equipotent vasoconstrictor effects ${ }^{5}$. These data, when added to the fact that AngII is very efficiently extracted from the circulation by the kidney ${ }^{4,69}$, and possibly sequestrated within that organ ${ }^{10}$, may lead to the hypothesis that also in human kidneys the effects of circulating AngI are less potent than those of circulating AngII. Such a difference in AngI/II effects does not necessarily apply to other vascular beds where, as opposed to the situation in the kidney, the conversion of AngI into AngII may be more pronounced ${ }^{7}$. If on the other hand, all circulating AngI would be converted on a 1:1 molar basis inte AngII in the plasma compartment before it reaches the renal vascular bed, the functional renal (hemodynamic) responses to AngI should be comparable to those of AngII.

These two opposing possibilities prompted us to study the effects of equimolar doses of AngI and AngII on the kidney. Both peptides were infused intravenously in order to allow conversion of AngI into AngII in plasma. A second objective of the study was to explore whether after cessation of the infusions the time course of the dissipation of the AngI/AngII effects on the kidney was congruent with the time course of the fall in plasma AngII. A discrepancy between these time courses could point towards accumulation of angiotensins in the kidney.

\section{Subjects and methods}

Ten healthy normotensive volunteers with a mean age of $49 \pm 2$ (mean \pm SEM) years and a body surface area of $1.76 \pm 0.06 \mathrm{~m}^{2}$ were included in this study. The protocol was approved by the Hospital Ethics Committee and written informed consent was obtained from all participants. Each subject had a medical history taken and underwent a physical examination. Routine laboratory tests were carried out before the start of the study. 


\section{Protocol}

During one week subjects were put on a moderate sodium restricted diet of 55 $\mathrm{mmol} /$ day; potassium intake was $80 \mathrm{mmol} / \mathrm{day}$. Compliance with the diet was checked by measuring sodium output in 24-hour urine collections obtained during the last three days of the study period. Completeness of urine collections was inferred from the concurrent creatinine excretion. Subjects refrained from smoking and alcohol; caffeine and caffeine-like substances were also forbidden on the study days. All volunteers were studied after an overnight fast in the morning of the last two days of the dietary period.

On these days two different experiments were conducted according to a randomized double-blind study design, where except for the infused substance (AngI or AngII), experimental conditions were similar on the two days. Studies started at 8.00 a.m and subjects remained supine during the entire session. In both arms an antecubital vein was cannulated with a $20 \mathrm{G}$ cannula: the one in the right arm was connected to a 3-way tap for the infusion of AngI/II and P-aminohippurate/inulin, whereas the one in the left arm was used for blood sampling. Subjects consumed $200 \mathrm{ml}$ of water every hour, to ensure diuresis, until the last blood samples had been drawn. After a two-hour equilibration period, necessary to reach steady state plasma concentrations of $\mathrm{PAH}$ and inulin, stepwise increasing equimolar doses of either human AngI or human AngII (Clinalfa AG, Laufelfingen, Switzerland) were administered. Infused doses were $0.3,1$ and 3 pmol $/ \mathrm{kg} . \mathrm{min}$. Each infusion step was continued for 30 minutes. Thereafter, the infusion was stopped and subjects were followed for another hour. The infusion rates were chosen on the basis of data from the literature and from earlier experiments performed in our laboratory.

Situdy variables were assessed and blood was drawn at baseline, after each dose of Angl or Angil and thirty $(t=120)$ and sixty $(t=150)$ minutes after cessation of the Angl/Angll infusion. Blood samples were drawn for measurement of PAH, inulin, hematocrit, and plasma levels of AngI and II, active plasma renin concentration (APRC), aldosterone (Aldo) and catecholamines. Moreover, mean arterial pressure (MAP) and heart rate (HR) were determined.

\section{Methods}

MAP and HR were measured by a semi-automatic oscillometric device (Dinamap Vital Signs Monitor 1846, Critikon, Tampa, FL, USA). Renal hemodynamics, i.e effective renal plasma flow (ERPF) and glomerular filtration rate (GFR) were measured as the clearance of $\mathrm{PAH}(\mathrm{PAH}$ : aminohippurate sodium; MSD, West Point, PA, USA) and inulin (Inutest, Laevosan Gesellschaft, Linz, Austria) respectively, using the continuous infusion method ${ }^{11}$. Both variables were corrected for body surface area and expressed as $\mathrm{ml} / \mathrm{min} .1 .73 \mathrm{~m}^{2}$. Effective renal blood flow 
(ERBF) was calculated using the formula: ERPF/(1-hematocrit). Filtration fraction (FF) was calculated as GFR/ERPF. Renal. vascular resistance (RVR) was calculated according to the formula: (MAP/ERBF)*80.000.

Active plasma renin concentration (APRC) was measured by the IRMA-method (Nichols Institute Diagnostics, Wychen, The Netherlands) with an intra-assay coefficient of variation (CV) of $2.9 \%$ and an inter-assay $\mathrm{CV}$ of $7.6 \%{ }^{12}$. Angll was determined by radio-immunoassay (RIA) following $\mathrm{Ph}$ Phenyl column extraction (Amersham Int., Amersham, UK; intra-assay CV $4.6 \%$ and inter-assay CV $7.7 \%)^{13}$. Aldosterone was assayed by means of a solid-phase protein binding RIA (Diagnostic Products Corporation, LA, USA; intra-and inter assay CV $4.3 \%$ and $6.7 \%$, respectively) ${ }^{14}$. PAH (intra-assay CV $4.2 \%$, inter-assay $\mathrm{CV}$ of $7.3 \%$ ) and inulin (intra-assay $\mathrm{CV} 4.5 \%$, inter-assay $\mathrm{CV} 8.1 \%$ ) levels were measured spectrophotometrically ${ }^{11,15}$. Norepinephrine (intra-assay CV $4.5 \%$, inter-assay CV $8.1 \%$ ), epinephrine (intra-assay $\mathrm{CV} 4.1 \%$, inter-assay $\mathrm{CV} 8.6 \%$ ) and dopamine (intra-assay CV $3.9 \%$, inter-assay CV $7.1 \%$ ) were assessed by a sensitive fluorimetric method, in which catecholamines are concentrated from plasma by liquid-liquid extraction and derivatized with a selective fluorescent agent prior to chromatography ${ }^{16}$.

For each hormone, all samples from the same individual were assayed in a single run.

\section{Data analysis}

Prior to statistical testing logarithmic or square root transformation of the data was performed, when appropriate. For each individual the difference in plasma AngII concentrations caused by the AngII infusion and those after the AngI infusion was calculated. Subsequently we tested, using confidence intervals $(\mathrm{C}$ !), whether these differences deviated significantly from zero.

To avoid the statistical problems which are inherent to the analysis of serial measurements ${ }^{17}$, we applied summary statistics (overall mean or median) to assess differences in the other variables between the AngI and AngII infusion regimens. To answer the main study question, the period from $t=0$ until $t=90$, coinciding with the angiotensin infusions, was analyzed separately. To determine whether after cessation of the AngL/AngII infusion variables had returned to baseline, we tested whether at the end of the experiment $(t=150)$ changes in variables differed significantly from zero.

Results are expressed as means \pm SEM. A p-value of less than 0.05 was considered significant. 


\section{Results}

After five days of sodium restriction ( $55 \mathrm{mmol} / 24$ hour) all subjects were in sodium balance (sodium excretion: $53 \pm 6 \mathrm{mmol} / 24$ hour), while potassium excretion averaged $58 \pm 8 \mathrm{mmol} / 24$ hour.

\section{Plasma levels of AngI and AngII}

At baseline plasma levels of both AngI and AnglI were comparable on the two study days (table 1). Changes in plasma AngI and AngII are depicted in figure 1a and $1 \mathrm{~b}$. AngII increased during both infusions, but the increment was significantly greater during the AngII than during the AngI infusion (figure 1a). Levels increased by $40 \pm 9 \mathrm{pmol} / \mathrm{l}$ during the AngII infusion as opposed to only $21 \pm 4$ $\mathrm{pmol} / \mathrm{l}$ during the AngI infusion $(\mathrm{p}<0.05)$. Sixty minutes after discontinuation of both infusions plasma AngII had returned to baseline.

No differences in responses of plasma AngI were observed between the AngI and the AngII infusion. During the two infusions plasma AngI declined by $14 \pm 3 \%$ and $14 \pm 5 \%$ respectively (figure $1 \mathrm{~b}$ ). Sixty minutes after discontinuation of the AngII infusion, Angl levels were still significantly suppressed by $22 \pm 9 \%$ $(p<0.05)$. In contrast, AngI levels had returned to baseline after stopping the AngI infusion.

Tabie 1. Hormonal baseline data (means \pm SEM)

\begin{tabular}{lcc}
\hline & AngI infusion & AngII infusion \\
\hline APRC $(\mathrm{mU} / \mathrm{l})$ & $24 \pm 2$ & $27 \pm 3$ \\
Angi $(\mathrm{pmot} / \mathrm{i})$ & $91 \pm 6$ & $86 \pm 7$ \\
Angli $(\mathrm{pmol} / \mathrm{l})$ & $14 \pm 2$ & $14 \pm 2$ \\
Aldo $(\mathrm{pmol} / \mathrm{l})$ & $209 \pm 36$ & $254 \pm 44$ \\
Epi $(\mathrm{nmol} / \mathrm{I})$ & $0.08 \pm 0.01$ & $0.08 \pm 0.01$ \\
Norepi $(\mathrm{nmol} / \mathrm{l})$ & $1.15 \pm 0.20$ & $1.10 \pm 0.23$ \\
Dopa $(\mathrm{nmol} / \mathrm{l})$ & $0.29 \pm 0.05$ & $0.23 \pm 0.02$ \\
\hline
\end{tabular}

APRC=active plasma renin concentration; AngI=angiotensin I; AngII =angiotensin II; Aldo=aldosterone: Epi=epinephrine: Norepi $=$ norepinephrine: Dopa $=$ Dopamine 


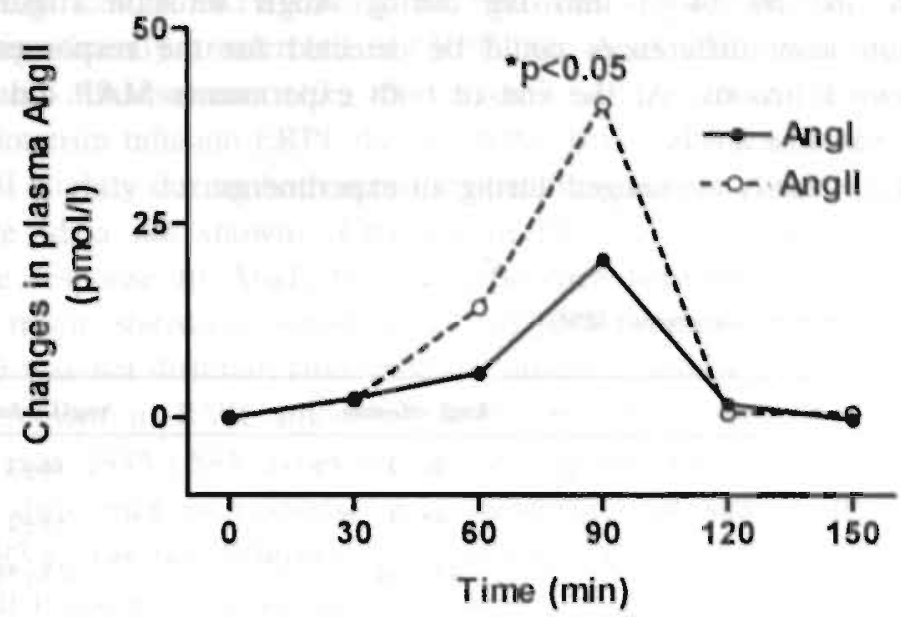

Figure 1a. Changes in plasma Angll concentrations (pmol/1). Angiotensin If (closed dots), Angiotensin II (open dots). " $p<0,05$ compared between the infusions

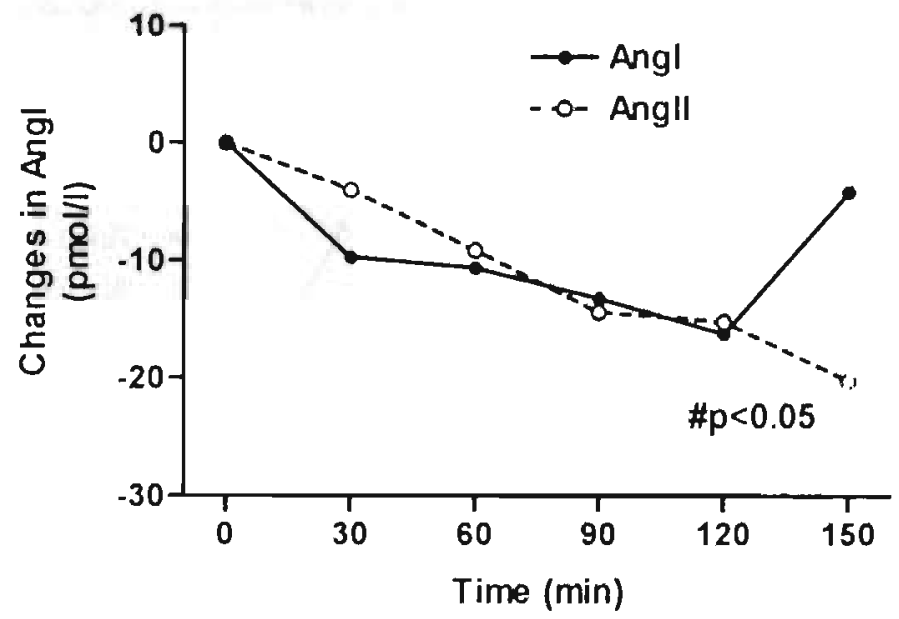

Figure 1b. Changes in plasma. Angl concentrations (pmol/1). Angiotensin I (closed dots). Angiotensin II (open dots). \#p<0,05 compared to baseline

Blood pressure and heart rate

Baseline MAP and HR were comparable on the study days (table 2). Both angiotensin infusions increased MAP to the same extent: by $15 \pm 3 \mathrm{~mm} \mathrm{Hg}$ during 
AngI infusion and by $14 \pm 5 \mathrm{~mm} \mathrm{Hg}$ during AngII infusion (figure 2). No statistically significant differences could be detected for the responses in MAP between the two infusions. At the end of both experiments MAP did not differ anymore from baseline levels.

HR remained virtually unchanged during all experiments.

Table 2. Hemodynamic baseline data (means \pm SEM)

\begin{tabular}{|c|c|c|}
\hline & Angl infusion & AngII infusion \\
\hline $\mathrm{MAP}(\mathrm{mm} \mathrm{Hg})$ & $90 \pm 3$ & $86 \pm 3$ \\
\hline HR (bpm) & $65 \pm 3$ & $65 \pm 2$ \\
\hline ERPF $\left(\mathrm{ml} / \mathrm{min} .1 .73 \mathrm{~m}^{2}\right)$ & $431 \pm 54$ & $423 \pm 58$ \\
\hline GFR $\left(\mathrm{ml} / \mathrm{min} .1 .73 \mathrm{~m}^{2}\right)$ & $101 \pm 10$ & $102 \pm 10$ \\
\hline$F F(\%)$ & $0.25 \pm 0.01$ & $0.25 \pm 0.01$ \\
\hline RVR (units) & $11639 \pm 1728$ & $11923 \pm 1735$ \\
\hline
\end{tabular}

AngI=angiotensin I; Angll=angiotensin. II; MAP=mean. arterial pressure; HR=heart rate: ERPF=effective. rena! plasma flow: $G F R=$ glomerular filtration rate; $\mathrm{FF}=$ filtration fraction: $\mathrm{RVR}=$ renal vascular resistance.

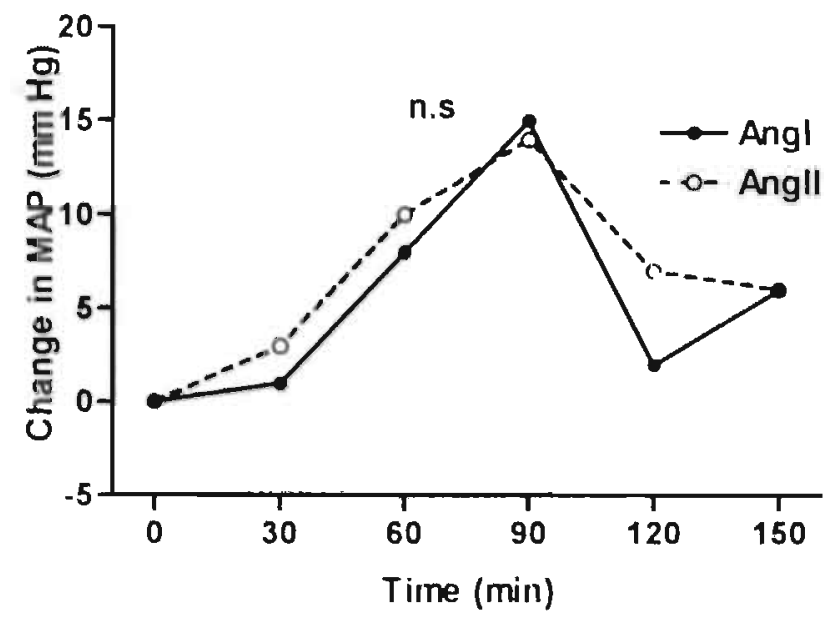

Figure 2. Changes in mean arterial pressure (mm Hg). Angiotensin I (closed dots). Angiotensin II (open dots)

\section{Renal responses}

Baseline renal hemodynamic data were not different on the two study days 
(table 2). Changes in ERPF during the infusions are depicted in figure 3. AngII caused a significantly greater fall in ERPF than AngI which was most pronounced at the highest infusion rates $(17 \pm 4 \%$ versus $7 \pm 4 \% ; p<0.05)$. Sixty minutes after either angiotensin infusion ERPF did not differ anymore from baseline.

GFR fell slightly during both infusions but responses to Angl and to AngII were comparable (data not shown). Changes in FF during Angll infusion tended to exceed the response to AngI, but the difference between the two infusions just failed to reach statistical significance $(17 \pm 5 \%$ versus $11 \pm 5 \% ; p=0.07)$. At $\mathrm{t}=150, \mathrm{FF}$ was not different from baseline on either infusion day.

The increment in RVR amounted $4377 \pm 969$ dynes.sec/ $\mathrm{cm}^{5}$ when Angll was infused versus $2845 \pm 584$ dynes.sec/ $\mathrm{cm}^{5}$ during the administration of Angl. This numerical difference in response was, however, not statistically significant. In addition, RVR was not different from baseline sixty minutes after cessation of the AngI/AngII infusion (data not shown).

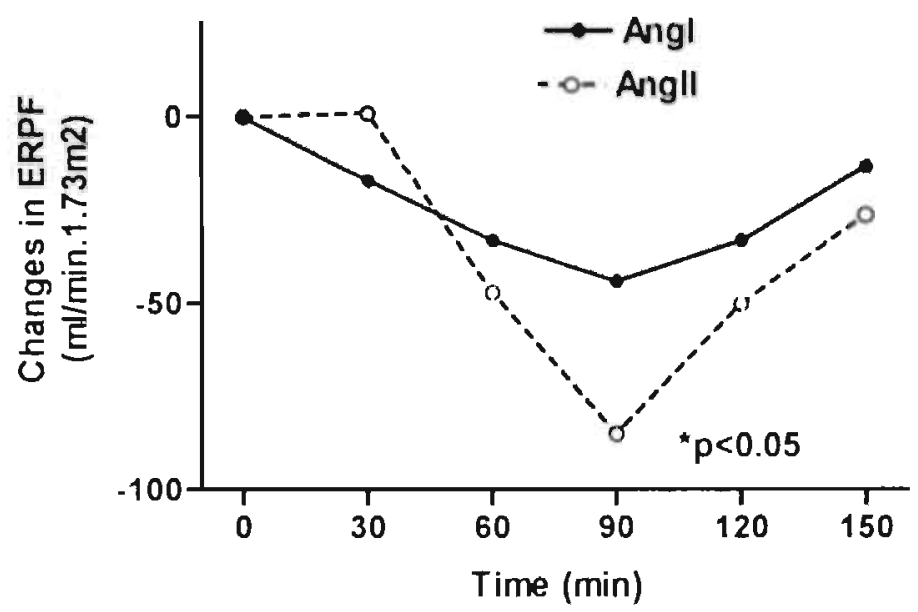

Figure 3. Changes in effective renal plasma flow $\left(\mathrm{ml} / \mathrm{min} \cdot 1.73 \mathrm{~m}^{2}\right)$. Angiotensin I (closed dots), Angiotensin. II (open, dots), " $p<0.05$ compared between the infusions

\section{Hormonal responses}

Hormonal data at baseline are given in table 1. Responses in APRC during the two infusions are shown in figure 4a. APRC fell during both angiotensin infusions but, on average, the percentage fall in APRC inflicted by the AngII infusion was significantly greater than that due to AngI $(33 \pm 5 \%$ versus $21 \pm 3 \%$; $<<0.05)$. At the end of the experiment $(t=150)$, APRC was still significantly suppressed after both substances $(\mathrm{p}<0.05)$, 
As illustrated in figure $4 \mathrm{~b}$, Aldo concentrations rose to the same extent during the AngI and AngII infusions, by $222 \pm 65 \%$ and $201 \pm 93 \%$ respectively (n.s). Aldo levels fell again after discontinuation of the infusions and did not differ anymore from baseline concentrations at $\mathrm{t}=150$.

Catecholamines did not change significantly during either angiotensin infusion.

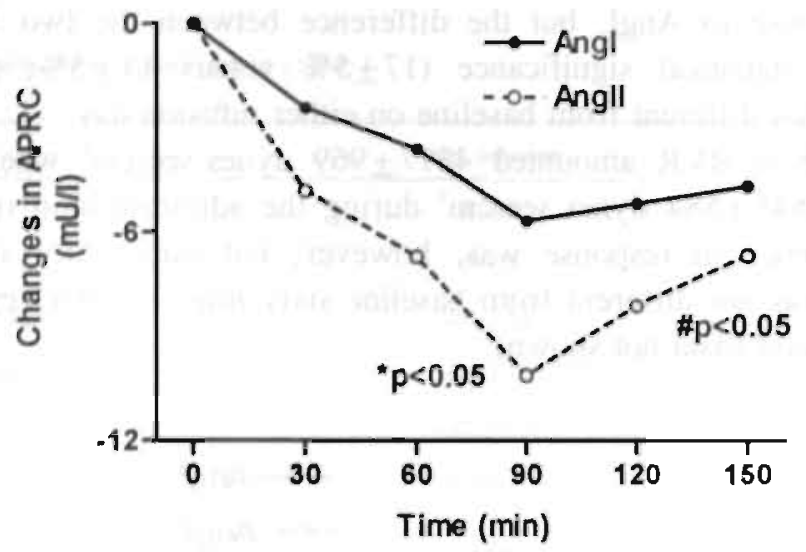

Figure 4a. Changes in active plasma renin concentrations (mU/)). Angiotensin I (closed dots), Angiotensin il (open dots). ${ }^{\mathrm{a}} \mathrm{p}<0,05$ compared between the infusion, \#p<0,05 compared to baseline

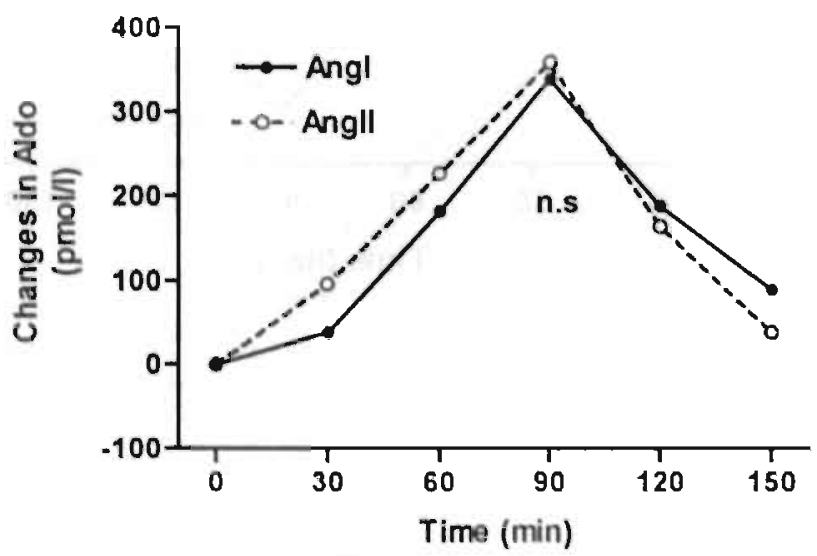

Figure 4b. Changes in plasma Aldosterone concentrations (pmol/1). Angiotensin I clatsed dats... Angiotensin II (open dots) 


\section{Discussion}

In the present study we compared the systemic and renal effects of equimolar doses of AngI and AngII. As the functional responses to both angiotensins may be influenced by dietary sodium, we studied the effects of AngI and II in subjects, who were in balance on a low sodium diet. Moreover, we infused [lle $]$-AngI and II, which are exact replicates of the endogenous peptides. To minimize carry-over effects the different infusions were given in random order and on separate days.

We anticipated that if, on a molar basis, there was a 1:1 conversion of AngI into AngII in the plasma compartment, the hemodynamic and humoral effects of the two peptides should be similar. If, on the other hand, the effects of AngI would be less prominent than those of AngII there would likely be insufficient conversion, either in plasma or at the tissue level. In particular, this would be relevant for the kidney where conversion of arterially delivered AngI is thought to be very low, if at all existent $t^{4}$.

One important result of the present study is that plasma AngII rose significantly less during the AngI than during the AngII infusion. Our data, therefore, could point to incomplete conversion of AngI into AngII, at least in the plasma compartment. However, since the concentrations of AngI remain in the picomolar range, which is well below the $\mathrm{Km}$ of $\mathrm{ACE}^{18}$, it is unlikely that saturation of $\mathrm{ACE}$ is responsible for the lesser increment in AngII levels after the Angl infusion. Moreover, with incomplete conversion one would expect some accumulation of AngI in plasma, which clearly was not the case. An alternative explanation for our findings could be that part of the infused AngI was rapidly metabolized by angiotensinases, either in plasma or in tissues ${ }^{19}$, thus leaving less AngI available for conversion. Although we cannot exclude this possibility, there are some striking features in our data that makes us think otherwise. Indeed, the rises in blood pressure and in plasma aldosterone, two well-known biological sequelae of an increase in AngII, were remarkably similar during the Angl and the AngII infusion. This suggests that the vascular wall and the adrenal cortex, as two of the major target tissues for the renin-angiotensin system, were facing similar AngII concentrations on both occasions. The lesser increment in plasma AngII concentrations after the AngI infusion could now be explained by tissue uptake of AngI and local conversion of this peptide into AngII. Since the rise in AngII was approximately $20 \%$ less during AngI than during AngII infusion, we would have to assume that about one-fifth of the administered AngI was converted at the tissue level. This fraction could even be higher if, after local conversion, the formed AngII would be released into the circulation.

Our study further shows discordant renal responses to AngI and AngII. In fact, the fall in ERPF during infusion of AngII was about twice as great as that during 
AngI infusion. In addition, AngI was less effective than AngII in suppressing renin. If our hypothesis about tissue uptake of AngI and local conversion is correct, the renal data point towards some disturbance of this mechanism in the kidney. Enhanced degradation of AngI in the kidney or a reduced capacity of this organ to convert AngI or both could all explain these findings. The group of Schalekamp has repeatedly shown that the kidney is not an important conversion site of arterially derived AngI but mainly metabolizes this peptide ${ }^{4.7 .19}$. Experiments in isolated perfused rat kidneys have also provided evidence that renal conversion of AngI is only limiteds. Data from experimental animals further suggest that higher renin levels, such as may occur during sodium restriction, are associated with reduced ACE-activity in the kidney ${ }^{20}$. If such a mechanism is also operative in man, this may have precluded renal conversion of AngI even more.

If there is only minimal conversion of AngI into AngII within the kidney, the fall in ERPF and in renin which were seen during the AngI infusion are most likely due to the effect of AngII that was formed in plasma and/or at extrarenal tissue sites before it reached the kidney.

As far as blood pressure, aldosterone and ERPF are concerned, variables had returned to baseline one hour after the infusions had been stopped and plasma AngII had fallen again to pre-infusion levels. Thus, with respect to these variables no dissociation between plasma levels of AngIl and its physiological effects were seen. However, with respect to renin such a dissociation did occur as renin was still suppressed one hour after cessation of the AngI or AngII infusion. The fall in renin may be attributed to short-loop feedback suppression by $\mathrm{AngII}^{21-23}$. Apparently, this suppressing effect on renin is longer-lasting than the other effects of AngII. A possible explanation for this discrepancy may be that AngII has accumulated in the kidne ${ }^{6,10}$.

During Angli infusion plasma levels of AngI declined significantly. This is in keeping with the data of Ménard and coworkers ${ }^{24}$, who also observed a fall in AngI during AngII infusion. Vos and associates even found a decrease in AngI concentrations when AngII was infused in subjects who had been treated with the ACE-inhibitor enalapril ${ }^{25}$. This decrement in AngI during AngII infusion can be fully explained by the fall in renin.

The drop in Angl levels during Angl infusion, however, is more surprising. As a matter of fact, we had expected a rise in plasma AngI concentrations, especially since we infused human AngI. Indeed, Vos and coworkers found a substantial increase in AngI levels during Angl infusion, but in their study not only the infused amounts of Angl were much higher, also the ACE-inhibitor enalapril had been administered for several days ${ }^{25}$. Thus, in the latter study accumulation of AngI could be expected. The same is true for the study of Admiraal and associates ${ }^{26}$. In our view, only an extremely rapid conversion of Angl into AngII with simultaneous 
suppression of renin release by AngII and, hence, reduced production of endogenous Angl could explain the fall in Angl levels which we observed in our study. Extra-pulmonary degradation of AngI $^{19}$ together with a high metabolic clearance rate of Angl $1^{9,26}$ could certainly be responsible for the dramatic fall in AngI levels.

Heart rate did not change and neither did plasma catecholamine concentrations. From earlier studies we learned that AngII concentrations had to increase thirteenfold in order to affect heart rate ${ }^{27}$. The infused amounts in our experiments, therefore could have been too low, to induce a change in sympathetic activity.

Taken together, our data suggest that the effects of Angl on blood pressure and aldosterone release may be brought about by AngII that is, at least partly, formed from the AngI at tissue sites. Consequently, the effects of exogenous AngI on blood pressure and aldosterone are comparable to those of equimolar doses of exogenous AngII. However, due to a low capacity of the kidney to convert AngI, the renal effects of AngI are less prominent than those of AngII. It is likely that the effects of AngI on the kidney require the formation of AngII at extrarenal tissue sites.

While most effects of both angiotensins subside soon after their administration is discontinued, suppression of renin release through the short feedback loop is longlasting. The latter is perhaps due to accumulation of AngII, which has been taken up from the circulation, in renal tissue. Although our hypotheses need to be tested in a more formal way, the data from the present study are at least consistent with the view that peripheral tissues are capable of regulating their own local production of AngII or uptake of this peptide from the circulation. 


\section{References}

1 Hilgers KF, Kuczera M, Wilhelm MJ, Wiecek A, Ritz E, Ganten D, Mann JFE. Angiotensin formation in the isolated rat hindlimb. J Hypertens 1989;7;789-798.

2 Kuczera M, Hilgers KF, Lisson C, Ganten D, Hilgenfeldt U, Ritz E, Mann JFE. Local angiotensin formation in the hindlimbs of uremic hypertensive and renovascular hypertensive rats. J Hypertens 1991;9:41-48.

3 Favre L, Valotton MB, Muller AF. Relationship between plasma concentrations of angiotensin $\mathrm{I}$, angiotensin II and plasma renin activity during cardiopulmonary bypass in man. Eur J Clin Invest 1974;4:135-140.

4 Admiraal PJJ, Danser AHJ, Jong MS, Pieterman H, Derkx FHM, Schalekamp MADH. Regional angiotensin II production in essential hypertension and renal artery stenosis. Hypertension 1993:21:173-184.

5 Hofbauer KG, Zsiedrich H, Rauh W, Gross F. Conversion of angiotensin I into angiotensin II in the isolated perfused rat kidney. Cli Sci 1973;44:447-456.

6 Navar LG, Rosivall L, Carmines P, Oparil S. Effects of locally formed angiotensin III on renal hemodynamics. Federation Proc 1986;45:1448-1453.

7 Danser AHJ, Koning MMG, Admiraal PJJ, Sassen LMA, Derkx FHM, Verdouw PD, Schalekamp MADH. Production of angiotensin I and II at tissue sites in the intact pig. Am J Physiol 1992;263:H429-H437.

8 Miller MJS, Scroop GC. Disappearance of angiotensin II and noradrenaline from the renal and femoral circulations of the dog. Clin Sci 1980;58:29-35.

9 Campbell DJ. Metabolism of prorenin, renin, angiotensinogen, and the angiotensins by tissues. In: Robertson MIS, Nicholls MG, Eds. The renin-angiotensin system. London, New York: Gower medical publishing 1993;23.1-23.23.

10 Zou L-X. Hymel A, Imig JD, Navar LG. Renal accumulation of circulating angiotensin III in angiotensin II-infused rats. Hypertension 1996;27:658-662.

11 Cole BR, Giangiacomo J, Ingelfinger JR, Rooson AM. Measurement of renal function without urine collection. A critical evaluation of the constant infusion technique for determination of inulin and para-aminohippurate. $\mathrm{N}$ Engl $\mathrm{J}$ Med 1972:287:1109-1114.

12 Simon D. Hartmann BJ, Badouaille G, Caillot G, Guyenne TT, Corvol P. Pau B, Marchand J. Two-site direct immunoassay specific for active renin. Clin Chem 1991;38:1959-1962.

13 Nussberger J, Brunner DB, Waeber B, Brunner HR. True versus immuno-reactive angiotensin II in human plasma. Hypertension 1985;7(Suppt I):I1-7.

14 Kubasik NP, Warren K, Sine HE. Evaluation of a new commercial radioassay kit for aldosterone using an iodinated tracer. Clin Biochem 1978;12:59-61.

15 Brun C. A rapid method for the determination of para-aminohippurate acid in kidney function tests. J Lab Clin Chem 1951;37:955-958. 
16 Van der Hoorn, Boomsma F, Man in't Veld AJ, Schalekamp MADH. Determination of catecholamines in human plasma by high-performance liquid chromatography: comparison between a new method with fluorescence detection and an established method with electrochemical detection. J Chromatography 1989;487:17-28.

17 Matthews JNS, Altman DG, Campbell MJ, Royston P. Analysis of serial measurements in medical research. Br Med J 1990;300-230-235.

18 Poulsen K, Jacobsen J. Enzymatic reactions of the renin-angiotensin system. In: Robertson JIS, Nicholls MG, Eds. The renin-angiotensin system. London, New York: Gower medical publishing 1993;5.1-5.12.

19 Danser AHJ, Koning MMG, Admiraal PJJ, Derkx FHM, Verdouw PD, Schalekamp MADH. Metabolism of angiotensin 1 by different tissues in the intact animal. Am J Physiol 1992;263:H418-H428.

20 Wilson SK, Lynch DR, Snyder SH. Angiotensin converting enzyme labeled with [ $\mathrm{H}$ ] captopril. J Clin Invest 1987;80:841-851.

21 Mersey JH, Ceballos L, Swartz S. Inhibition of captopril-induced renin release by angiotensin II. J Cardiovasc Pharmacol 1987;10:575-579.

22 Vander AJ, Geelhoed GW. Inhibition of renin secretion by angiotensin II. Proc Soc Exp Biol Med 1965;120:399-403.

23 De Champlain J, Genest J, Veyratt R, Boucher R. Factors controlling renin secretion in man. Arch Int Med 1966;117:355-363.

24 Ménard J, Guyene T, Chatellier G, Kleinbloesem CH, Bernadet P. Renin release regulation during acute renin inhibition in normal volunteers. Hypertension 1991; 18:257-265.

25 Vos PF, Boer P. Braam B. Koomans HA. Efficacy of intrarenal ACE-inhibition estimated from the renal response to angiotensin I and II in humans. Kidney Int $1995 ; 47: 274-281$.

26 Admiraal PJJ, Derkx FHM, Danser AHJ, Pieterman H. Schalekamp MADH. Metabolism and production of angiotensin I in different vascular beds in subjects with hypertension. Hypertension 1990; 15:44-55.

27 Motwani JG, Struthers AD. Dose-response study of the redistribution of intravascular volume by angiotensin II in man. Cli Sci 1992:82:397-405. 
66 


\section{Chapter 6}

\section{Possible discrimination between the effects of plasmatic versus tissue angiotensin II in man}

MME Krekels, SA Rodriguez, AJHM Houben, MJMJ Fuss, PMH Schiffers, PW de Leeuw 


\section{Abstract}

\section{Objective}

The purpose of this study was to evaluate whether it is possible to discriminate between the effects of tissue and plasma angiotensin II (AngII) in man. To this end an ACE-inhibitor was infused while plasma levels of AngII were maintained by exogenous AngII.

\section{Methods}

Nine healthy male volunteers on a sodium-restricted diet were studied on five separate occasions, during which in random order simultaneous infusions of enalaprilate (E) with either placebo (P) or AngII in doses of $0.3,0.5,1$ or 3 ng/kg.min were given. Mean arterial pressure (MAP), heart rate, forearm blood flow (FBF), effective renal plasma flow (ERPF), glomerular filtration rate (GFR), renin, AngII and aldosterone (Aldo) were assessed at baseline, after 30 minutes of the combined infusion and again 30 minutes after discontinuation of the AngII/P infusion.

\section{Results}

Plasma AngII levels were maintained at baseline levels only during the infusion of E with $0.5 \mathrm{ng} / \mathrm{kg} \cdot \min$ of AngII. With this combination MAP and Aldo did not change either. However, as compared to baseline ERPF significantly fell, while renal vascular resistance rose with the same combination $(p<0.05$ and $p<0.005$ respectively). Renin was significantly, but not entirely suppressed by the infusion of $\mathrm{E}$ with $0.5 \mathrm{ng} / \mathrm{kg}$. min of Angll. With the other doses of AngII more pronounced changes were noted. Both FBF and GFR remained unaltered during all experiments. Thirty minutes after cessation of the AngII infusions, plasma levels of AngII were back to baseline in all experiments. However, differences remained for ERPF, RVR and renin after the various infusions.

\section{Conclusions}

Maintenance of plasma A.ngl! during E infusion elicits renal vasoconstriction and incompletely suppresses renin, while leaving blood pressure and Aldo levels unchanged. After cessation of the AngII infusion, renal vasoconstriction persists and the more so when higher doses of AngII had been used. These effects could be related to renal uptake of AngIl from the circulation. 


\section{Introduction}

Over the last decade evidence has accumulated that, besides being a circulating system, the renin-angiotensin system (RAS) is also present in many tissues ${ }^{13}$. Campbell even suggested that the circulating RAS merely delivers renin and angiotensinogen to the tissues, where angiotensin I (AngI) and angiotensin II (AngII) are generated locally ${ }^{4}$. Although data from both animals and humans suggest that AngI and AngII may, indeed, be formed within tissues ${ }^{5.9}$, several organs are also capable of extracting angiotensins directly from the plasma ${ }^{10.11}$. It is noteworthy, though, that the extraction of plasma AngII by the kidney, an organ with an exquisite sensitivity for the action of AngII, is much higher as compared to that by other tissues, such as the heart or the hindlimb ${ }^{12}$. These observations point to a more active role of certain tissues in the regulation of angiotensin mediated effects. Whatever the processes involved (uptake or local production of AngII), it is unlikely that plasma concentrations of AngII sufficiently reflect the concentrations of this peptide hormone at the tissue level. Similarly, the physiological effects of AngII may not entirely relate to its plasma concentrations.

Although there is ample evidence from experimental studies that the regulation. of tissue RAS is different and independent from the regulation of plasma RAS ${ }^{13,14}$, until now it has been difficult to study tissue RAS in humans. Despite several attempts to dissociate the effects of AngII from its plasma levels, in none of these studies plasma AngII remained unaltered ${ }^{15,16}$. This prompted us to set up a series of experiments, in which we attempted to block angiotensin converting enzyme (ACE) without lowering plasma AngII. To this end, we concurrently infused the ACEinhibitor enalaprilate with varying doses of AngII. In doing so, we aimed at finding a dose of AngIl that would leave plasma AngII unaltered during the administration of the ACE-inhibitor.

Following 30 minutes of combined infusion, the administration of Angll was suddenly stopped to allow plasma AngII to fall again. With the ACE-inhibitor infusion still continuing, changes in hemodynamic and neurohumoral variables that would occur upon the cessation of angiotensin infusion would now most likely be due to the fall in plasma angiotensin II.

As it has been suggested that the circulating RAS is more important for acute cardiovascular homeostasis, whereas tissue RAS is essential for long-term regulation of the circulation ${ }^{17}$, discrimination between the effects of circulating RAS and tissue RAS may be most prominent during acute intervention or manipulation of the RAS. In other words, if the effects of acute manipulation of the RAS are mediated primarily by circulating RAS, than the observed effects should show a tight relationship with (changes in) plasma AngII. If they are not, than other factors, such as tissue AngII, may also play a role. 


\section{Subjects and methods}

Nine healthy normotensive male volunteers with a mean age of $24 \pm 1$ $\left(\right.$ mean \pm SEM) years and a body surface area of $1.93 \pm 0.05 \mathrm{~m}^{2}$ were included in this study. The protocol was approved by the Hospital Ethics Committee and written informed consent was obtained from all participants. Each subject had a medical history taken and underwent a physical examination. Routine laboratory tests were carried out before the start of the study.

\section{Protocol}

During twelve days subjects were put on a moderate sodium restricted diet of 55 mmol/day; potassium intake was $80 \mathrm{mmol} / \mathrm{day}$. Compliance with the diet was checked by measuring sodium output in 24-hour urine collections obtained during the last 6 days of the study period. Completeness of urine collections was estimated from the concurrent creatinine excretion. Subjects refrained from smoking and alcohol; caffeine and caffeine-like substances were also forbidden on the study days. All volunteers were studied after an overnight fast in the morning of each of the last five days of the dietary period. Five different experiments were conducted according to a randomized single-blind placebo-controlled study design, where except for the dose of AngII, experimental conditions were similar on the five days.

All studies started at 8.00 a.m and subjects remained supine during the entire session. In both arms an antecubital vein was cannulated with a $20 \mathrm{G}$ cannula: the one in the right arm was connected to a 3-way tap for the infusion of AngII/placebo, enalaprilate and $\mathrm{P}$-aminohippurate/inulin, whereas the one in the left arm was used for blood sampling. Subjects consumed $200 \mathrm{ml}$ of water every hour, to ensure diuresis, until the last blood samples had been drawn. After a twohour equilibration period, necessary to reach steady state plasma concentrations of PAH and inulin, a bolus injection of $4 \mathrm{ml}(=4 \mathrm{mg}$ ) of enalaprilate (MSD, Haarlem, The Netherlands) was given followed by a continuous infusion of 0.02 $\mathrm{mg} / \mathrm{min}$. In random order on the different study days a 30 minute infusion of either placebo $(0.9 \%$ saline $)$ or $\left[\mathrm{Ile}^{5}\right]$ AngII (Clinalfa AG, Laufelfingen, Switzerland) in doses of $0.3,0.5,1$ or $3 \mathrm{ng} / \mathrm{kg}$.min was started concurrently with the enalaprilate. After 30 minutes of combined infusion the placebo/AngII infusion was stopped, whereas the enalaprilate infusion was continued for another 30 minutes.

The Angll infusion rates were chosen on the basis of data in the literature on attained plasma AngII levels during AngII infusions and from earlier experiments in our laboratory. At least one of our infusion regimens was expected to maintain plasma AngII levels at baseline level. Study variables were assessed and blood was 
drawn at baseline, after 30 minutes of combined infusion $(t=30)$ and at the end of each experiment $(t=60)$. Blood samples were drawn for measurement of $\mathrm{PAH}$, inulin, hematocrit and plasma levels of AngII, active plasma renin concentration (APRC), aldosterone (Aldo) and angiotensin converting enzyme (ACE). Moreover, mean arterial pressure (MAP), heart rate (HR) and forearm blood flow (FBF) were assessed.

\section{Methods}

MAP and HR were measured by a semi-automatic oscillometric device (Dinamap Vital Signs Monitor 1846, Critikon, Tampa, FL, USA). Renal hemodynamics, i.e effective renal plasma flow (ERPF) and glomerular filtration rate (GFR) were measured as the clearance of PAH (PAH: aminohippurate sodium; MSD, West Point, PA, USA) and inulin (Inutest, Laevosan Gesellschaft, Linz, Austria) respectively, using the continuous infusion method ${ }^{18}$. Effective renal blood flow (ERBF) was calculated using the following formula: ERPF/(1-hematocrit). Filtration fraction (FF) was calculated using the equation: GFR/ERPF. Renal vascular resistance (RVR) was calculated according to the formula: $(\mathrm{MAP} / \mathrm{ERBF}) * 80000$.

The Dinamap cuff was replaced by a pneumatic cuff for five minutes during measurements of FBF. FBF was estimated by ECG-triggered venous occlusion plethysmography ${ }^{19}$. A pneumatic cuff connected to a rapid cuff inflator was placed around the left arm. The cuff was inflated to $50 \mathrm{~mm} \mathrm{Hg}$ during three heart beats to impede venous back flow and was deflated again during two heart beats. Midforearm expansion was measured continuously over a 5 minute period using a mercury-in-silastic strain gauge stretched to $2 \%$ past its resting length and connected to a plethysmographic system (Periflow, Janssen Scientific Instruments, Belgium) and a computerized data acquisition system. Before each recording another cuff was placed around the left wrist and inflated to $200 \mathrm{~mm} \mathrm{Hg}$ to exciude the hand circulation. Forearm vascular resistance (FVR) was calculated as: MAP/FBF.

Active plasma renin concentration (APRC) was assessed by the IRMA-method (Nichols Institute Diagnostics, Wychen, The Netherlands) with an intra-assay coefficient of variation (CV) of $2.9 \%$ and an inter-assay $\mathrm{CV}$ of $7.6 \%{ }^{20}$. AngIl was determined by radio-immunoassay (RIA) following $\mathrm{Ph}$ Phenyl column extraction (Amersham Int. Amersham, UK; intra-assay $\mathrm{CV} 4.6 \%$ and inter-assay $\mathrm{CV} 7.7 \%)^{21}$. Aldosterone was assayed by means of a solid-phase protein binding RIA (Diagnostic Products Corporation, LA, USA; intra-and inter assay CV $4.3 \%$ and $6.7 \%$, respectively) ${ }^{22}$. $\mathrm{PAH}$ (intra-assay $\mathrm{CV} 4.2 \%$, inter-assay $\mathrm{CV} 7.3 \%$ ), inulin (intraassay CV $4.5 \%$, inter-assay CV $8.1 \%$ ) and ACE (intra-assay CV $3.9 \%$, inter-assay 
CV $7.1 \%$ ) levels were measured spectrophotometrically ${ }^{18.23 .24}$.

For each substance, all samples from the same individual were assayed in a single run.

\section{Data analysis}

To avoid the statistical problems which are inherent to the analysis of serial measurements ${ }^{25}$, we applied summary statistics to assess differences between the infusion regimens. The two periods ( 0 to 30 minutes for combined infusions and 30 to 60 minutes for enalaprilate only) were considered separately. In order to determine which infusion rate would leave plasma AngII unaltered, we first analyzed mean changes in plasma AngII with their confidence intervals (CI) at the end of the combined infusion $(\mathrm{t}=30)$. Subsequently, changes in all other variables were tested at $t=30$ by one-way analysis of variance or by the Kruskal-Wallis test depending on the homogeneity of variance or normality of the data.

Prior to statistical testing logarithmic or square root transformation of the data was performed, when appropriate. When the F-ratio was significant, contrasts were used to compare the different infusion regimens. One contrast was defined a priori, namely between the infusion regimen during which plasma AngII remained unaltered and the control experiment where only the ACE-inhibitor was given. If this yielded a significant effect, the next step was to determine whether changes induced by the combined infusion differed significantly from zero. The latter was done to answer the main study question.

All other data are presented in the graphical analyses. Data points at $t=60$ were analyzed in the same way. Results are expressed as means \pm SEM. A p-value of less than 0.05 was considered significant.

\section{Results}

After six days of sodium restriction all subjects were in sodium balance $(38 \pm 7$ mmol/24 hour), while potassium excretion amounted $58 \pm 7 \mathrm{mmol} / 24$ hour.

Baseline measurements of the study population are given in table 1. Baseline data were comparable on all five study days. ACE-activity in plasma was adequately inhibited (measured ACE-activity below 2U/1) both at $t=30$ and $t=60$ in all experiments. 
Table 1. Baseline data on the five experimental days.

\begin{tabular}{lccccc}
\hline & E+placebo & E+ 0.3 ng AII & E+0.5 ng AII & E+1 ng AII & E+3 ng AII \\
\hline Ang II (pmol/l) & $15.0 \pm 2.5$ & $14.1 \pm 2.2$ & $12.7 \pm 2.2$ & $16.6 \pm 2.2$ & $14.5 \pm 2.3$ \\
APRC (mU/1) & $53 \pm 10$ & $57 \pm 9$ & $61 \pm 8$ & $41 \pm 6$ & $39 \pm 8$ \\
Aldo (pmol/l) & $345 \pm 53$ & $424 \pm 74$ & $280 \pm 53$ & $522 \pm 103$ & $469 \pm 117$ \\
MAP (mm Hg) & $83 \pm 3$ & $84 \pm 3$ & $86 \pm 2$ & $82 \pm 4$ & $88 \pm 3$ \\
HR (bpm) & $62 \pm 3$ & $59 \pm 3$ & $65 \pm 5$ & $57 \pm 3$ & $55 \pm 2$ \\
FBF (ml/100ml/min) & $1.9 \pm 0.2$ & $2.2 \pm 0.3$ & $2.3 \pm 0.2$ & $2.1 \pm 0.5$ & $2.7 \pm 0.7$ \\
ERPF (ml/min. $\left.1,73 \mathrm{~m}^{2}\right)$ & $468 \pm 35$ & $449 \pm 30$ & $591 \pm 49$ & $492 \pm 38$ & $495 \pm 38$ \\
GFR (ml/min. $\left.1.73 \mathrm{~m}^{2}\right)$ & $118 \pm 7$ & $114 \pm 6$ & $126 \pm 5$ & $119 \pm 6$ & $123 \pm 5$ \\
\hline
\end{tabular}

$\mathrm{E}=$ enalaprilate $\mathrm{ANGII}=$ angiotensin $\mathrm{II} ; \mathrm{APRC}=$ active plasma renin concentration;

Aldo=aldosterone $\mathrm{MAP}=$ mean arterial pressure; $\mathrm{HR}=$ heart rate; $\mathrm{FBF}=$ forearm blood flow;

$\mathrm{EIRPF}=$ effective renal plasma flow; GFR = glomerular filtration rate 


\section{Plasma AngII concentrations}

Changes in plasma AngII at thirty and sixty minutes are shown in figure 1. During the control experiment (enalaprilate plus placebo) plasma AngII levels fell by $7.3 \pm 1.4 \mathrm{pmol} / \mathrm{l}(\mathrm{CI}:-10.3$ to $-4.4 \mathrm{pmol} / \mathrm{l} ; \mathrm{p}<0.05)$. Also, when the peptide was infused at a rate of $0.3 \mathrm{ng} / \mathrm{kg} \cdot \mathrm{min}$, plasma AngII fell significantly. After 30 minutes of the combined infusion the concentration of AngII had fallen by $5.2 \pm 1.9$ $\mathrm{pmol} / \mathrm{l}$ (CI:-9.5 to $-0.9 \mathrm{pmol} / \mathrm{l} ; \mathrm{p}<0.05$ ). With the two highest infusion rates (i.e. 1 and $3 \mathrm{ng} / \mathrm{kg}$. $\mathrm{min}$ ) plasma AngII increased by $9.9 \pm 3.7 \mathrm{pmol} / \mathrm{l}$ (CI: 1.3 to 18 ) and $51 \pm 14 \mathrm{pmol} / \mathrm{l}$ (CI: 18 to 84 ) respectively (both $\mathrm{p}<0.05$ ). Only when 0.5 $\mathrm{ng} / \mathrm{kg}$.min of AngII was infused, plasma AngII did not differ significantly from baseline after thirty minutes (change $0.2 \pm 1.0 \mathrm{pmol} / \mathrm{l}$; $\mathrm{CI}:-2.3$ to +2.7 ; ns).

At the end of the experiments $(t=60)$ plasma AngII had fallen below baseline levels when $0,0.3$ or $0.5 \mathrm{ng} / \mathrm{kg}$. min had been infused in the first half hour, while they were back again at baseline with the two highest infusion rates (figure 1). By analysis of variance, however, differences between the various experiments were not significant.

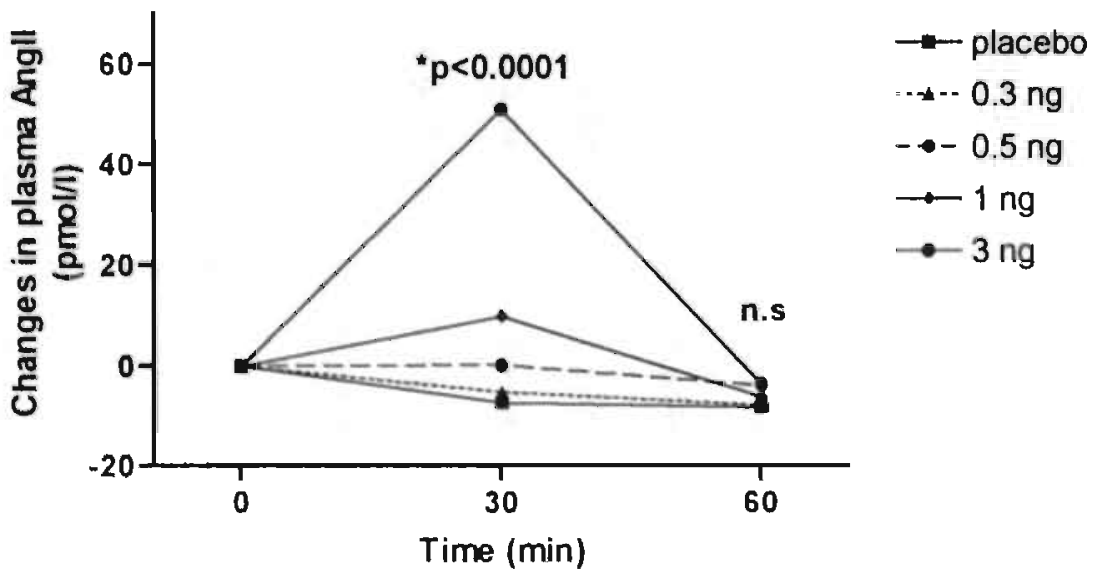

Figure 1. Absolute changes in plasma Angll concentrations during the various experiments. " $p<0,0001$ as compared between the different AngII infusion regimens combined with $\mathrm{ACE}$ inhibition 


\section{Blood pressure and heart rate}

Basal values of MAP and HR, defined as the mean of the last six measurements during the two-hour equilibration period, were comparable on the different study days (table 1). The absolute changes in MAP as recorded during the various experiments are depicted in figure 2. At $t=30$ a significant overall difference existed among the five experiments $(p<0.002)$ and pairwise analysis revealed that the fall in MAP was significantly greater during the control experiment than in the experiment with the $0.5 \mathrm{ng} / \mathrm{kg}$.min infusion $(\mathrm{p}<0.02)$. In the latter study the blood pressure response did not differ significantly. from zero.

At the end of the experiments at $t=60$, i.e. 30 minutes after discontinuation of the AngII infusion, MAP had fallen in a way that paralleled the fall in pressure during ACE-inhibition alone. At that time the overall analysis indicated that there were no differences anymore between the five infusion protocols (figure 2).

No significant changes in HR were observed during any of the experiments.

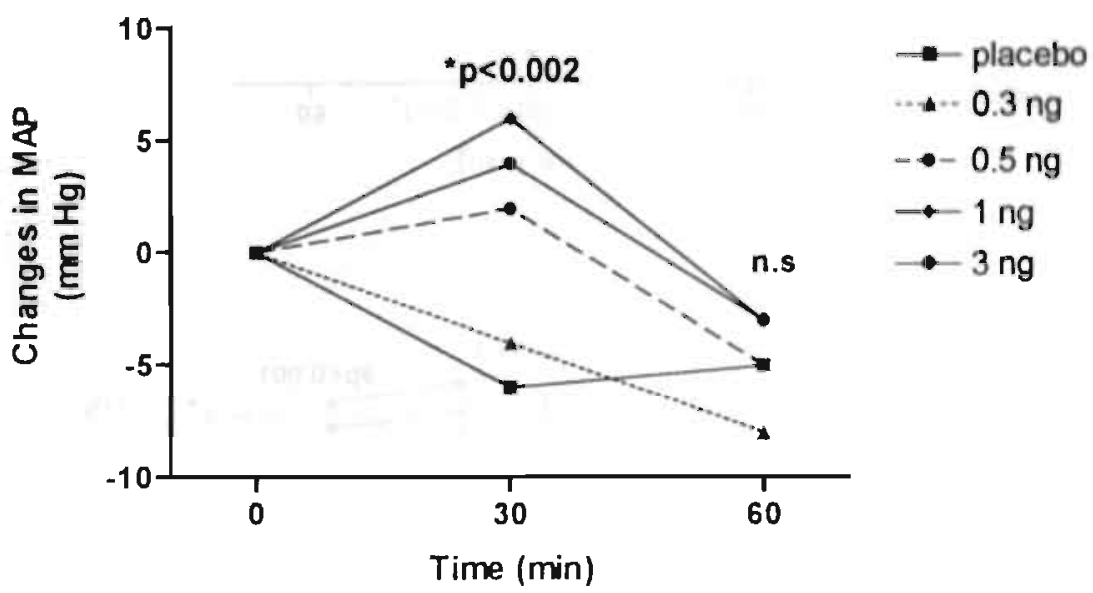

Figure 2. Absolute changes in mean arterial pressure (MAP) during the various experiments. " $p<0,02$ as compared between the different Angll infusion regimens combined with $\mathrm{ACE}$ inhibition

\section{Regional hemodynamics}

Although baseline values of ERPF were comparable on the various study days, there was an overall difference in ERPF at $\mathrm{t}=30(\mathrm{p}<0.002)$. Compared to a rise in ERPF at $\mathrm{t}=30$ during the control experiment, a fall in ERPF was seen during the $0.5 \mathrm{ng} / \mathrm{kg}$.min experiment (figure 3a). The difference between these two responses 
was highly significant $(p<0.002)$. Moreover, the fall in ERPF that occurred during the $0.5 \mathrm{ng}$ experiment differed significantly from zero $(\mathrm{p}<0.05)$.

At $t=60$ the overall difference in ERPF remained statistically significant ( $p<0.001$ ). Although ERPF had risen from $t=30$ onwards during both the control experiment and the experiment where $0.5 \mathrm{ng} / \mathrm{kg}$.min of AngII had been infused previously, there was still a significant difference in ERPF between the two studies $(\mathrm{p}<0.05)$. However, as shown in figure $3 \mathrm{a}$ ERPF in the latter study did not differ anymore from baseline at that time.
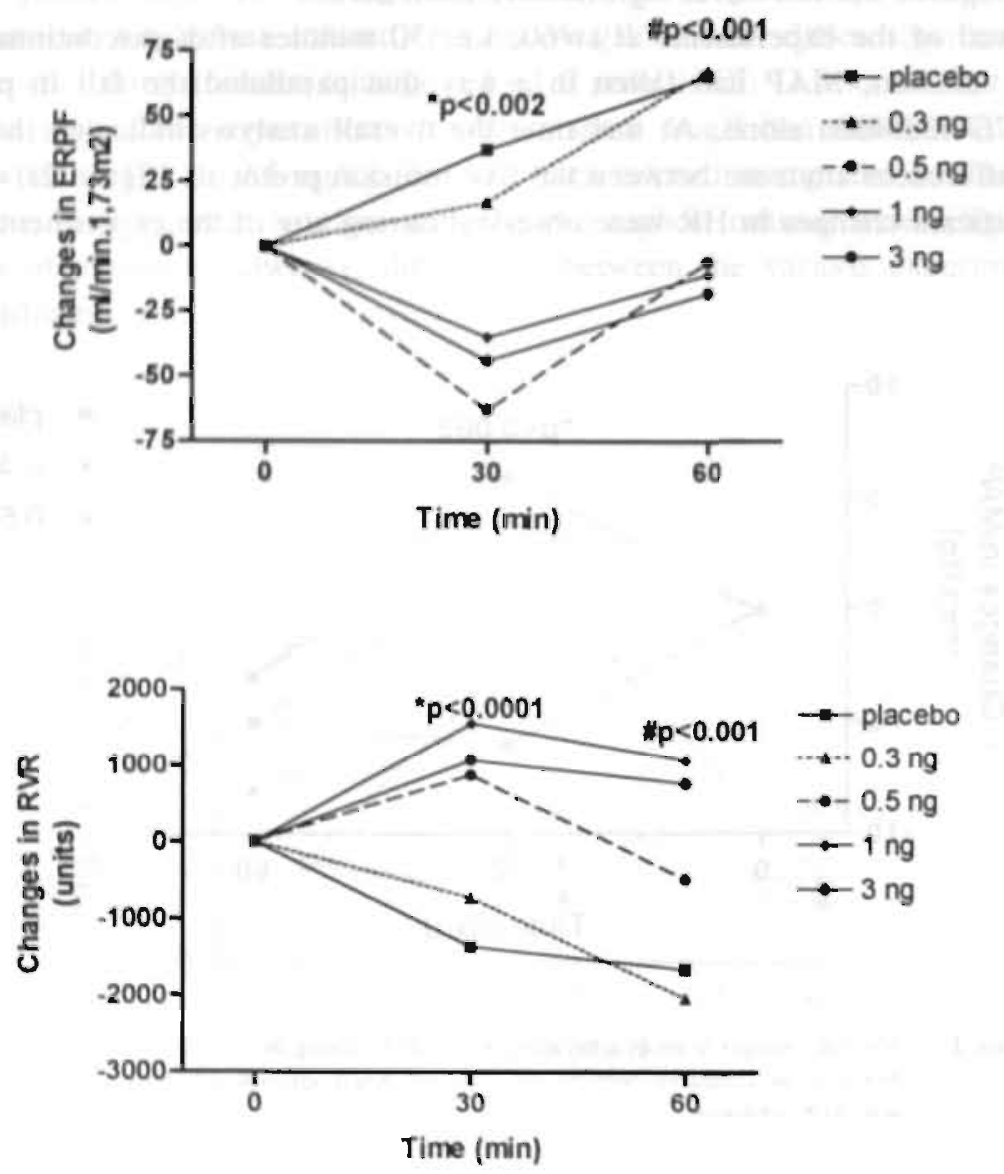

Figure $3 \mathrm{a}$ and $3 \mathrm{~b}$.

Absolute changes in effective renal plasma flow (ERPF) and renal vascular resistance (RVR) during the various experiments. Upper panel (a): "p<0,02 as compared berween the different Angll infusion regimens combined with ACE inhibition, $\| p<0,001$ as compared between the different infusion regimens after cessation of the Angll. Lower panel (b): idem 
Changes in RVR more or less were the opposite from those in ERPF (figure 3b). A significant overall difference between the various infusion regimens was found at $t=30(p<0.0001)$, with again a difference between the control and the 0.5 $\mathrm{ng} / \mathrm{kg}$.min experiment $(\mathrm{p}<0.005)$. Indeed, the fall in RVR during the control experiment was completely prevented and even reversed by the infusion of 0.5 $\mathrm{ng} / \mathrm{kg}$.min of AngII. At $\mathrm{t}=60$ there was still a significant overall difference in RVR between the five experiments $(p<0.001)$ as well as a difference between the control and the $0.5 \mathrm{ng} / \mathrm{kg}$.min experiment $(\mathrm{p}<0.05)$. GFR remained virtually unchanged during all experiments and although FF tended to change in parallel with RVR, such trends never reached statistical significance.

Data for forearm blood flow were calculated using all measurements during the last minute of the 5-minute measurement interval. Baseline data were not different on the study days (table 1) and none of the infusion regimens induced any changes in FBF or FVR.

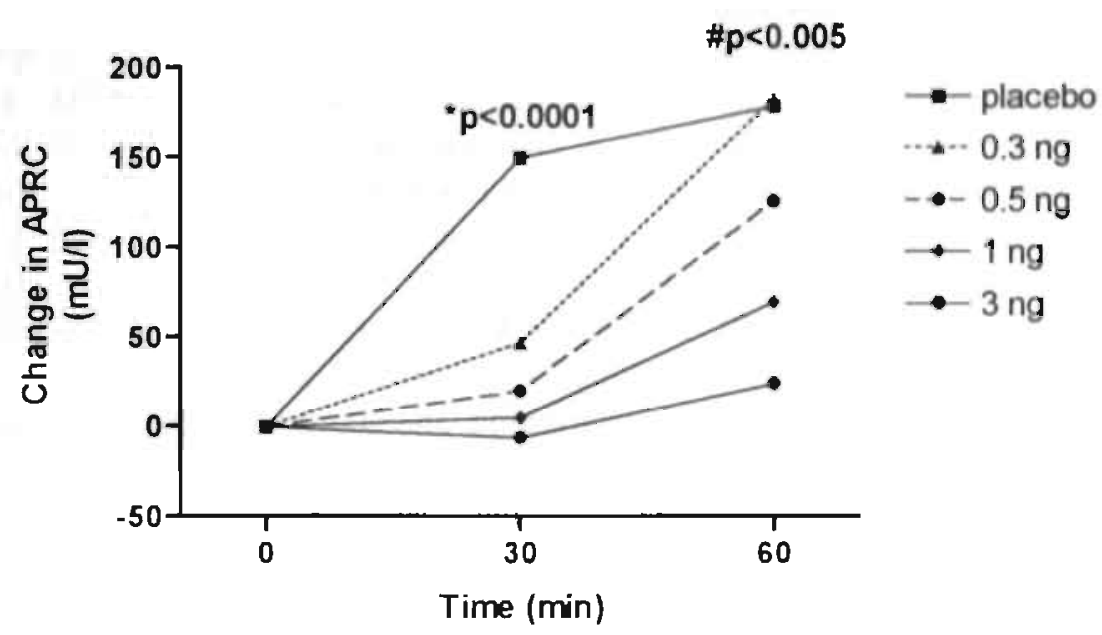

Figure 4. Absolute changes in active plasma renin concentration (APRC) during the various experiments. " $p<0,001$ as compared between thr different Angll infusion regimens combined with $\mathrm{ACE}$ inhibition, $/ \mathrm{p}<0,005$ as compared between the different infusion regimens after cessation of the Angll 


\section{Hormonal responses}

There was a marked overall difference between APRC responses during the different infusion regimens $(p<0.0001$; figure 4$)$. Pairwise analysis revealed that compared to control, APRC was significantly inhibited by the infusion of 0.5 $\mathrm{ng} / \mathrm{kg}$.min of AngII at $\mathrm{t}=30(\mathrm{p}<0.01)$. The rise in APRC, however, was not completely prevented by this dose as the rise in APRC was still different from zero $(p<0.05)$. At the end of the experiments $(t=60)$ an overall difference between the five studies remained $(\mathrm{p}<0.005)$ but at that time no difference emerged anymore between the control and the $0.5 \mathrm{ng}$ data.

Changes in Aldo at $\mathrm{t}=30$ were also different between the five infusion regimens $(\mathrm{p}<0.0001)$. The decline in Aldo, which was seen during the control experiment, was completely prevented by the $0.5 \mathrm{ng} / \mathrm{kg}$. $\mathrm{min}$ infusion of AngII $(\mathrm{p}<0.02$; data not shown). Both at $t=30$ and at $t=60$ changes in aldosterone were not different from zero with this infusion rate.

\section{Graphical analysis of the data}

When one closely examines the data as they are presented in figures 2 through 4 , a striking pattern emerges. With respect to the hemodynamic changes (MAP', ERPF, $R V R$ ) at $i=30$, there seems to be a clustering of data points for the control experiment and the experiment during which $0.3 \mathrm{ng} / \mathrm{kg}$. min of AngII was given on the one hand and the three other infusion regimens on the other, with a clear separation between these two clusters. At $t=60$ this clustering and separation remained for ERPF (and RVR) but not for MAP. Interestingly, such a pattern was not so evident for the hormonal changes. It even seems that the lowest dose of Angll, which hardly affected the hemodynamic alterations, had already a profound effect on renin release.

Finally, it should be emphasized that while plasma AngII levels were back to baseline and even below that at $t=60$ (with no difference between the five studies), clear differences remained with respect to hemodynamic and hormonal data.

In figure 5 we have plotted for all infusion experiments the average changes in response variables at $t=30$ against the concurrent changes in measured AngII concentrations. It can easily be seen that a linear relationship exists between changes in circulating AngII and the effector variable only for Aldo. For MAP such a relationship may exist when circulating AngII rises modestly but with greater increases in AngIl the response of MAP seems to level off. Interestingly, estimated $\mathrm{Y}$-intercepts are not significantly different from zero for MAP and Aldo, while they are for ERPF, RVR and APRC. 

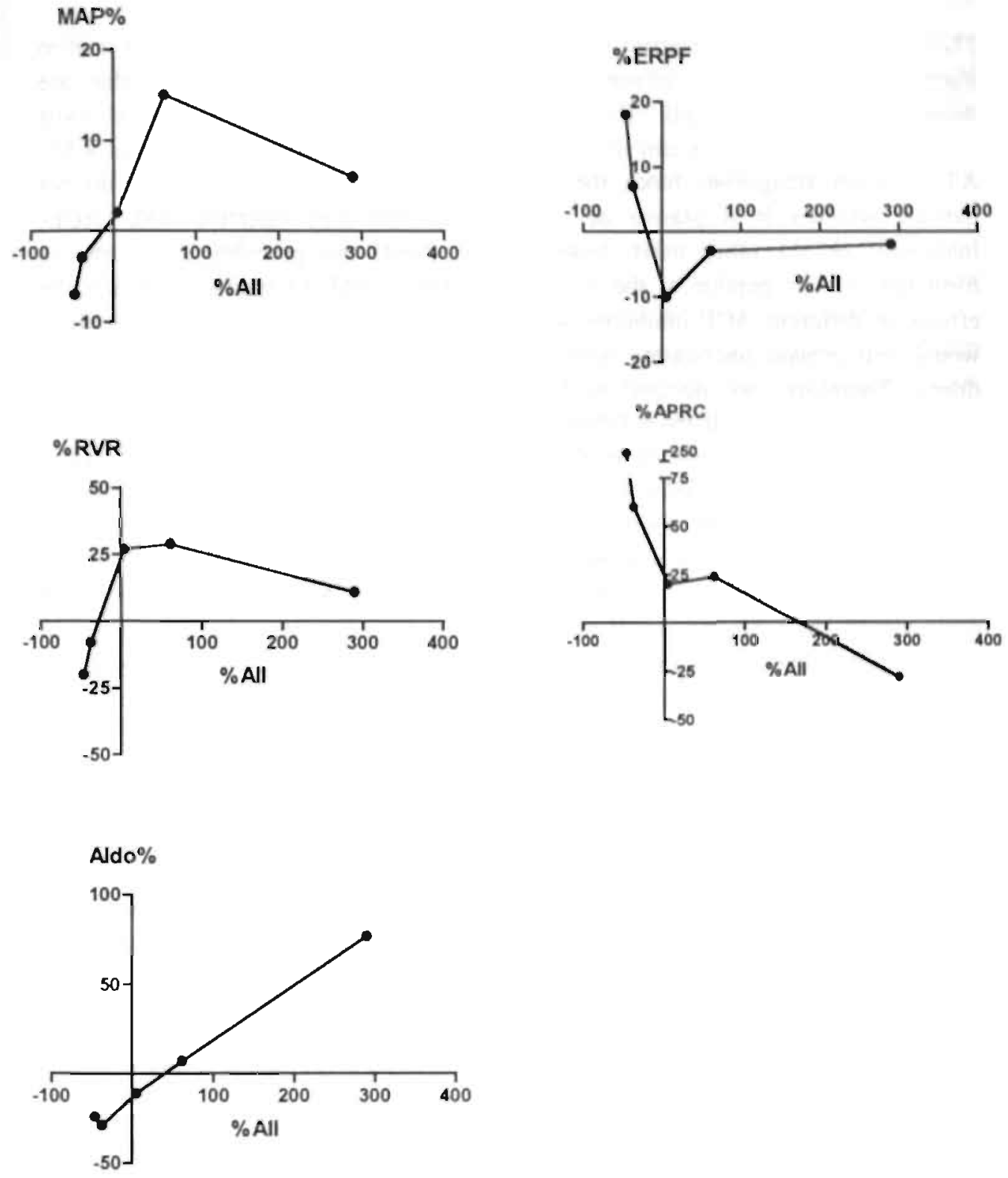

Figure 5. The average changes in response variables at $\quad t=30 \quad(Y$-axis) against the concurrent changes in measured Angll concentrations (X-axis) during the different, infusion regimens 


\section{Discussion}

The present study was designed to evaluate whether it would be possible in man to discriminate between the effects mediated by plasma AngII and those that are dependent on tissue AngII. Unfortunately, there are no pharmacological tools available with which one can differentially modulate the plasma and tissue RAS. AT1-receptor antagonists block the action of AngII on target organs but do not indicate whether it is plasma or tissue AngIl that they interfere with. ACEinhibitors, on the other hand, lower plasma AngIl but probably also suppress formation of this peptide at the tissue level. One could, of course, compare the effects of different ACE-inhibitors with varying degrees of lipophilicity but there would still remain uncertainty with respect to actual tissue penetration of these drugs. Therefore, we decided to block ACE-activity while at the same time preventing plasma AngII from falling by a concurrent infusion of AngII. As simple as this approach may seem, as difficult it is to execute. Ideally, one would like to clamp the AngII concentration in plasma by continuously adjusting the infusion rate to the prevailing plasma AngII concentration but with present-day methodology such an approach is not yet possible.

In our study we have used various infusion rates of Angll to determine which dosis would leave plasma AngII unaltered. The different infusions were given in random order and on separate days to minimize carry-over effects. Moreover, we infused [Ile'] AngIl which is an exact replicate of endogenous AngII.

\section{Plasma Angll concentrations}

As shown in figure 1 enalaprilate alone acutely reduced circulating AngII by almost $50 \%$. Angll infused at a rate of $0.5 \mathrm{ng} / \mathrm{kg}$. min together with the ACE-inhibitor was able to prevent this fall. While a lower infusion rate had no effect on the fall in plasma AngII, higher infusion rates caused significant increments in plasma AngII levels. Although other investigators have also studied a combination of ACEinhibition and superimposed AnglI infusion, in these studies the AngII was usually given before plasma AngII could have been reduced by the ACE-inhibitor and in none of these studies plasma Angll was maintained at baseline levels ${ }^{15}, 26-28$.

Whatever infusion rate was maintained during the first half hour, plasma AngII had returned to baseline or even below that in all experiments 30 minutes after stopping the AngIl infusion. Thus, at $\mathrm{t}=60$ there were no differences between the various experiments with respect to plasma AngII. Therefore, if plasma AngII would be the most important determinant of angiotensin's actions, the response variables that we measured should also be comparable at that time. Our data, however, indicate otherwise. 


\section{Blood pressure and heart rate}

Data from the literature dealing with the effects of combined administration of AngII and an ACE-inhibitor on blood pressure are difficult to interpret since we are either not informed about attained plasma levels of $\mathrm{AngII}^{15}$, or plasma AngII was not maintained at baseline levels ${ }^{26,27}$ or a non-natural analogue of AngIl was used $^{28}$. The design of our study, on the other hand, allows a more direct conclusion. The data from the present experiments show that blood pressure, for one, closely follows acute changes in plasma AngII. The fall in pressure induced by the ACE-inhibitor alone was completely prevented when plasma AngII was maintained at baseline levels. Moreover, at the end of the experiments there were not only no differences in plasma AngII, but also no differences in pressure.

Finally, graphical analysis of the data (figure 5) suggests a close relationship between changes in plasma AngII and blood pressure with perhaps tachyphylaxis occurring when circulating angiotensin increases substantially. Thus, acute interference with the renin-angiotensin system is associated with changes in blood pressure that seem to be entirely dependent on plasma Angll, there being no evidence for a role of tissue AngII. Of course, our data do not exclude the possibility that with time tissue factors such as reduced local formation of AngIl or accumulation of vasodilating substances contribute to the hypotensive response to ACE-inhibition.

Heart rate did not seem to be affected by changes in plasma AngII. However, data from the literature show that a thirteen fold increase in plasma AngII may be required before changes in heart rate can be recorded ${ }^{29}$.

\section{Regional hemodynamics}

With respect to the effects of AngII on the peripheral circulation our data are iess easy to interpret. We studied two regional circulations as examples of a visceral (kidney) and a non-visceral (forearm) vascular bed. In line with many other observations $^{30}$ we found that acute ACE-inhibition alone enhanced renal blood flow and reduced renal vascular resistance, leaving glomerular filtration rate virtually unchanged. Surprisingly, though, only a small amount of AngII was already able to attenuate this response. When circulating AngII was kept constant during infusion of $0.5 \mathrm{ng} / \mathrm{kg}$. min of AngII, ERPF was even reduced and RVR increased. Thus, in the face of acute ACE-inhibition the same plasma level of AngII is associated with a strikingly enhanced renal vasoconstriction. How can we explain this sudden increase in the sensitivity of the renal vasculature which apparently is independent from plasma AngII? One possibility would be rapid upregulation of Angil receptors secondary to ACE-inhibition but since circulating angiotensin II remained unaltered, one would have to assume that this effect was related to extravascular 


\section{References}

1 Campbell DJ. Circulating and tissue angiotensin systems. J Clin Invest 1987;79:1-6.

2 Dzau VJ. Circulating versus local renin-angiotensin system in cardiovascular homeostasis. Circulation 1988;77(suppl I):I1-I4.

3. Unger T, Badoer E, Ganten D, Lang RE, Rettig R. Brain angiotensin: pathways and pharmacology. Circulation 1988;77(suppl I):I40-I54.

4 Campbell DJ. Metabolism of prorenin, renin, angiotensinogen, and the angiotensins by tissues. In: Robertson JS, Nicholls MG, Eds. The renin-angiotensin system. London, New York: Gower medical publishing 1993;23.1-23.23.

5 Aiken JW, Vane JR. Inhibition of converting enzyme of the renin-angiotensin system in kidneys and hindlegs of dogs. Circ Res 1972;30:263-273.

6 Collier JG, Robinson BF. Comparison of effects of locally infused angiotensin I and II on hand veins and forearm arteries of man: Evidence for converting enzyme activity in limb vessels. Clin Sci Mol Med 1974;47:189-192.

7 Hilgers KF, Kuczera M, Wilhelm MJ, Wiecek A, Ritz E, Ganten D, Mann JFE. Angiotensin formation in the isolated rat hindlimb. J Hypertens 1989;7:789-798.

8 Kuczera M, Hilgers KF, Lisson C, Ganten D, Hilgenfeldt U, Ritz E, Mann JFE. Local angiotensin formation in hindlimbs of uremic and renovascular hypertensive rats. J Hypertens 1991;9:41-48.

9 Admiraal PJJ, Danser AHJ, Jong MS, Pieterman H, Derkx FHM, Schalekamp MADH. Regional angiotensin II production in essential hypertension and renal artery stenosis. Hypertension 1993;21:173-184.

10 Miller M.IS, Scroop GC. Disappearance of angiotensin II and noradrenaline from the renal and femoral circulations of the dog. Clin Sci 1980;58:29-35.

11 Admiraal PJ, Derkx FHM, Danser AHJ, Pieterman H, Schalekamp MADH. Metabolism and production of angiotensin $\mathbb{l}$ in different vascular beds in subjects with hypertension. Hypertension 1990;15:44-55.

12 Campbell DJ. Tissue renin-angiotensin system: Sites of angiotensin formation. J Cardiovasc Pharmacol 1987;10(suppl 7):S1-S8.

13 Campbell DJ, Habener JF. Cellular localisation of angiotensinogen gene expression in brown adipose tissue and mesentery: quantification of ribonucleic acid abundance using hybridisation in situ. Endocrinology 1987;121:16-26.

14 Dzau VJ. Molecular and physiological aspects of tissue renin-angiotensin system: emphasis on cardiovascular control. J Hypertens 1988;6(suppl 1):S7-\$12.

15 Mersey JH, Ceballos L, Swartz S. Inhibition of captopril-induced renin release by angiotensin II. J Cardiovasc Pharmacol 1987;10:575-579.

16 Ménard J, Guyene T, Chatellier G, Kleinbloesem CH, Bernadet P. Renin release regulation during acute renin inhibition in normal volunteers. Hypertension $1991: 18: 257-265$. 
17 Reams GP. Angiotensin converting enzyme in renal and cerebral tissue and implications for successful blood pressure management. Am J Cardiol 1991;69:59C64C.

18 Cole BR, Giangiacomo J, Ingelfinger JR, Rooson AM. Measurement of renal function without urine collection. A critical evaluation of the constant infusion technique for determination of inulin and para-aminohippurate. $N$ Engl J Med $1972 ; 287: 1109-1114$.

19 Whitney RJ. The measurements of volume changes in human limbs. J Physiol 1953;121:1-27.

20 Simon D, Hartmann BJ, Badouaille G, Caillot G, Guyenne TT, Corvol P, Pau B, Marchand J. Two-site direct immunoassay specific for active renin. Clin Chem 1991:38:1959-1962.

21 Nussberger J, Brunner DB, Waeber B, Brunner HR. True versus immunoreactive angiotensin II in human plasma. Hypertension 1985;7(Suppl I):I1-I7.

22 Kubasik NP. Warren K, Sine: HE. Evaluation of a new commercial radioassay kit for aldosterone using an iodinated tracer. Clin Biochem 1978;12:59-61.

23 Brun C. A rapid method for the determination of para-aminohippurate acid in kidney function tests. J Lab Clin Chem 1951:37:955-958.

24 Peters RHM, Golbach AJ, Van den Bergh FAJTM. Automated determination of angiotensin converting enzyme in serum. Clin Chem 1987:33(7):1248-1251.

25 Matthews JNS, Altman DG, Campbell MJ, Royston P. Analysis of serial measurements in medical research. Brit Med J 1990;300:230-235.

26 LeBoff MS, Dluhy RG, Hollenberg NK, Moore TJ, Koletsky RJ, Williams GH. Abnormal renin short feedback loop in essential hypertension is reversible with converting enzyme inhibition. J Clin Invest 1982;70:335-341.

27 Seely EW, Moore TJ, Rogacz S, Gordon MS, Gleason RE, Hollenberg NK, Williams GH. Angiotensin-mediated renin suppression is altered in non-modulating hypertension. Hypertension 1989;13:31-37.

28 Swartz SL, Williams GH, Hollenberg NK, Moore TJ, Dluhy RG. Converting enzyme inhibition in essential hypertension: the hypotensive response does not reflect only reduced angiotensin II formation. Hypertension 1979;1:106-111.

29 Motwani JG, Struthers AD. Dose-response study of the redistribution of intravascular volume by angiotensin II in man. Clin Sci 1992;82:397-405.

30 Brunner HR, Waeber B, Nussberger J. Angiotensin-converting enzyme inhibitors. In: Messerli FH, ed. Cardiovascular Drug Therapy, 2nd edition. Philadelphia: WB Saunders Company, 1996;695-696.

31 Scroop GC, Walsh JA, Whelan RF. A comparison of the effects of intra-arterial and intravenous infusions of angiotensin and noradrenaline on circulation in man. Clin Sci 1965;29:315-326.

32 Muller AF, Gardiner SM, Campton AM, Bennett T. Regional haemodynamic effects of captopril, enalaprilat and lisinopril in conscious water-replete and water-deprived Brattleboro rats. Clin Sci 1990;79:393-401. 
33 Drexler H, Hiroi M, Riede U, Banhardt U, Meinertz T, Just H. Skeletal muscle flow, metabolism and morphology in chronic congestive heart failure and effects of short and long term angiotensin converting enzyme inhibition. Am J Cardiol 1988;62:82E-85E.

34 Crozier IG, Ikram H, Nicholls MG, Jans S. Global and regional haemodynamic effect of ramipril in congestive heart failure. J Cardiovasc Pharmacol 1989;14:688693. 


\section{Chapter 7}

\section{The role of sodium intake on the effects of plasma and tissue angiotensin II in man}

MME Krekels, AJHM Houben, NC Schaper, SA Rodriguez, PMH Schiffers, PW de Leeuw

(submitted for publication) 


\section{Abstract}

\section{Objective}

The present study sought to determine the role of sodium intake on the effects of plasma and tissue AngII in more detail. To this end, we measured both during a low and during a high sodium diet the effects of ACE-inhibition alone (with falling plasma levels of AngII) and the effects of ACE-inhibition with concurrent AngII infusion (during which plasma AngII levels remained unaltered).

\section{Methods}

Seven healthy male volunteers were studied both on a low $(55 \mathrm{mmol} / \mathrm{day})$ and a high (200 mmol/day) sodium diet. During each diet three experiments were performed, during which in random order simultaneous infusions of enalaprilate (E) with either placebo (P) or AngII in doses of 0.3 or $0.5 \mathrm{ng} / \mathrm{kg}$.min were given. The AngII/P infusion was given during the first thirty minutes, concurrently with the $\mathrm{E}$ infusion. After 30 minutes of combined infusion, the AngII/P infusion was stopped, whereas the E infusion was continued for another hour. Mean arterial pressure (MAP), heart rate, effective renal plasma flow (ERPF), glomerular filtration rate (GFR), renin (APRC), AngII, aldosterone (Aldo) and catecholamines were assessed at baseline, after 30 minutes of combined infusion and again 30 and 60 minutes after discontinuation of the AngII/P infusion.

\section{Results}

On both diets levels of AngII remained unaltered during the combined infusion of $\mathrm{E}$ and $0.5 \mathrm{ng} / \mathrm{kg}$.min. Data from the enalaprilate and the $0.5 \mathrm{ng}$ experiment, therefore, were used for analysis. When only E was infused, the fall in AngII and MAP and the rise in ERPF and APRC were significantly more pronounced during the low salt diet. When the E was combined with AngII, levels of AngII remained unchanged. Despite this, ERPF fell significantly, whereas APRC still rose. Only MAP and aldosterone, like plasma AngII levels, did not change. As opposed to E alone, no effect of sodium intake was observed during the combined infusion. Also after discontinuation of the Angll infusion, when experimental conditions were similar to the infusion with $\mathrm{E}$ alone, the responses on the low salt diet were comparable to those on the high salt diet.

\section{Conclusions}

In the face of ACE-inhibition without the usual fall in plasma AngII, we found proof for renal vasoconstriction on both diets. In addition, when AngII was given before hand, the effects of sodium intake on ACE-inhibition were absent. This seems indirect evidence for renal uptake and accumulation of AngII in the kidney. 


\section{Introduction}

Over the last decade evidence has accumulated in favor of a more active role of tissues in the regulation of angiotensin-mediated effects. For example, several organs seem capable of extracting angiotensins directly from plasma ${ }^{1.2}$. In this respect, the extraction of plasma angiotensin II (AngII) by the kidney has proved to be greater than that by other tissues, such as the heart or the hindlimb ${ }^{3}$. There is not only evidence for uptake of angiotensins from the circulation, but also for production of these peptides in various tissues. Indeed, many data from the literature show that there is considerable production of angiotensins in heart, kidney, skin and skeletal muscle tissue ${ }^{2.47}$.

As will be described elsewhere, we found indirect evidence for renal uptake of AngII in man. In that study, we simultaneously infused an ACE-inhibitor, enalaprilate, with AngII in such amounts that plasma AngII remained unaltered. We observed that when plasma AngII concentrations were maintained at baseline levels, systemic ACE-inhibition was associated with a striking renal vasoconstriction. Moreover, despite the fact that after discontinuation of the Angll infusion, plasma concentrations of AngII rapidly fell, renal vasoconstriction persisted. These renal effects were even more prominent when higher doses of AngII had been infused. On the basis of these data, we hypothesized that AngII had been taken up by the kidney from the circulation. However, since our subjects were in balance on a low salt diet, we could not exclude the possibility that sodium restriction had rendered the kidney more susceptible to AngII. The latter would be in keeping with the data of Navis and coworkers, who showed that in sodiumrestricted humans the dosages of AngII required to prevent the enalaprilate-induced fall in blood pressure, caused a profound fall in renal blood flow ${ }^{8}$.

This prompted us to study the role of sodium intake on the effects of plasma and tissue AngII in more detail. To this end, we measured both during a low and during a high sodium diet the effects of ACE-inhibition alone (with falling plasma levels of AngII) and the effects of ACE-inhibition with concurrent AngII infusion (during which AngII levels remained unaltered). We hoped that the latter infusion regimen would enable us to discriminate between plasma and tissue effects of ACE-inhibition. The experiments with ACE-inhibition alone served as a control experiments.

\section{Subjects and methods}

Seven healthy male normotensive volunteers with a mean age of $24 \pm 2$ years and a body surface area of $1.95 \pm 0.05 \mathrm{~m}^{2}$ were included in this study. The protocol was 
approved by the Hospital Ethics Committee and written informed consent was obtained from all participants. Each subject had a medical history taken and underwent a physical examination. Routine laboratory tests were carried out before the start of the study.

\section{Protocel}

Subjects were put, in random order, on a moderate sodium restricted diet of 55 mmoles/day and a sodium repleted diet of $200 \mathrm{mmoles} /$ day for ten days each. Potassium intake on both diets was fixed at $80 \mathrm{mmoles} /$ day. Diets were calculated for each volunteer by the hospital dietitian. Compliance with the diet was checked by measuring sodium output in 24-hour urine collections obtained during the last 4 days of each dietary period. Completeness of urine collections was estimated from the concurrent creatinine excretion. Subjects refrained from smoking and alcohol; caffeine and caffeine-like substances were also forbidden on the study days. All volunteers were studied after an overnight fast in the morning of the last three days of the dietary period.

On these days three different experiments were conducted according to a randomized double-blind study design, where except for the infusion regimen experimental conditions were similar. Studies started at 8.00 a.m and subjects remained supine during the entire session. In both arms an antecubital vein was cannulated with a $20 \mathrm{G}$ cannula: the one in the right arm was connected to a 3-way tap for the infusion of PAH/inulin, enalaprilate and AngII or placebo, whereas the one in the left arm was used for blood sampling. All subjects consumed $200 \mathrm{ml}$ of water every hour, to ensure diuresis, until the last blood samples had been drawn. After a two hour equilibration-period, necessary to reach steady state plasma concenirations of $\mathrm{PAH}$ and inulin, a bolus injection of $4 \mathrm{ml}(=4 \mathrm{mg})$ of enalaprilate (MSD, Haarlem, The Netherlands) was given followed by a continuous infusion of $0.01 \mathrm{mg} / \mathrm{min}$ during 90 minutes. In random order on the different study days and different diets a 30 minute infusion of either placebo ( $0.9 \%$ saline) or [Ile ${ }^{5}$ ] AngII (Clinalfa AG, Laufelfingen, Switzerland) in a dose of 0.3 or 0.5 $\mathrm{ng} / \mathrm{kg} \cdot \min$ was started concurrently with the enalaprilate. After 30 minutes of combined infusion, the placebo/Angll infusion was stopped, whereas the enalaprilate infusion was continued for another hour until the end of the experiment $(t=90)$.

The AngII infusion rates were chosen on the basis of earlier experiments performed in our laboratory, where we had found that at least one of these doses would leave plasma AngII unaltered when infused concurrently with enalaprilate.

Study variables were assessed at baseline, after 30 minutes of combined infusion and 30 and 60 minutes after the cessation of placebo or AngII. Blood samples were 
drawn for measurement of $\mathrm{PAH}$, inulin, hematocrit, AngII, active plasma renin concentration (APRC), aldosterone (Aldo), angiotensin converting enzyme (ACE) and catecholamines (epinephrine, norepinephrine and dopamine). In addition, mean arterial pressure (MAP) and heart rate (HR) were assessed.

\section{Methods}

MAP and HR were measured by a semi-automatic oscillometric device (Dinamap Vital Signs Monitor 1846, Critikon, Tampa, FL, USA). Renal hemodynamics, i.e. effective renal plasma flow (ERPF) and glomerular filtration rate (GFR) were measured as the clearance of PAH (PAH: para-aminohippurate sodium; MSD, West Point, PA, USA) and inulin (Inutest, Laevosan Gesellschaft, Linz, Austria), using the continuous infusion method ${ }^{9}$. Both variables were corrected for body surface area and expressed as $\mathrm{ml} / \mathrm{min} .1 .73 \mathrm{~m}^{2}$. Effective renal blood flow (ERBF) was calculated using the formula: ERPF/1-hematocrit, whereas renal vascular resistance (RVR) was calculated as: (MAP/ERBF)*80.000.

$\mathrm{PAH}$ (intra-assay $\mathrm{CV} 4.2 \%$, inter-assay $\mathrm{CV}$ of $7.3 \%$ ), inulin (intra-assay CV $4.5 \%$, inter-assay CV $8.1 \%$ ) and ACE (intra-assay CV $3.9 \%$, inter-assay CV $7.1 \%)$ levels were measured spectrophotometrically ${ }^{9.11}$.

APRC was measured by the IRMA method (Nichols Institute Diagnostics, Wychen, The Netherlands) with an intra-assay coefficient of variation (CV) of $2.9 \%$ and an inter-assay $\mathrm{CV}$ of $7.6 \%{ }^{12}$. AngII was determined by radio-immunoassay (RIA) following Ph Phenyl column extraction (Amersham Int., Amersham, UK; intraassay $\mathrm{CV} 4.6 \%$ and inter-assay $\mathrm{CV} 7.7 \%)^{13}$. Aldo was assayed by means of a solid-phase protein binding RIA (Diagnostic Products Corporation, LA, USA; intra-and inter assay $\mathrm{CV} 4.3 \%$ and $6.7 \%$, respectively) ${ }^{14}$. Norepinephrine (intraassay CV $4.5 \%$, inter-assay CV $8.1 \%$ ), epinephrine (intra-assay CV $4.1 \%$, interassay CV $8.6 \%$ ) and dopamine (intra-assay CV $3.9 \%$, inter-assay CV $7.1 \%$ ) were assessed by a sensitive fluorimetric method, in which catecholamines are concentrated from plasma by liquid-liquid extraction and derivatized with a selective fluorescent agent prior to chromatography ${ }^{15}$.

For each determination, all samples from the same individual were assayed in a single run.

\section{Data analysis}

The first step in the analysis was to determine for each subject and for both diets during which of the two combined enalaprilate/AngII infusions ( 0.3 or 0.5 $\mathrm{ng} / \mathrm{kg}$.min) plasma AngII remained constant, i.e. within $5 \%$ of baseline. Only data from those experiments where no changes in plasma AngII were observed, were 
used for the analysis of the combined infusions. Data from the experiments during which enalaprilate only had been given (control experiment) and data from the combined infusion studies were analyzed separately.

To avoid the statistical problems which are inherent to the evaluation of serial measurements, we applied summary statistics on the overall responses to assess differences in variables between the two diets ${ }^{16}$. Prior to statistical testing logarithmic or square root transformation of the data was performed, when appropriate. Differences between the two diets or between the start and the end of the experiments were tested by either one-way analysis of variance or the KruskalWallis test depending on the homogeneity of variance or normality of the data.

Results are expressed as means \pm SEM or as medians and ranges when appropriate. A p-value of less than 0.05 was considered significant.

\section{Results}

Twenty-four hour sodium excretion averaged $176 \pm 25 \mathrm{mmol}$ during the high salt diet, as opposed to $39 \pm 6 \mathrm{mmol}$ during the low salt diet $(p<0.05)$. Daily potassium excretion, however, was comparable on the two diets $(58+7$ and $60+8 \mathrm{mmol}$ respectively). ACE-activity in plasma was adequately inhibited after the administration of enalaprilate at all time points in all experiments (measured ACEactivity below $2 \mathrm{U} / \mathrm{I})$.

On the low sodium diet plasma AngII still fell when enalaprilate was combined with the lower dose of AngII, but remained constant when a dose of $0.5 \mathrm{ng} / \mathrm{kg}$. min was infused. On the other hand, plasma AngII did not change with either the 0.3 or $0.5 \mathrm{ng} / \mathrm{kg}$.min infusion when subjects were adhering to the high sodium diet. Therefore, for the further analysis of the combined infusion studies only data from the $0.5 \mathrm{ng} / \mathrm{kg}$. min experiments were used.

\section{Plasma AngIl concentrations}

Baseline plasma AngII concentrations were comparable on both study days for each dietary period but were significantly increased during the low sodium period as compared to the high sodium period (table 1). The effect of sodium intake on the changes in plasma AngII. induced by ACE-inhibition (ACE-i) alone and by combined infusion are depicted in figure $1 \mathrm{a}$ and $\mathrm{b}$. On both diets a significant fall in AngII was noted during the control experiment (ACE-inhibition alone), but the percentage fall was substantially greater during the low sodium diet $(p<0.002)$. When ACE-i was combined with AngIl for 30 minutes, plasma levels of the peptide initially remained constant but they fell again on both diets after 
discontinuation of AngII infusion. Decrements in plasma AngII were, however, similar for the two dietary periods as opposed to the control experiments.

Table 1. Baseline hormonal data (means \pm SEM)

\begin{tabular}{lcccc}
\hline & \multicolumn{2}{c}{ Low salt diet } & \multicolumn{2}{c}{ High salt diet } \\
& E & E + AngII & E & E + Angll \\
\hline APRC $(\mathrm{mU} / 1)$ & $25 \pm 3$ & $31 \pm 6$ & $53 \pm 7$ & $62 \pm 9 *$ \\
Angll $(\mathrm{pmol} / \mathrm{l})$ & $9.3 \pm 3.0$ & $10.4 \pm 2.0$ & $11.5 \pm 1.0$ & $12.7 \pm 2.3 *$ \\
Aldo $(\mathrm{pmol} / 1)$ & $219 \pm 80$ & $163 \pm 33$ & $296 \pm 61$ & $280 \pm 56$ \\
Epi $(\mathrm{nmol} / 1)$ & $0.06 \pm 0.01$ & $0.07 \pm 0.01$ & $0.15 \pm 0.03$ & $0.12 \pm 0.04 *$ \\
Norepi $(\mathrm{nmol} / 1)$ & $0.92 \pm 0.14$ & $0.87 \pm 0.19$ & $0.96 \pm 0.15$ & $0.79 \pm 0.18$ \\
Dopa $(\mathrm{nmol} / 1)$ & $0.26 \pm 0.06$ & $0.24 \pm 0.05$ & $0.46 \pm 0.10$ & $0.36 \pm 0.09$ \\
\hline
\end{tabular}

$\mathrm{E}=$ Enalaprilate; AngII=angiotensin II: $\mathrm{APRC}=$ active. plasma renin concentration; AngI= angiotensim I; Aldo= aldosterone; Epi $=$ Epinephrine; Norepi $=$ Norepinephrine; Dopa $=$ Dopamine, $p<0.05$ difference between the diets.

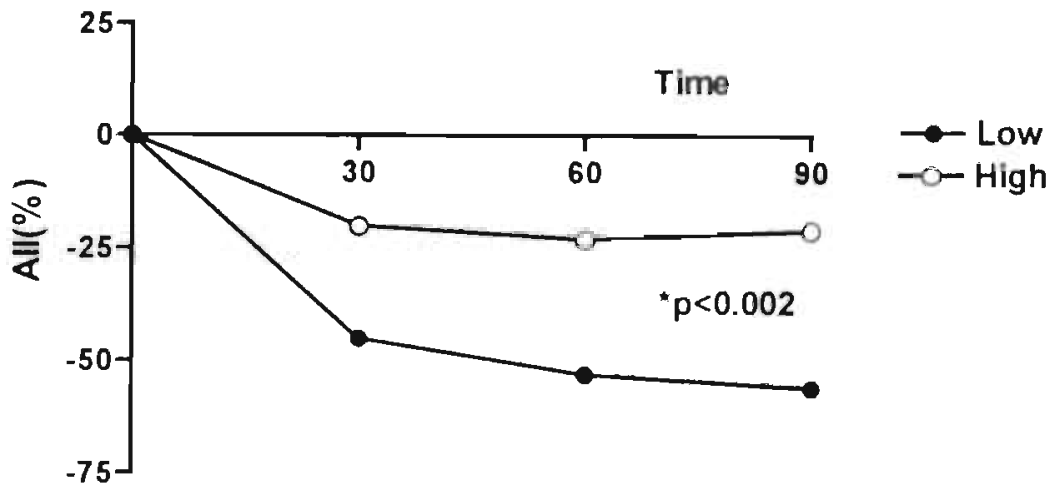

Figure 1a. Changes in plasma Angll concentrations (pmol/l) during ACE-inhibition alone. Low salt diet (closed dots), high. salt diet (open dots). " $p=0.002$ compared between the diets 


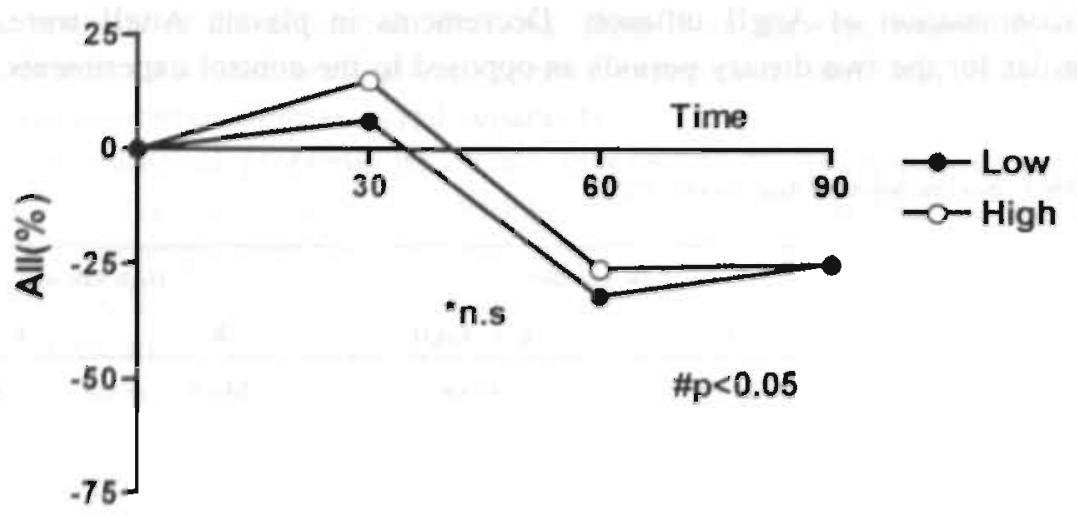

Vigure Ib. Changes in plasma Angll concentrations (pmol//) during combined infusion. Low salt diet (closed dots), high salt diet (open dots). " p $<0.05$ compared to baseline

\section{Blood pressure and heart rate}

Basal values of MAP and HR, defined as the mean of the last six measurements during the two-hour equilibration period, were comparable on the different study days during one dietary period as well as between the two diets (table 2). While ACE-inhibition alone had no effect on MAP during the high sodium diet, it reduced pressure significantly during the low sodium diet (figure 2a). This difference in response between both dietary periods was statistically significant $(p<0.02)$. No such effect of diet was demonstrable for the experiments where enalaprilate had been combined with AngII for the first 30 minutes. In fact, on both diets blood pressure remained stable during the combined infusion and fell equally after cessation of AngII (figure 2b).

No significant changes in HR were observed during any of the experiments.

Table 2. Baseline hemodynamic data (means \pm SEM)

\begin{tabular}{|c|c|c|c|c|}
\hline & \multicolumn{2}{|c|}{ Low salt tiet } & \multicolumn{2}{|c|}{ High sale diet } \\
\hline & E & E + AngII & E & E + AngIII \\
\hline MAP (mm Hg) & $84 \pm 3$ & $86 \pm 2$ & $83 \pm 3$ & $86 \pm 3$ \\
\hline HR: (bpm) & $63 \pm 3$ & $65 \pm 5$ & $61 \pm 3$ & $60 \pm 3$ \\
\hline ERPE $\left(\mathrm{ml} / \mathrm{min} .1 .73 \mathrm{~m}^{2}\right)$ & $519 \pm 48$ & $591 \pm 52$ & $573 \pm 49$ & $572 \pm 37$ \\
\hline GFR $\left(\mathrm{ml} / \mathrm{min} .1 .73 \mathrm{~m}^{2}\right)$ & $133 \pm 9$ & $126 \pm 5$ & $118 \pm 7$ & $126 \pm 5$ \\
\hline RVR (units) & $7963 \pm 707$ & $7279 \pm 551$ & $7197 \pm 742$ & $7182 \pm 392$ \\
\hline
\end{tabular}

E = Enalaprilate; AngI =angiotensin II: Angl=angiotensin I: MAP=mean arterial pressure; HR =heart rate: ERPF-effective renal plasma flow; GFR = glomerulat filtration rate; FF=filtration fraction:

$\mathrm{RVR}=$ renal vascular resistance 

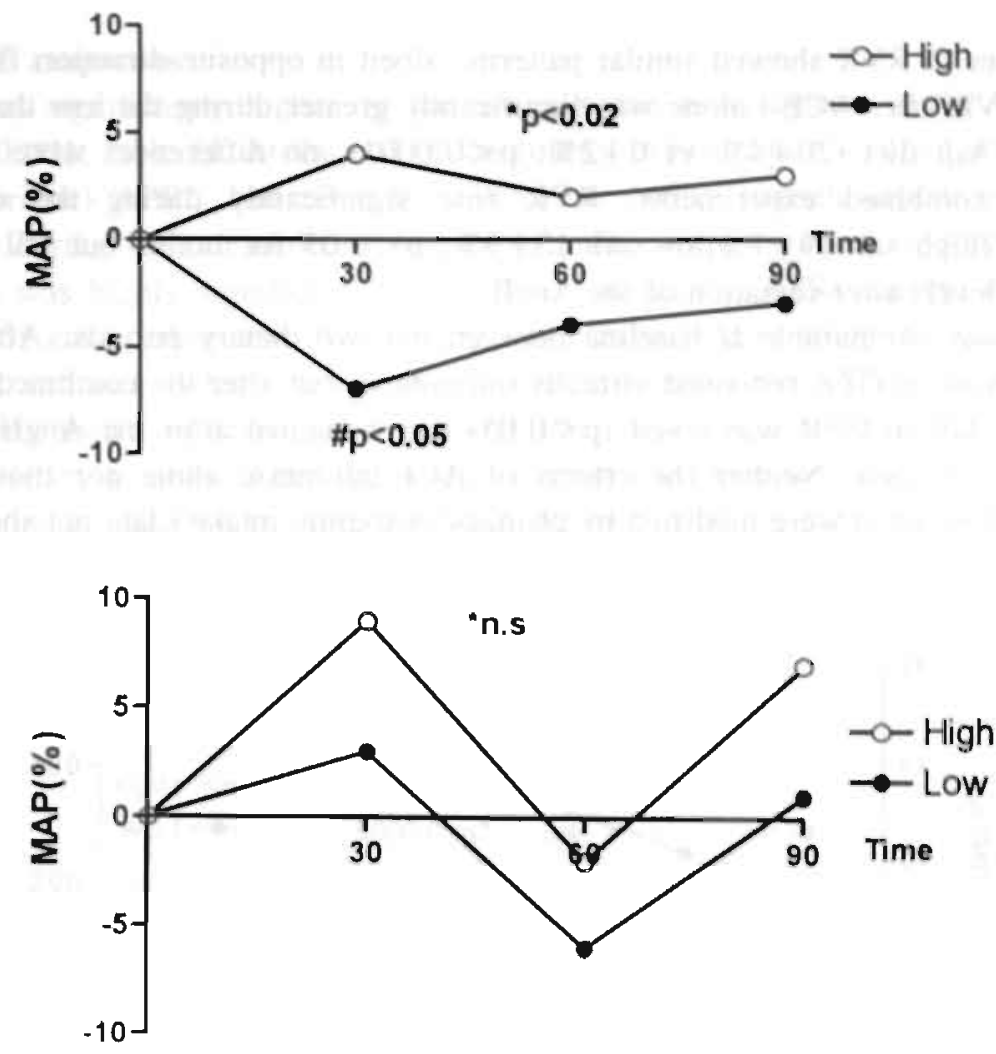

Figure 2a. Changes in mean arterial pressure $(\mathrm{mm} \mathrm{Hg})$ during $\mathrm{ACE}$-inhibition alone, Low salt. diet (closed dots), high salt diet (open dots), $" \mathrm{p}<0.02$ compared between the diets. Hp $<0.05$ compared to baseline

Figure 2b. Changes in mean arterial pressure (mm $\mathrm{Hg}_{\mathrm{g}}$ during combined infusion. Low salt diet (closed dots), high salt diet (open dots)

\section{Renal hemodynamics}

Baseline values of ERPF were comparable on all study days (table 2). Changes in ERPF during the experiments on the two diets for both the control and the AngII experiments are depicted in figure $3 \mathrm{a}$ and $\mathrm{b}$. Whereas during sodium repletion no changes in ERPF were observed, ERPF rose by $24 \pm 6 \%$ on the low salt diet after 90 minutes of enalaprilate infusion. The difference between these two responses was highly significant (figure $3 \mathrm{a} ; \mathrm{p}<0.0002$ ). When plasma AngII was maintained at baseline level during the first 30 minutes of ACE-inhibition, no difference in ERPF responses were apparent for the two dietary periods. Following a small yet statistically significant fall in ERPF of $8 \pm 2 \%$ (high salt) and $9 \pm 3 \%$ (low salt) respectively during the combined infusions (both $p<0.05$ ), ERPF rose again to baseline levels after discontinuation of the AngII (figure $3 \mathrm{~b}$ ). 
Changes in RVR showed similar patterns, albeit in opposite direction. While the fall in RVR after ACE-i alone was significantly greater during the low than during the high salt diet $(20 \pm 4 \%$ vs $0 \pm 2 \% ; \mathrm{p}<0.0001)$, no differences were observed for the combined experiments. RVR rose significantly during the combined infusion (high salt: $19 \pm 7 \%$; low salt: $15 \pm 9 \% ; \mathrm{p}<0.05$ for both), but fell again to baseline levels after cessation of the AngII.

GFR was comparable at baseline between the two dietary periods. After ACEinhibition alone GFR remained virtually unchanged, but after the combined infusion an initial fall in GFR was noted $(\mathrm{p}<0.05)$ that remained after the AngII infusion had been stopped. Neither the effects of ACE-inhibition alone nor those of the combined infusion were modified by changes in sodium intake (data not shown).
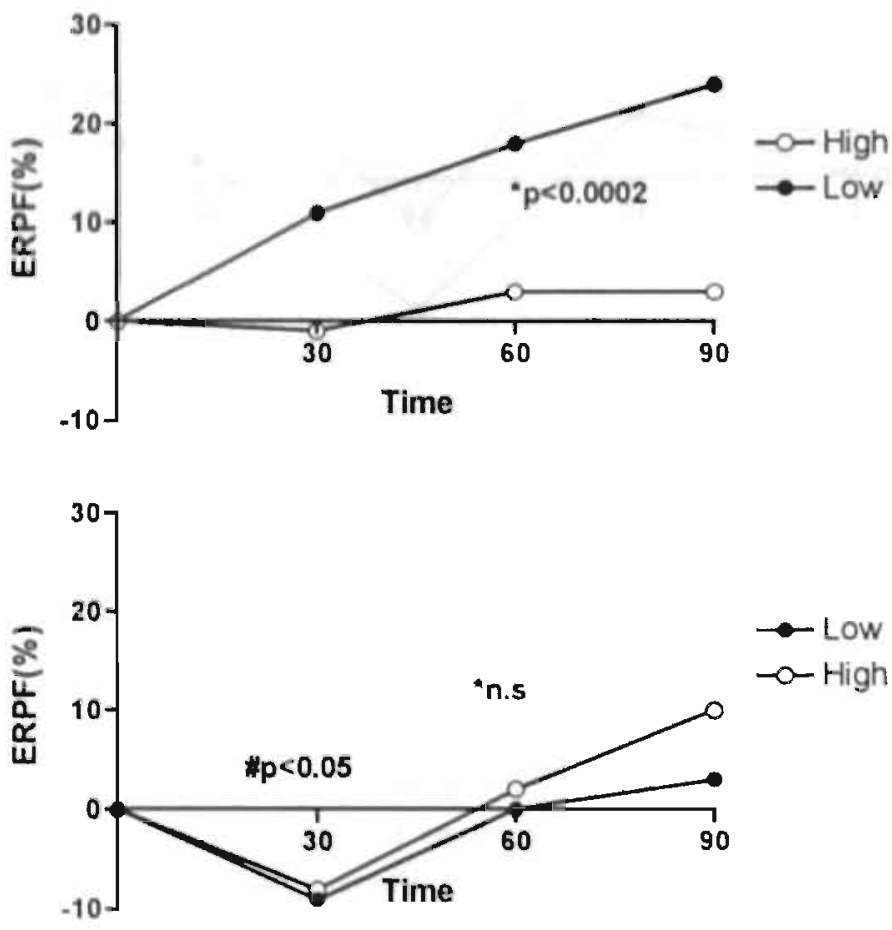

Figure 3a. Changes in effective renal plasma, flow $\left(\mathrm{ml} / \mathrm{min} .1 .73 \mathrm{~m}^{2}\right)$ during ACE-inhibition alone. Low salt. diet (elosed dots), high salt diet (open dots). $" p<0.0002$ compared between the diets

Figure 3b. Changes in effective renal plasma flow ( $\left.\mathrm{ml} / \mathrm{min} .1 .73 \mathrm{~m}^{2}\right)$ during combined infusion. Low salt diet (closed dots), high salt diet (open dots). $t p<0.05$ compared to baseline 


\section{Hormonal responses}

APRC was significantly higher on the low salt diet as compared to the high salt diet ( $p<0.001$; table 1). At the end of the control experiment (i.e. after 90 minutes of enalaprilate) APRC had risen by $338 \pm 37 \%$ during sodium depletion and by $41 \pm 18 \%$ during sodium repletion (figure $4 a$ ). This difference in responses on the two diets was highly significant $(p<0.0003)$. Changes in APRC during combined infusion of enalaprilate and AngII were comparable. After thirty minutes of the combined' infusion, when plasma AngII was still unaltered, APRC had already significantly increased above baseline $(\mathrm{p}<0.05)$, there being no difference between the two dietary periods. After the AngIl infusion had been stopped, APRC tended to rise more on the low salt diet but the difference with the high salt diet was not significant (figure $4 \mathrm{~b}$ ).

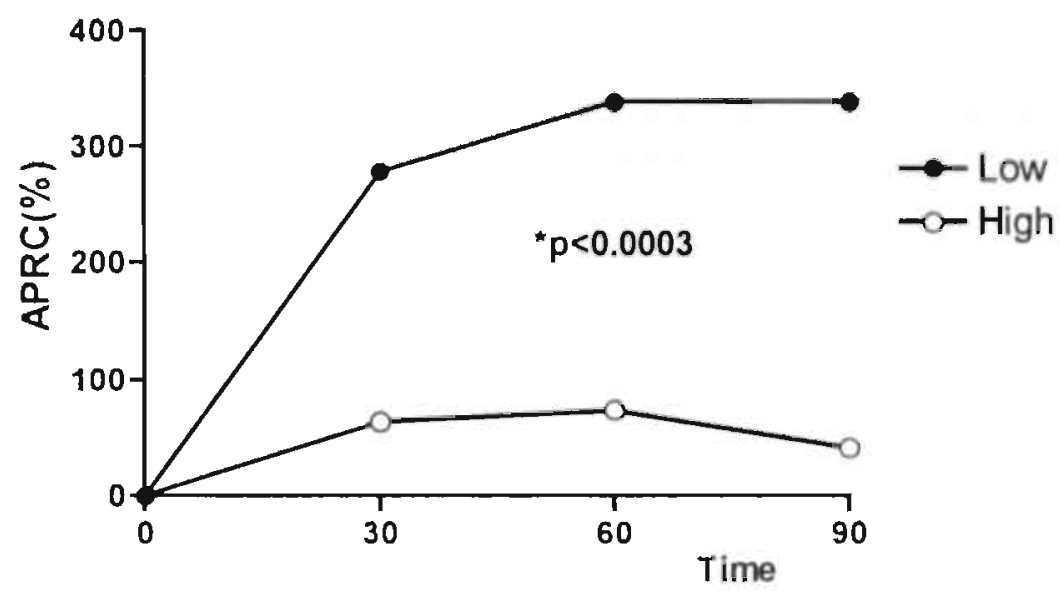

Figure 4a. Changes in active plasma renin concentration (mU/1) during ACE-inhibition alone. Low salt diet (closed dots), high salt diet (open dots), $" p<0.0003$ compared between the diets

Baseline Aldo levels were not different between the diets (table 2). Aldo levels fell after enalaprilate alone, but changes were not different between the diets. When enalaprilate was given together with AngII Aldo concentrations initially increased to fall after the discontinuation of AngII. Again, no differences in responses were observed on the two diets (data not shown). 
Baseline norepinephrine and dopamine concentrations were comparable on the two dietary salt intakes, but epinephrine levels were significantly higher on the low salt diet $(\mathrm{p}<0.05 ;$ table 1$)$. All catecholamines remained unchanged on both diets during all experiments.

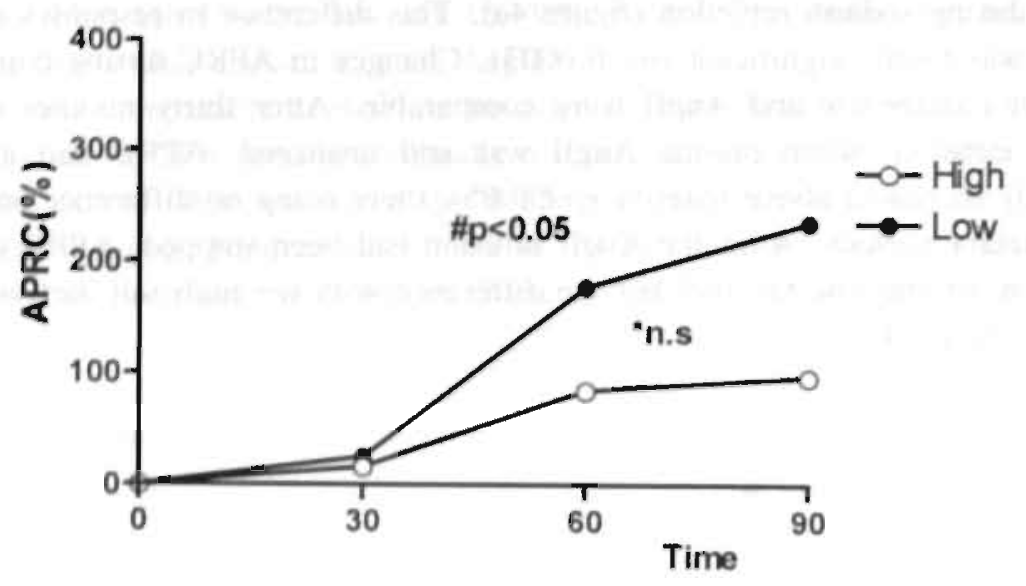

Figure $4 \mathrm{~b}$. Changes in active plasma renin concentration ( $\mathrm{mU} / \mathrm{T})$ during combined infusion. Low salt diet (closed dots), high salt diet (open dots). Ip $<0.05$ compared to baseline

\section{Discussion}

The present study evaluated the role of sodium intake on the effects of plasma and tissue AngIl. To differentiate between these effects is rather difficult, as no pharmacological tools are yet available with which one can modulate the plasma. and tissue RAS separately. In a previous study, we employed a method which allowed us, albeit indirectly, to study the effects of tissue AngII and plasma AngII separately. We blocked ACE-activity while at the same time we prevented plasma AngII from falling by a concurrent infusion of AngII. We speculated that when during combined infusion the effects of the ACE-inhibitor were abolished, changes in plasma levels of AngII would be responsible for the effects of ACE-inhibition. If, however, this was not the case, tissue levels of AngII would be more likely to be responsible. In that particular study, we found that renal hemodynamics and renin release were not controlled by plasma AngII, but rather by intrarenal levels of AngII.

In the present study we sought to determine whether such effects are influenced by sodium intake. To this end, we have infused the ACE-inhibitor either alone or together with AngII during a low and during a high sodium diet. The different 
infusions were given in random order and on separate days to minimize carry-over effects. Moreover, we infused [Hle $\left.{ }^{5}\right]$ Angll which is an exact replicate of the endogenous peptide.

\section{Effects of ACE-inhibition alone}

Although on both diets plasma AngII fell to comparable levels during ACEinhibition, the percentage fall in AngII was much greater during the low salt diet. Moreover, the rise in renin during ACE-inhibition also was more pronounced during sodium depletion as compared to sodium repletion. In line with many other investigators we found a distinctive difference in hormonal responses to the ACEinhibitor with the different states of sodium balance ${ }^{17.18}$. In response to a low sodium diet renin release from the juxta-glomerular apparatus is increased ${ }^{19}$; subsequently, more renin is offered to the tissues and thus more AngII is formed within the tissues. When an ACE-inhibitor is administered while the RAS is activated, AngII concentrations both in plasma and in tissues are likely to fall to a greater extent than when the RAS is suppressed. It is, therefore, not surprising that, as Angil levels declined by $56 \%$ on the low salt diet but only by $21 \%$ on the high salt diet, the effects in the kidney and the other tissues were stronger during the low sodium intake. As a consequence of this exaggerated fall in AngII, the rise in renin levels, secondary to the interruption of the negative feedback suppression by AngII, was also more pronounced. The same was demonstrated by Jackson and associates, who suggested that the negative feedback effect of AngII on renin release was of relatively greater magnitude during sodium depletion ${ }^{18}$.

With respect to suppression of aldosterone concentrations during ACE-inhibition, we were not able to demonstrate a difference between the diets. Jackson et al., on the other hand, found that besides AngII, also aldosterone showed a more profound fall on a low salt diet ${ }^{18}$. These controversial results are difficult to explain. In the latter study enalaprilate was given orally and the peak effect occurred 8 hours after administration of enalaprilate. Perhaps, a sodium-dependent dissociation in aldosterone response does occur, but later in time. Our ninety minute infusion, therefore, could have been too short to allow the dissociation to appear.

As AngII stimulates catecholamine release from the adrenal medulla, one would expect that converting enzyme inhibition induces a decrement in norepinephrine levels. However, like other investigators we did not find any change in plasma catecholamines during ACE-inhibition ${ }^{20-22}$.

Except for the dissociation in hormonal responses between the diets during ACE inhibition, we also observed different responses of both renal and systemic hemodynamics on the two diets. That is, the fall in blood pressure and renal vascular resistance was more pronounced when subjects adhered to a low sodium 
diet, whereas on this diet renal plasma flow was increased to a greater extent. These results are in keeping with other data in the literature, showing that the hemodynamic responses to ACE-inhibitors are more pronounced when subjects are in balance on a low sodium diet ${ }^{18.23 .24}$. The results from our control experiments thus confirm that the effects of ACE-inhibition with the concurrent falls in plasma and tissue AngII, are influenced to a major extent by the state of sodium balance of the individual. These data are neither new nor unexpected, but they stress once more the importance of sodium intake when one studies the renin-angiotensin system.

\section{Effects of ACE-inhibition in combination with AngII}

When an infusion of $0.5 \mathrm{ng} / \mathrm{kg}$.min AngII was added to the enalaprilate infusion, plasma levels of AngII remained unaltered on both diets. Surprisingly, with this approach, we observed a fall in renal plasma flow. The magnitude of the renal vasoconstrictor response, however, was similar on the two diets. We have to assume that in the kidney the vasoconstrictor effect of AngII prevailed over the vasodilating action of enalaprilate. This can be explained either by incomplete inhibition of ACE in the kidney or by uptake of AngII from plasma. We are in favor, however, of the renal uptake hypothesis, as it is very unlikely that a vasoconstrictor response is elicited by incomplete renal $\mathrm{ACE}$-inhibition. In support of the renal uptake hypothesis, Van Kats and coworkers recently demonstrated in the pig, that arterially delivered AngII can indeed be taken up by the kidney, thus leading to higher intrarenal levels of AngII' ${ }^{25}$. We feel, therefore, that our data, albeit indirectly, suggest that such a mechanism may also be operative in human kidneys:

In contrast with the control experiment (enalaprilate alone) sodium intake did not seem to have any influence on the effects of the combined infusions of enalaprilate with Angil. As the fall in AngII on the low salt diet exceeded that on the high salt diet, it is likely that the biological sequelae of a fall in plasma AngII are more pronounced too during low sodium intake. Why is it then that during the combined infusion of AngII and enalaprilate the effect of sodium was absent? In the case of blood pressure and aldosterone the situation seems clear because changes in these variables depend entirely upon changes in plasma AngII. Since there were no changes in plasma AngII during the combined experiments on either diet, no differences in the responses of blood pressure or aldosterone were to be expected.

In the kidney maintenance of plasma AngII elicited a vasoconstrictor response which was independent of the diet. A possible explanation for these findings is that, when renal AngII production is inhibited by enalaprilate, the kidney starts taking up AngII from plasma. Normally, however, plasma AngII would fall, so that the 
kidney would get depleted from Angll. During our combined infusions, on the other hand, renal uptake of AngII was still possible so that this organ could satisfy its 'hunger for AngII'. As plasma AngII was available for uptake during both dietary periods, it follows that the vasoconstrictor response did not have to differ.

Although intrarenal levels of AngII in the kidney due to uptake, appear to be higher than in plasma, the rise in renin during combined infusion of enalaprilate and AngII on both diets was not completely abolished. In our view another mechanism, at least partly, must be responsible for the rise in renin during ACEinhibition. In this respect there could be a role for bradykinin ${ }^{26,27}$.

A closer look at the data after the discontinuation of AngII reveals an interesting feature. Because the effects of AngII are known to last only for one circulation time, one would expect the effects of ACE-inhibition one hour after cessation of the AngII to mimic those during the control experiment (ACE-inhibition alone). However, when AngII was infused beforehand, the effects of ACE inhibition were comparable on both diets. This is in contrast to the effects which were observed on the low salt diet which exceeded those on the high salt diet, when no Angll was infused in the previous thirty minutes. In other words, while the experimental procedures were similar after discontinuation of the Angil, the effects of ACEinhibition were not. Because the half life of AngII is known to last less than a minute it is very unlikely that this phenomenon can be attributed to infused AngII. In our opinion, these data strongly suggest uptake and accumulation of AngII in the kidney and possibly also in other tissues. We hypothesize that the uptake of AngII by various tissues was facilitated because the plasma compartment was relatively saturated with AngII, while the tissues were depleted in AngII by our enalaprilate infusion. By this mechanism the tissues may have been loaded with Angll during the exogenous AngII infusion.

In spite of the fact that the evidence for uptake and accumulation is indirect, we think that our results corroborate other data from the literature. Indeed, evidence has been found, just recently, for entrapment of AngII in the kidney25. This Angll appeared to be relatively protected against rapid degradation and could, therefore, exert its effects for a longer period of time. In other words, the half-life of intrarenal AngII was much longer as compared to that of plasma AngII. Of course, this theory can be extended to the other study variables. For instance, as a consequence of the accumulation of AngII in the kidney, also renin is inhibited to the same extent on both diets. This in turn leads to virtually the same renin levels in the plasma compartment. Accordingly, the same amounts of renin are delivered to the tissues, where AngII is generated locally ${ }^{28}$. This may explain why plasma AngII levels after cessation of the AngII were not influenced either by the sodium status, as was the case during the control experiment. 
In summary, we found that during ACE-inhibition and AngII infusion, despite the fact that AngII remained unaltered, the kidney reponded with vasoconstriction as though it was exposed to higher levels of AngII. This vasoconstrictory respone was not influenced by the individual's sodium balance. In addition, when the AngII infusion was stopped and the experimental conditions were similar to the experiment where only enalaprilate was infused, the effects of ACE-inhibition were not comparable to those during the control experiment. We feel that these data provide evidence, albeit indirectly, for uptake and accumulation of AngII in the human kidney. 


\section{References}

1 Miller MJS, Scroop GC. Disappearance of angiotensin II and noradrenaline from the renal and femoral circulations of the dog. Clin Sci 1980;58:29-35.

2 Admiraal PJJ, Derkx FHM, Danser A.HJ, Pieterman H, Schalekamp MADH. Metabolism and production of angiotensin I in different vascular beds in subjects with hypertension. Hypertension 1990;15:44-55.

3 Campbell DJ. Tissue renin-angiotensin system: Sites of angiotensin formation. J Cardiovasc Pharmacol 1987;10(suppl 7):S1-S8.

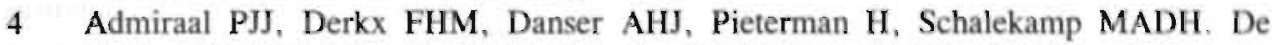
novo production of angiotensin I by the affected and unaffected kidney in subjects with renal artery stenosis; role of circulating and non-circulating renin. Hypertension 1990;16:555-563.

5 Admiraal PJJ, Danser AHJ, Jong MS, Pieterman H, Derkx FHM, Schalekamp MADH. Regional angiotensin II production in essential hypertension and renal artery stenosis. Hypertension 1993;21:173-184.

6 Danser AHJ, Koning MMG, Admiraal PJJ, Derkx FHM, Verdouw PD, Schalekamp MADH. Metabolism of angiotensin I by different tissues in the intact animal. Am J Physiol 1992;263:H418-H428.

7 Danser AHJ, Koning MMG, Admiraal PJJ, Sassen LMA, Derkx FHM, Verdouw PD, Schalekamp MADH. Production of angiotensin I and II at tissue sites in the intact pig. Am J Physiol 1992;263:H429-H437.

8 Navis G, De Jong PE, Donker AJ, van der Hem GK, De Zeeuw D. Effects of enalaprilic acid on sodium excretion and renal hemodynamics in essential hypertension. J Clin Hypertens 1985;1(3):228-238.

9 Cole BR. Giangiacomo J. Ingelfinger IR, Rooson AM. Measurement of renal function without urine collection. A critical evaluation of the constant infusion technique for determination of inulin and para-aminohippurate. $\mathrm{N}$ Engl J Med $1972 ; 287: 1109-1114$.

10 Brun C. A rapid method for the determination of para-aminohippurate acid in kidney function tests. J Lab Clin Chem 1951:37:955-958.

11 Peters RHM, Golbach AJ, Van den Bergh FAJTM. Automated determination of angiotensin converting enzyme in serum. Clin Chem 1987;33(7):1248-1251.

12 Simon D. Hartmann BI, Badouaille G, Caillot G, Guyenne TT, Corvol P. Pau B, Marchand J. Two-site direct immunoassay specific for active renin. Clin Chem 1991;38:1959-1962.

13 Nussberger J, Brunner DB, Waeber B. Brunner HR. True versus immunoreactive angiotensin II in human plasma. Hypertension 1985;7(Suppl I):I1-7.

14 Kubasik NP, Warren K, Sine HE. Evaluation of a new commercial radioassay kit for aldosterone using an iodinated tracer. Clin Biochem 1978;12:59-61. 
15 Van der Hoorn, Boomsma F, Man in't Veld AJ, Schalekamp MADH. Determination of catecholamines in human plasma by high-performance liquid chromatography: comparison between a new method with fluorescence detection and an established method with electrochemical detection. J Chromatography 1989;487:17-28.

16 Matthews JNS, Altman DG, Campbell MJ, Royston P. Analysis of serial measurements in medical research. Br Med J 1990;300-230-235.

17 Millar JA, McGrath BP, Matthews PG, Johnston CI. Acute effects of captopril on blood pressure and circulating hormone levels in salt repleted and salt depleted normal subjects and essential hypertensive subjects. Cli Sci 1981;61:75-83.

18 Jackson B, Cubela R, Johnston CI. Effect of dietary sodium on angiotensin converting enzyme (ACE) and the acute hypotensive effect of enalapril (MK-421) in essential hypertension. J Hypertens 1984;2:371-377.

19 Hackenthal E. Taugner R. Nobiling R. Intrarenal and intracellular distribution of renin and angiotensin

In: Robertson JIS, Nicholls MG, Eds. The renin-angiotensin system. London, New York: Gower medical publishing 1993;18.1-18.14.

20 Muiesen G, Alecandri CL, Agabiti-Rosei E. Angiotensin converting enzyme inhibition, catecholamines, and haemodynamics in essential hypertension. Am J Cardiol 1982;49:295-300.

21 Campbell BC, Sturani A, Reid Л. Evidence of parasymphathetic activity of the angiotensin converting enzyme inhibitor "captopril, in normotensive men. Cli Sci 1985;68:49-56.

22 Ajayi AA, Campbell BC, Howie CA, Reid JL. Acute and chronic effects of the converting enzyme inhibitors enalapril and lisinopril on reflex control of heart rate in normotensive men. J Hypertens 1985;3:47-53.

23 Hollenberg NK, Williams GH, Taub KJ, Ishikawa I, Brown C, Adams DF. Renal vascular response to interruption of the renin angiotensin system in normal men. Kidney Int 1977; 12:285-293.

24 Hollenberg NK, Meggs LG, Williams GH, Katz J, Garnic. JD, Harrington DP. Sodium intake and renal responses to captopril in normal man and in essential hypertension. Kidney Int 1981;20:240-245.

25 Van Kats JP, Danser AHJ, Van Meegen IR, Verdouw PD, Schalekamp MADH. Angiotensin I-II conversion in the kidney, J Hypertens 1996;14(suppl1):S73.

26 Millar JA, Johnston CI. Sequential changes in circulating levels of angiotensin I and II, renin and bradykinin after captopril. Med J Aust 1979;(Suppl 2):XV-XVII.

27 Campbell DJ "Kladis A, Duncan AM. Bradykinin peptides in kidney, blood and other tissues of the rat. Hypertension 1993;21;155-165.

28 Campbell DJ. Metabolism of prorenin, renin, angiotensinogen, and the angiotensins by tissues. In: Robertson JIS, Nicholls MG, Eds. The renin-angiotensin system. London, New York: Gower medical publishing 1993;23.1-23.23. 
Chapter 8

General Discussion 


\section{Introduction}

Salt is an indispensable ingredient of modern society. Except for being a tasty constituent of food, however, it also has profound effects on cardiovascular homeostasis and under certain conditions may even be harmful to the individual' ${ }^{1}$. In this respect, the relationship between salt intake and hypertension remains a controversial issue. On the one hand, there is evidence from epidemiological studies that the prevalence and severity of an elevated pressure are related to average sodium intake when different populations are compared ${ }^{2.3}$. On the other, however, such an association is less striking within given populations ${ }^{4}$. From a sceptic point of view, therefore, one would be inclined to conclude that the hypertensive effect of sodium is apparent only when extreme situations are compared and that the observed cross-cultural differences are due to "ecological confounding's.

Several years ago the results of the Intersalt study were published showing a significant positive relationship between urinary sodium excretion (as an index of salt intake) and systolic blood pressure across 52 populations ${ }^{6}$. However, these results were largely determined by only four populations with an extremely low salt intake. When these four populations were excluded from the analysis, the relationship between urinary sodium excretion and blood pressure was no longer apparent. Recently, the results of Intersalt have been revisited after multivariate correction for regression dilution bias ${ }^{7}$. The updated report shows even stronger associations with concordant results across and within populations.

Although unadjusted data from the largest within-population study that is available today, the Scottish Heart Health Study ${ }^{8}$, revealed an association between sodium and blood pressure, the relationship disappeared after adjustment for several confounding factors. In the light of the data from Intersalt and the Scottish Heart Health Study (the most rigorous studies known) Swales concluded that previously reported associations between salt intake and blood pressure must be largely attributable to confounding factors ${ }^{9}$.

An interesting finding that has been put forward by the Intersalt investigators is that the rise in blood pressure with age is stronger in societies with a high salt intake. This suggests that sodium exerts at least a permissive action on long-term blood pressure regulating mechanisms. Perhaps, such a long-term effect of sodium is more important than the acute or short-term modulation of blood pressure.

Despite their flaws, the epidemiological studies provide some evidence that the relationship between sodium intake and blood pressure is curvilinear rather than linear. In other words, the effect of sodium on blood pressure is more apparent in the low and medium than in the high range of sodium intake. Although the threshold level is not known, it is estimated to be somewhere between 50 and 
$100 \mathrm{mmol}$ per day ${ }^{5,10}$. However, such a characteristic may also be dependent on age $^{11,12}$. Furthermore, a marked heterogeneity in blood pressure responsiveness to alterations in dietary sodium intake has been observed, which has given rise to the concept of sodium sensitivity ${ }^{10}$.

\section{Sodium restriction in hypertension}

The response to sodium restriction in patients with essential hypertension is rather unpredictable. In fact, only about $50 \%$ to $60 \%$ of such patients show a fall in blood pressure on a low salt diet and the relationship between changes in sodium intake and changes in blood pressure is not evidently linear ${ }^{13}$. Furthermore, elderly patients and subjects with moderate to severe hypertension may benefit more from sodium restriction than younger patients with milder forms of hypertension ${ }^{14,15}$. We must also realize that it may take some time before the effect of sodium restriction on blood pressure becomes fully apparent ${ }^{16}$. Even more striking is the observation that some individuals respond with a rise rather than a fall in pressure during salt restriction ${ }^{17}$. Thus, there is again a marked heterogeneity in the way blood pressure changes when dietary salt consumption is reduced.

The results from both the epidemiological studies and the intervention trials can be explained by assuming that people differ in their susceptibility to the blood pressure raising effect of salt $^{10}$. This phenomenon of so-called sodium sensitivity of blood pressure has received a great deal of attention over the past fifteen years as will be discussed below.

\section{Sodium sensitivity of blood pressure}

The concept of sodium sensitivity originates from observations made almost twenty years ago when individual blood pressure responses to variations in salt intake were explored. Subjects were classified as being salt-resistant or salt-sensitive depending upon the magnitude of their blood pressure change when going from a low to a high sodium diet ${ }^{18.19}$. Subsequently, many studies have addressed the issue of sodium sensitivity but the experimental protocols and the working definition of sodium sensitivity in these studies have varied considerably ${ }^{20,21}$. For instance, some investigators employed an intravenous sodium load or diuretics to study the sodium-dependency of blood pressure, while others have studied the effects of dietary intervention. Moreover, some authors have defined sodium sensitivity in terms of absolute changes in pressure while others relied more on relative changes. Both diastolic and mean blood pressure have been taken as the target pressure and the classification into salt-sensitive and salt-resistant individuals has been based on the extremes of blood pressure changes during a sodium challenge by some and on 
a simple dichotomy by others. It is evident, therefore, that it is hardly possible to compare the results from the various laboratories. There have not been many studies in which the reproducibility of sodium sensitivity testing has been assessed, but available information suggests that for several working definitions the categorization of subjects is reasonably reproducible ${ }^{21-25}$.

The key question with respect to sodium sensitivity of blood pressure is whether this represents an all-or-nothing or a gradual phenomenon. From the discussion above one may already infer that the latter possibility is the more likely one. Indeed, when one plots the sodium-dependent changes in blood pressure as a histogram, the data follow a Gaussian distribution both in normotensives and in hypertensives $^{26,27}$. In this thesis we present data from a large group of hypertensive patients who were subjected to sodium restriction (Chapter 3). When their changes in blood pressure after one week of reduced salt intake were examined, we also found such a Gaussian distribution (figure 1). In our opinion, therefore, it is better to speak of the degree of sodium sensitivity than of sodium sensitivity as a categoric phenomenon with an arbitrary cut-off point. A greater degree of sodium sensitivity then seems to occur in subjects who are older or more obese or who have a higher basal blood pressure. In addition, several other genetic, metabolic and neurohumoral correlates have been identified ${ }^{10.28}$. There is also a preponderance of data linking sodium sensitivity to a renal abnormality ${ }^{10.20}$, although the nature of this abnormality is not well understood.

Most investigators tend to believe that a defect in sodium excretion leads to a greater expansion of extracellular volume and thus higher blood pressures in saltsensitive individuals.

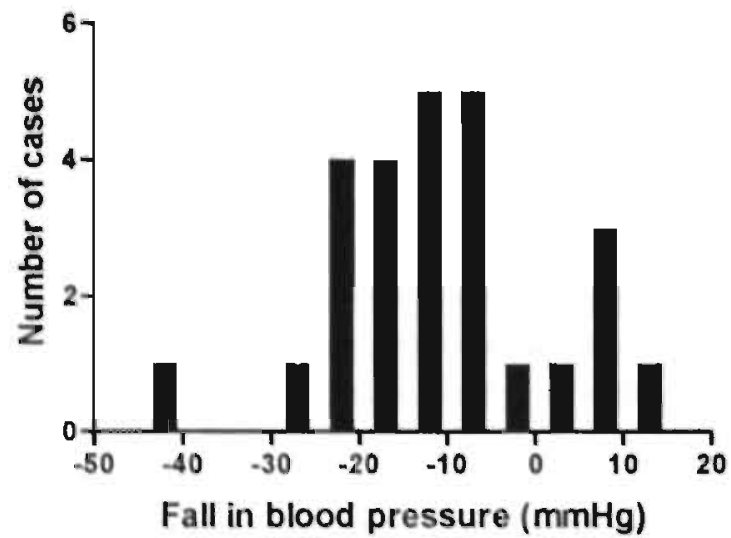

Figure 1. Frequency distribution of changes in blood pressure during sodium restriction 
However, before discussing the evidence for this hypothesis in more detail, it is necessary to first review the renal excretory response to a (sudden) change in sodium intake. Since our studies deal with sodium restriction only, we will focus on the renal adaptation to a low salt diet.

\section{The renal adaptation to sodium restriction}

The kidney responds to alterations in body fluid volumes by rapidly adjusting urinary sodium output, but the mechanisms that control body sodium are incompletely understood. If there is an increase in extracellular or effective circulating volume, sodium excretion will rise in order to restore this volume. Conversely, sodium output will fall in case of volume depletion. When a subject switches from a high to a low salt diet, it takes a few days before urinary sodium excretion matches the new intake. In other words, during the first day of restriction sodium excretion still is in excess of sodium intake, thus leading to a fall in extracellular volume ${ }^{29}$. It is assumed that in subsequent days sodium excretion and extracellular volume gradually fall to their new steady state. The latter is based upon the observations by Strauss and coworkers who also noted that, once a subject is in balance on a very low sodium intake, even a small increase in the amount of sodium ingested will be excreted ${ }^{30}$. This had led to the hypothesis that there is a critical state between surplus and deficit of body sodium that the organism tries to maintain following changes in sodium intake. If more sodium is ingested, the excess will be excreted while sodium will be retained when intake falls below the critical state. The concept of Strauss and associates was further elaborated on by Hollenberg who introduced the term 'set point for sodium homeostasis'st. This set point or basal level of body sodium as it was later called by Simpson ${ }^{32}$ would be maintained when sodium intake is very low. The idea of a set point of sodium homeostasis was criticized by Bonventre and Leaf who argued that a shift in sodium intake is associated with concurrent alterations in total body sodium and in body weight ${ }^{33}$. In fact, they considered the regulation of sodium in the body as a series of steady states with contributions from many systems, only one of which would be sodium intake. Later, Simpson has tried to unify both views by pointing out that the set point and the steady state theory are not mutually exclusive because the basal level of body sodium represents a very special steady $\operatorname{state}^{32}$. Against the theory of a particular set point that the organisms tries to be on all the time is the observation that cumulative sodium balance and extracellular volume change with the level of sodium intake ${ }^{34,35}$. Thus, available evidence suggests that the transition from high to low sodium intake is associated with a fall in body sodium towards a new steady state. It is not unreasonable to hypothesize that this fall in body sodium stops below a certain critical level as proposed by Hollenberg ${ }^{31}$ and Simpson ${ }^{32}$. 
Most investigators emphasize the exponential decay in sodium excretion (with a half-time of approximately 24 hours) when a subject switches from a high to a low salt diet $t^{30.33,35,36}$. However, Simpson questions whether this is an adequate and valid assumption $^{32}$ and the data described in Chapter 2 of the present thesis seem to support his doubts. When we put a group of essential hypertensive patients on a low salt diet, containing $55 \mathrm{mmol}$ of sodium per day, we did, indeed, find an exponential decay in sodium excretion when the data of the whole group were analyzed. However, we were struck by the fact that even after one week of sodium restriction (when in the whole group average sodium output matched intake), the variability in sodium excretion between subjects was as great as it was before the dietary intervention. We then proceeded by examining all individual patterns of changes in sodium excretion separately. This analysis revealed four different patterns by which subjects can attain their new level of sodium excretion. Of course, we cannot exclude the possibility that there are even more patterns. Although the recognition of the various patterns may seem a rather hap-hazard process, all excretion data had been given to a panel of four assessors who had to agree on the categorization of the data. The pattern, that we designated as type 1 , was indeed the typical exponential decay but this pattern was encountered in only one-third of the patients. In 10 patients we found an oscillating pattern as if the kidney was 'seeking' the appropriate ievel of sodium output. In another third of the patients an initial fall in sodium excretion was followed by a secondary rise and in 17 patients sodium excreiion remained high for several days after the change in diet. It is not surprising, therefore, that there were marked differences in cumulative sodium loss between patients.

Since our study was a descriptive one without aiming to find the mechanisms behind the different sodium excretory patterns, we cannot but speculate about the nature of the differences in renal responses. In the light of the foregoing discussion about the regulation of body sodium one would be inclined to attribute the different patterns to variations in the responsiveness of sodium conserving mechanisms. A greater sodium loss, such as occurred in group 4 , could then be due to either insufficient activation of sodium-retaining hormonal systems, e.g. the reninangiotensin system, or to a tendency of the organism to get rid of an excess of body sodium (with appropriate suppression of sodium-retaining mechanisms). In group 2 and 3 a sodium-retaining and a sodium-losing state alternate. Perhaps pattern 3 is a slow variant of pattern 2. Clearly, further studies are necessary to explore the nature of the various patterns but at this time it is important to realize that the kidney has many ways to adapt to changes in sodium intake. Consequently, it cannot be predicted beforehand how cumulative sodium balance will change following sudden restriction of dietary sodium. 


\section{Renal function, sodium balance, and sodium sensitivity}

Given the variability in sodium excretory patterns as described above, increases or decreases in salt intake may be associated with greatly varying amounts of sodium that are gained or lost by the body. Thus, on the premise that body sodium is an important determinant of blood pressure, the kidney may play a decisive role in the pathogenesis of sodium sensitivity. This view is supported, amongst others, by the fact that both in normotensives and in hypertensives the age-related increase in the prevalence of salt sensitivity correlates with a concurrent decline in creatinine clearance $\mathrm{e}^{20}$. Moreover, a salt-induced rise in blood pressure is associated with a reduced vasodilator response in the kidney ${ }^{37}$. Finally, the observation that sodiumsensitive subjects retain more sodium and gain more weight upon a high salt diet suggests that the kidneys of these individuals are unable to excrete a sodium load fast enough ${ }^{38}$. Conversely, these sensitive subjects need more time to achieve sodium balance when they are put on a salt-restricted diet. The latter data suggest that salt-sensitive patients are characterized by a sluggish renal response to alterations in sodium intake, rather than by a primary tendency to retain sodium. Indeed, Wedler and coworkers have even presented evidence against the sodiumaccumulation theory ${ }^{39}$. When they analyzed their data on the blood pressure effects of sodium restriction, they also noted a longer half-time for the elimination of sodium in salt-sensitive hypertensive subjects. In normotensives, on the other hand, half-times did not differ between sodium-sensitive and sodium-resistant subjects. They further found that the greater the sodium intake, the longer the elimination half-time. From these and some other observations the investigators concluded that the time to reach sodium balance may increase after salt-sensitivity has been established rather than before that. In other words, the tendency of sodiumsensitive hypertensives to retain more sodium may be a secondary phenomenon.

The data presented in Chapter 4 of this thesis indirectly support those of Wedler and associates. In our hypertensive population the average fall in body sodium was comparable for those with the greatest and those with the least fall in blood pressure. Thus, being more sodium sensitive does not necessarily imply being less able to conserve sodium during a phase of sodium restriction. On the basis of these observations we have come to the conclusion that, although the development of sodium sensitivity may be related to aging or to a decline in renal function, there is as yet no compelling evidence that a tendency to retain an excessive amount of sodium is a primary event in salt-sensitive hypertension. Furthermore, it is difficult to see how a primary renal defect in sodium excretion could be operative only during sodium loading and not during sodium restriction when there is a tendency to lose extra sodium. The latter is precisely what occurred in group 4 of the patients described in Chapter 2 of this thesis. Those patients had the greatest fall in pressure (in other words: were the most sodium-sensitive) and their renal 
adaptation to the new sodium intake appeared to be very slow. Available data, therefore, seem to support the view that the kidney of salt-sensitive people is characterized by an inability to respond fluently enough to (acute) changes in sodium consumption. This abnormality could either reside in the kidney itself or represent a failure to recruite extrarenal mechanisms that are involved in sodium homeostasis such as the renin-angiotensin system. There is also evidence that vascular abnormalities may be involved in sodium sensitivity ${ }^{40,41}$.

Even though a greater degree of sodium sensitivity may be accompanied by a defect in renal sodium excretion, changes in body sodium may be a covariate rather than a cause of salt-sensitive hypertension. In fact, in our studies we could not detect any relationship whatsoever between changes in blood pressure and cumulative sodium loss (Chapter 3 and 4). These results are consistent with those from at least two other studies ${ }^{42,43}$. Another interesting observation that tallies nicely with our data comes from Koomans and coworkers ${ }^{44}$. In patients with endstage renal disease these investigators found an enhanced sensitivity of blood. pressure to changes in sodium intake, and they even noted an inverse correlation between creatinine clearance and the degree of sodium sensitivity. In the same study, however, they observed only a weak relationship between salt-induced increases in extracellular volume and concomitant rises in pressure. Remarkably, for any increment in extracellular volume, the pressure tended to rise steeper in patients with more advanced renal failure. Also in comparison to normal subjects, a similar expansion of extracellular volume was associated with greater rises in pressure in the renal failure patients ${ }^{45}$. Thus, volume retention per se cannot be the sole factor that is making the pressure sodium-sensitive. Although an abnormality of sodium balance may contribute to the degree of sodium sensitivity, it does not seem to be a prerequisite. Likewise, a rightward shift in the pressure-natriuresis curve as suggested by Guylon ${ }^{46}$, may be a secondary rather than a causative phenomenoñ.

\section{The renin-angiotensin system and sodium sensitivity}

Most investigators have described low levels of renin and prorenin ${ }^{26,47}$ or a blunted rise in renin with sodium restriction in salt-sensitive people ${ }^{18,47-51}$. Likewise, sodium-sensitive individuals display a blunted suppression of renin during a highsalt diet, leading to inappropriately high renin levels. However, from a theoretical point of view an unresponsive renin system could merely be due to only modest changes in body sodium during the dietary intervention. With this in mind, we measured cumulative sodium balance during one week of sodium restriction in hospitalized patients with essential hypertension. Renin levels were assessed at the end of this period. In this study (Chapter 3 ) we found, as already stated above, that 
the degree of sodium sensitivity of blood pressure could not be explained by differences in cumulative sodium loss. In fact, when we divided the subjects in tertiles according to the final fall in pressure, the tertile with no change in pressure had the same fall in cumulative sodium balance as the tertile which showed the greatest decrement in pressure. Moreover, the magnitude of the blood pressure fall did not correlate whatsoever with the amount of sodium lost. However, renin levels at the end of the observation period (with all subjects being in sodium balance) were significantly higher in the tertile with no change in pressure than in the tertile with the greatest fall in pressure. These data strongly suggested that not sodium loss, but the degree of renin activation is the key factor which determines to what extent blood pressure responds to alterations in sodium intake.

In a second study (Chapter 4 ) we went a little further by examining the dynamic behavior of renin and aldosterone after a sudden decrease in sodium intake. This study, in a smaller group of patients, confirmed our earlier findings that there is no relationship between cumulative sodium loss and the change in blood pressure. Contrary to others ${ }^{26}$ we could not find a relationship either between baseline renin levels (i.e. when patients were still on their habitual diet) and the final changes in blood pressure. However, a weak positive relationship was observed between the early renin response, that is the rise in renin during the first three days of sodium restriction, and the difference between final and initial blood pressure. In other words, a greater renin response during the first few days of sodium restriction is qssociated with a lesser fall in pressure. Although our data confirmed that salt sensitivity is linked to a blunted responsiveness of the renin system ${ }^{10,19,23,26,42,51,52}$, they also demonstrated that renin levels at the new steady state (i.e. after one week) had no relationship with the ultimate changes in blood pressure. From these data we concluded that a relative or absolute inability of the renin system to change with alterations in salt intake determines the degree of sodium sensitivity of blood pressure. This unresponsiveness (or perhaps delayed responsiveness) is not coupled to the low-renin state as a number of patients with normal renin levels appeared to display the same phenomenon. A relatively 'fixed' renin system may, however, be related to the non-modulator status as described by Hollenberg and coworkers ${ }^{53.54}$. According to their theory the intrarenal production of angiotensin II is inappropriately high in relation to sodium intake, thereby shifting the pressurenatriuresis curve to the right. As attractive as this hypothesis may seem, it does not account for the fact that renal sodium output is sometimes impaired (as during sodium loading) and sometimes facilitated (as during sodium restriction). On the basis of our own data and those from the literature, we have come to an alternative, although related, hypothesis. Assuming that the regulation of volume control takes precedence over other regulatory systems, including those which are engaged with blood pressure, we may explain our findings as follows. When a 
subject is confronted with a sudden decrease in sodium intake, sodium excretion by the kidney will fall only slowly. Counterregulating sodium-conserving mechanisms will be activated to prevent the organism from too great a volume loss. Activation of the renin-angiotensin system probably is one of the main, if not the most important, defense mechanisms against volume depletion. If, for some reason, activation of renin is insufficient the organism faces the threatening of dehydration, necessitating the recruitment of other sodium-conserving mechanisms. As blood pressure itself is a very powerful regulator of sodium excretion, it follows that a drop in pressure may halt ongoing sodium loss. Thus, one could consider the sodium-related fall in pressure as a protective mechanism. In this view, sodium sensitivity of blood pressure is an adaptive phenomenon of volume control rather than a primary abnormality. Exactly the opposite may then occur during sodium loading. Further studies are necessary, however, to put this hypothesis to the test and to explore by which mechanisms blood pressure falls under these circumstances.

\section{The renin-angiotensin system: general aspects}

If the hypothesis presented above is correct, sodium sensitivity of blood pressure is an important protective mechanism coming into play when the renin-angiotensin system fails. But even when our view is wrong, the crucial role of the reninangiotensin system cannot be emphasized enough. In the second part of this thesis, therefore, we have focused our attention on the (patho)physiology of this system. Since we wanted to investigate some fundamental aspects of the function of angiotensin II, the effector peptide of the system, we turned from patients to normal volunteers in order to better understand the physiological mechanisms that are normally involved in cardiovascular regulation.

Classic endocrinology holds the view that the renin-angiotensin system is a circulating system with renin being produced in the kidney and acting in plasma on circulating angiotensinogen. The decapeptide angiotensin I (AngI) which is created by this reaction, is further degraded to the octapeptide angiotensin II (AngII). The latter reaction is catalyzed by angiotensin-converting enzyme (ACE) which is abundantly present in the pulmonary capillary bed. AngII then enters the systemic circulation to exert its effect on various target tissues such as the kidney, the adrenal cortex, the vascular wall and the brain. Local effects are mediated by specific receptors, mainly of the ATI type.

Over the past decade evidence has accumulated in favor of the existence of local renin-angiotensin systems ${ }^{35}$. Since most components of the renin-angiotensin system have been found at the tissue level, it is conceivable that AngIl may be produced locally. In particular, ACE is richly present on the endothelial cells of all blood 
vessels ${ }^{36}$. However, it is still uncertain whether AngII that is present in tissues is formed locally or taken up by tissues from the circulation. The same applies to the other components of the renin-angiotensin system. By means of molecular biological techniques mRNA's for angiotensinogen, renin and ACE have been demonstrated in many tissues involved in cardiovascular regulation ${ }^{55}$, making local synthesis of these substances a distinct possibility. Most of this information, however, has been obtained in experimental animals and it is not certain whether the situation is entirely similar in humans. Some investigators believe that tissue renin, e.g. in the heart, is not locally synthesized, but rather taken up from the circulation $^{57}$. It has to be stressed that tissue renin needs both renin substrate (angiotensinogen) and ACE before it can generate angiotensin II. On the other hand, only tissue ACE is required to allow local conversion of Angl into Angll. Since ACE is so ubiquitously present in the vascular system, local conversion of AngI seems almost inevitable. Accordingly, the functional role of tissue renin is much more debated than the role of tissue ACE. If tissue ACE is functionally active, its substrate AngI may either be synthesized locally or taken up from plasma.

Although it is generally held that most Angl is converted in the pulmonary vascular bed, the quantitative contribution of other vascular beds to conversion of arterially delivered AngI should not be overlooked ${ }^{58}$. Nevertheless, circulating AngII is mainly derived from conversion of blood-borne AngI and there is little evidence that locally converted AngI reaches the circulation in the form of AngII ${ }^{58}$.

Recent observations demonstrate that, especially in the kidney, circulating AngII may accumulate during AngII infusion ${ }^{59}$. These data are compatible with tissue uptake of AngII and suggest that tissue AngII may be derived from two sources: local production and uptake from the circulation.

As described in this thesis we have tried, in a series of experiments, to gain more insight into the possible role of tissue angiotensins in man. The first question we asked ourselves was whether the hemodynamic and humoral effects of circulating angiotensin I should be explained by conversion of AngI into AngII in the plasma compartment or rather by tissue conversion of AngI. Subsequently, we performed two experiments to assess, in man, whether it is possible to discriminate between the effects of blood-borne angiotensin II and those of tissue angiotensin II.

\section{Comparison of the effects of angiotensin I and angiotensin II}

In plasma, Angl circulates in concentrations that are several times higher than those of AngII, suggesting that conversion of AngI in plasma is a slow process. Still, $\mathrm{ACE}$ is a key factor in the production of AngII. A compelling question, therefore, 
is to what extent a rise in circulating AngI is able to produce hemodynamic and humoral effects. One may achieve a rise in plasma Angl by exposing the individual, for instance, to mild volume depletion. This manoeuvre, however, will also increase circulating renin which in turn stimulates the release of AngI and AngII from extrarenal tissue sites $^{60}$. We preferred, therefore, to infuse AngI and to compare the effects of this peptide to those of equimolar doses of AngII. We reasoned that if all infused AngI would be converted to AngII on a 1:1 molar basis, the effects of the two angiotensins should be similar. Any discrepancy between the results of both infusion experiments would likely be related to either insufficient conversion of AngI (in plasma or at the tissue level) or uptake and degradation of Angl. The results of our experiments have been described in Chapter 5 of this thesis. They show that attained plasma levels of AngII following infusion of AngII amount to approximately $80 \%$ of those reached when AngII had been infused. Still, AngI and AngII had similar effects on blood pressure and on aldosterone release suggesting that AngIl concentrations in the target tissues (peripheral vasculature and adrenal cortex) were comparable after AngI and after AngII infusion. Thus, it is tempting to speculate that about. $80 \%$ of the infused AngI had been converted in the plasma, most probably by soluble ACE, whereas the remaining $20 \%$ was converted at the tissue level. These proportions are remarkably similar to those found by others in completely different experiments ${ }^{58,60,61}$. Compared to the changes in blood pressure and in aldosterone, the effects of AngI on the kidney were less than those of Angli. This was not only true for the renal hemodynamic changes but also for the extent of renin suppression. Hence, our data are compatible with those suggesting no or only low-grade conversion of arterially delivered Angl in the kidney $^{58,60,61}$. If this is true, it is likely that the fall in renal perfusion and the suppression of renin occurring during AngI administration are not caused by intrarenally converted AngI, but rather by AngI that has been converted elsewhere in the vascular bed and that has subsequently entered the systemic circulation again as AngII.

\section{Plasma versus tissue angiotensin II}

A matter that is still difficult to pursue in the intact human being is the differentiation between the effects of plasma AngII and those of tissue AngII. As we have argued in Chapter 6 of this thesis, classical pharmacological experiments with either different ACE-inhibitors or drugs that bind to angiotensin receptors, are bound to yield uninterpretable results. In the studies that we performed, and that we have described in Chapters 6 and 7, we attempted to block the formation of AngII by enalaprilate, while at the same time leaving plasma AngII unchanged by a concurrent infusion of this peptide. We have, indeed, succeeded in creating such a 
situation. When subjects were studied, who were in balance on a low salt diet, it soon became evident that there was a marked dissociation in response between the kidney and other tissues. Compared to ACE-inhibition alone (with falling levels of plasma AngII), ACE-inhibition with maintained plasma AngII completely abolished the fall in blood pressure and in aldosterone. Thus, the effects of converting enzyme inhibition on the systemic vasculature and on aldosterone release seem to be mediated entirely by plasma AngII.

Our data further show that the kidney responds differently to interference with AngII formation. While ACE-inhibition alone was associated with substantial vasodilation, the opposite was found during the combined experiment. Since it is difficult to see how renal vasoconstriction could be brought about in the face of unaltered levels of circulating AngII, we assume that the fall in renal plasma flow during combined administration of enalaprilate and angiotensin II is due to an increase in intrarenal AngII levels. Theoretically, the latter could be the result of either enhanced intrarenal production of AngII or of uptake of Angil from the plasma. Again, it is difficult to see why the kidney would speed up the synthesis of AngII during a state of ACE-inhibition with constant plasma levels of AngII. In our view, therefore, renal uptake of AngII is a more likely explanation. Recent experimental data support the potential existence of an uptake mechanism ${ }^{50.62}$. We may now think of the kidney as an organ that becomes 'hungry' for AngII during ACE-inhibition. In other words, when intrarenal leveis of AngII fall, the kidney may start to take up as much AngII as possible from the circulation, even when intrarenal ACE is not entirely blocked. The extracted AngII may be stored in a compartment of the kidney that is relatively protected against angiotensinases. Indeed, others have pointed also to the compartmentalization of angiotensin in the kidney ${ }^{60-62}$. The prolonged presence of AngII in the kidney may thus explain the slow return of renal perfusion and renin release after the combined enalaprilate/angiotensin II infusions (Chapter 6).

We stretched our experimental design a little further by studying subjects not only on a sodium restricted diet but also when they were adhering to a high salt diet. This would allow us to define the role of sodium in the modulation of plasma and tissue AngII. As expected and often described before "high sodium intake blunted all effects of enalaprilate, when given alone. Interestingly, though, we could not find any effect of diet on the alleged tissue AngII. Notably, renal responses were similar on both diets. Since a high salt diet also depletes the kidney from renin and angiotensin $\mathrm{II}$, it is likely that during ACE-inhibition the kidney was equally "hungry" for AngII on both diets. This would explain why both the renovascular and the renin-suppressing action of AngII were similar on both diets when plasma AngII was held constant.

In conclusion, the results of our experiments lend support for the theory that 
tissues can both convert circulating AngI into AngII and extract AngII from the circulation. A special situation seems to exist in the kidney where AngII may exert a prolonged action. The uptake of AngII in renal tissue is probably enhanced under conditions of intrarenal AngII depletion. The latter occurs during ACE-inhibition or during high salt intake. Both conditions render the kidney hungry for AngII. 


\section{References}

1 Antonios TFT, MacGregor GA. Salt-more adverse effects. Lancet 1996;348:250251.

2 Dahl LK. Possible role of salt intake in the development of essential hypertension. In: Cottier P, Bock KD, eds. Essential hypertension: an international symposium. Berlin: Springer Verlag, 1960;61-75.

3 Freis ED. The role of salt in hypertension. Blood Press 1992;1:196-200.

4 Simpson. FO. Salt and hypertension: a sceptical review of the evidence. Cin Sci 1979;57 (suppl 5):463s-480s.

5 Grobbee DE. Electrolyte intake and human hypertension. In: Swales JD, ed. Textbook of Hypertension. Oxford: Blackwell Scientific Publications, 1994;539-551.

6 Intersalt Cooperative Research Group. Intersalt: an international study of electrolyte excretion and blood pressure. Results for 24 hour sodium and potassium excretion. Br Med J 1988;297:319-328.

7 Elliott P, Stamler J, Nichols R, Dyer AR, Stamler R, Kesteloot H, Marmot M for the Intersalt Cooperative Research Group. Intersalt revisited: further analyses of 24 hour sodium excretion and blood pressure within and across populations. Br Med J 1996;312:1249-1253.

8 Smith WCS, Crombie IK, Tavendale RT, Gulland SK, Tunstall-Pedoe HD. Urinary electrolyte excretion, alcohol consumption and blood pressure in the Scottish Heart Health Study. Br Med J 1988;297:329-330.

9 Swales JD. Salt and blood pressure. Blood Press 1992;1:201-204.

10 Weinberger MH. Salt sensitivity of blood pressure in humans. Hypertension 1996:27:481-490.

11 Elliott P. Dyer A. Stamler R. The Intersalt study: results for 24 hour sodium and potassium, by age: and sex. J Hum Hypertens 1989;3:323-330.

12 Khaw KT, Barrett-Connor E. The association between blood pressure, age, and dietary sodium and potassium: a population study. Circulation 1988;77:53-61.

13 Cutler JA, Follmann D. Elliott P, Suh I. An overview of randomized trials of sodiunn reduction and blood pressure. Hypertension 1991;17 (suppl I): 1-27-1-33.

14 Grobbee DE, Hofman A. Does sodium restriction lower blood pressure? $\mathrm{Br}$ Med J 1986;293:27-29

15 Law MR, Frost CD. Wald NJ. Dietary salt and blood pressure. J Hypertens 1991;9 (suppl 6):S37-\$4

16 Law MR, Frost CD, Wald NJ. By how much does dietary salt reduction lower blood pressure? III. Analysis of data from trials of salt reduction. Br Med J 1991:302:819-824.

17 Longworth DL, Drayer JIM, Lieber MA, Laragh JH. Divergent blood pressure. responses during short-term sodium restriction in hypertension. Clin Pharmacol Ther $1980 ; 27: 544-546$ 
18 Kawasaki T, Delea CS, Bartter FC, Smith H. The effect of high-sodium and lowsodium intakes on blood pressure and other related variables in human subjects with idiopathic hypertension. Am J Med 1978;64:193-198.

19 Fujita T, Henry WL, Bartter FC, Lake CR, Delea CS. Factors influencing blood pressure in salt-sensitive patients with hypertension. Am J Med 1980;69:334-344.

20 Weinberger MH. Sodium sensitivity of blood pressure. Curr Opin Nephrol Hypertens 1993;2:935-939.

21 Sullivan JM. Salt sensitivity. Definition, conception, methodology, and long-term issues. Hypertension 1991;17 (suppl I):I-61-I-68.

22 Sharma AM, Schattenfroh S, Kribben A, Distler A. Reliability of salt sensitivity testing in normotensive subjects. Klin Wochenschr 1989;67:632-634.

23 Overlack A, Ruppert M, Kolloch R, Gobel B, Kraft K, Diehl J, Schmitt W, Stumpe KO. Divergent hemodynamic and hormonal responses to varying salt intake in normotensive subjects. Hypertension 1993;22:331-338.

24 Draaijer P, De Leeuw P, Maessen J, Van Hooff J, Leunissen K. Salt-sensitivity testing in patients with borderline hypertension: reproducibility and potential mechanisms. J Hum Hypertens 1995;9:263-269.

25 Weinberger MH, Fineberg NS. Sodium and volume sensitivity of blood pressure. Age and pressure changes over time. Hypertension 1991;18:67-71.

26 Weinberger MH, Miller JZ, Luft FC, Grim CE, Fineberg NS. Definitions and characteristics of sodium sensitivity and blood pressure resistance. Hypertension 1986;8 (supp/ II):II-127-11-134.

27 Luft FC, Miller JZ, Weinberger MH, Christian JC, Skrabal F. Genetic influences on the response to dietary salt reduction, acute salt loading, or salt depletion in humans. J Cardiovasc Pharmacol 1988;12 (suppl 3):S49-S55.

28 Muntzel M, Drüeke T. A comprehensive review of the salt and blood pressure relationship. Am J Hypertens 1992;5:1S-42S.

29 Rose BD. Clinical physiology of acid-base and electrolyte disorders. Third edition. New York: McGraw-Hill Inc, 1989;225-247.

30 Strauss MB, Lamdin E, Smith WP. Bleifer DJ. Surfeit and deficit of sodium. A kinetic concept of sodium excretion. Arch Intern Med 1958;102:527-536.

31 Hollenberg NK. Set point for sodium homeostasis: surfeit, deficit, and their implications. Kidney Int 1980;17:423-429.

32 Simpson FO. Sodium intake, body sodium, and sodium excretion. Lancet $1988 ; 2: 25-29$.

33 Bonventre JV, Leaf A. Sodium homeostasis: steady states without a set point. Kidney Int 1982;21:880-883.

34 Brown WJ Jr, Brown FK, Krishan I. Exchangeable sodium and blood volume in normotensive and hypertensive humans on high and low sodium intake. Circulation 1971;43:508-519.

35 Walser M. Phenomenological analysis of renal regulation of sodium and potassium balance. Kidney Int 1985;27:837-841. 
36 Sagnella GA, Markandu ND, Singer DRJ, MacGregor GQ. Kinetics of sodium excretion during changes in dietary sodium intake in man - an exponential process? Clin Exp Hypertens 1990,A(12):171-178.

37 Van Paassen P, De Zeeuw D, Navis G, De Jong PE. Does the renin-angiotensin system determine the renal and systemic hemodynamic response to sodium in patients with essential hypertension? Hypertension 1996;27:202-208.

38 Hollenberg NK, Williams GH. Abnormal renal sodium handling in essential hypertension: relation to failure to renal and adrenal modulation of responses to angiotensin II. Am J Med 1986;81:412-418.

39 Wedler B, Brier ME, Wiersbitzky M, Gruska S, Wolf E, Kallwellis R, Aronoff GR, Luft FC. Sodium kinetics in salt-sensitive and salt-resistant normotensive and hypertensive subjects. J Hypertens 1992;10:663-669.

40 Draaijer P, Kool MJ, Maessen JM, Van Bortel LM, De Leeuw PW, Van Hooff JP, Leunissen KM. Vascular distensibility and compliance in salt-sensitive and saltresistant borderline hypertension. J Hypertens 1993;11:1199-1207.

41 Draaijer P, De Leeuw PW, Van Hooff JP, Leunissen KM. Nailfold capillary density in salt-sensitive and salt-resistant borderline hypertension. J Hypertens 1993; 11:1195-1198.

42 Fraser R, Davies DL, Zoccali C, Usherwood T, Beretta-Piccoli C, Brown JJ, Cumming AMM, Lever AF, Robertson JS, Watt R. Relation of blood pressure and body sodium content during sodium depletion in normal and hypertensive subjects. I Cardiovasc Pharmacol 1984;6 (suppl 1):S107-S114.

43 Dustan HP, Kirk KA. Corcoran Lecture: the case for and against salt in hypertension. Hypertension 1989;13:696-705.

44 Koomans HA, Roos JC, Boer P, Geyskes GG, Dorhout Mees EJ. Salt sensitivity of blood pressure in chronic renal failure. Evidence for renal control of body fluid distribution in man. Hypertension 1982;4:190-197.

45 Koomans HA, Roos JC, Dorhout Mees EJ. Delawi IMK. Sodium balance in renal failure. A comparison of patients with normal subjects under extremes of sodium intake. Hypertension 1985;7:714-721.

46 Guyton AC. Arterial pressure and hypertension. Philadelphia: WB Saunders;1980.

47 Pecker MS, James GD, Laragh JH, Sealy JE. Plasma prorenin is inversely related to the salt sensitivity in borderline to mild hypertension. II Am Soc Nephrol $1993 ; 4: 537$.

48 Longworth DL, Drayer JIM, Weber MA, Laragh JH. Divergent blood pressure responses during short term sodium restriction in hypertension. Clin Pharmacol Ther 1980;27:544-546.

49 Parfrey PS, Markandu ND Roulston JE, Jones BE, Jones JC, MacGregor GA. Relation between arterial pressure, dietary sodium intake and renin system in essential hypertension. Br Med J 1981;283:94-97.

50 Koolen MI, Van Brummelen P. Sodium sensitivity in essential hypertension: role of the renin-angiotensin-aldosterone system and predictive value of an intravenous frusemide test. J Hypertens 1984;2:55-59. 
51 Sullivan JM, Ratts TE. Sodium sensitivity in human subjects. Hemodynamic and hormonal correlates. Hypertension 1988;11:717-723.

52 Campese VM. Salt sensitivity in hypertension. Renal and cardiovascular implications. Hypertension 1994;23:531-550.

53 Hollenberg NK, Williams GH. Abnormal renal sodium handling in essential hypertension: relation to failure to renal and adrenal modulation of responses to angiotensin II. Am J Med 1986;81:412-418.

54 Williams GH, Hollenberg NK. 'Sodium-sensitive' essential hypertension: emerging insights into pathogenesis and therapeutic implications. Contemp Nephrol 1985:3:303-331.

55 Dzau VJ, Pratt RE. Cardiac, vascular, and intrarenal renin-angiotensin systems in normal physiology and disease. In: Robertson JIS, Nicholls MG, Eds. The reninangiotensin system, vol 1. London: Gower Medical Publishing, 1993;42.1-42.11.

56 Caldwell PRB, Seegal BC, Hsu KC, Das M, Soffer RL. Angiotensin-converting enzyme: vascular endothelial localization. Science 1976;191:1050-1051.

57 Danser AHJ, Van Kats JP, Admiraal PJJ, Derkx FHM, Lamers JMJ, Verdouw PD, Saxena PR, Schalekamp MADH. Cardiac renin and angiotensins: uptake from plasma versus in situ synthesis. Hypertension 1994;24:37-48.

58 Admiraal PJJ, Danser AHJ, Jong MS, Pieterman H, Derkx FHM, Schalekamp MADH. Regional angiotensin II production in essential hypertension and renal artery stenosis. Hypertension 1993:21:173-184.

59 Zou L-X, Hymel A, Imig JD, Navar LG. Renal accumulation of circulating angiotensin II in angiotensin II-infused rats. Hypertension 1996;27:658-662.

60 Admiraal PJJ. In vivo production of angiotensins I and II. Thesis, Rotterdam;1993.

61 Danser AHJ, Koning MMG, Admiraal PJ, Sassen LMA, Derkx FHM, Verdouw PD, Schalekamp MADH. Production of angiotensins I and II at tissue sites in the intact pig. Am J Physiol 1992;263:H429-H437.

62 Van Kats JP, Danser AHJ, Van Meegen JR, Verdouw PD, Schalekamp MADH. Angiotensin I-II conversion in the kidney. J Hypertens 1996;14 (suppl 1):S73 (abstract). 


\section{Chapter 9}

\section{Summary and}

concluding remarks 


\section{Summary and concluding remarks}

This thesis deals with two important aspects of blood pressure control: body sodium and the renin-angiotensin system. Over the past century both factors have received ample attention in the literature. Still, their respective roles in the pathogenesis and maintenance of hypertension are only poorly understood.

Normally, an increase in sodium intake with a concurrent rise in body sodium will suppress renin, angiotensin and aldosterone. With a reduction in sodium intake the opposite occurs. The renin-angiotensin-aldosterone system is primarily a system involved in the homeostasis of body sodium but it has also clear blood pressure raising effects. A disturbed balance between body fluid volumes and the activity of the renin-angiotensin system may, therefore, have pathophysiological significance, not only in hypertension but also in, for instance, congestive heart failure.

The aim of the present thesis was to explore in more detail some fundamental aspects of sodium handling by the kidney and the role of the renin-angiotensin system as a function of sodium balance.

In chapter 1 a brief introduction is given about hypertension, some pathophysiological mechanisms in this disorder and the general aims of the studies.

In chapter 2 the response of the kidney to a sudden reduction in sodium intake is explored. As it is generally assumed that urinary sodium output falls according to an exponential function, the rate constant of the decay function must vary considerably between individuals if one is to explain large variations in cumulative sodium loss between individuals. To examine differences in sodium output following sudden sodium restriction, ninety untreated essential hypertensives were admitted to a metabolic ward for seven days and put on a sodium restricted diet of $55 \mathrm{mmol} /$ day. In these patients changes in urinary sodium excretion were rather variable and could be described by at least four different patterns. One group gradually reached sodium balance according to an exponential function, whereas another group showed an abrupt fall in sodium excretion on the third day of sodium restriction and an extremely fluctuating sodium excretion thereafter. A third group reached sodium balance on day four, but displayed a rise in sodium excretion during the following days and a fourth group attained sodium balance only very slowly or not at all. Compared to the others, the latter group lost more sodium and at the same time displayed a greater fall in blood pressure.

On the basis of these data we concluded that there are multiple patterns by which sodium balance can be reached following a reduction in sodium intake. 
In chapter 3 we investigated whether a certain degree of sodium sensitivity of blood pressure in essential hypertensives during sodium restriction is related to cumulative sodium loss. To this end one hundred and seventeen untreated essential hypertensives were admitted to a metabolic ward for seven days and put on a sodium restricted diet of $55 \mathrm{mmol} /$ day. During these seven days urinary excretion of sodium was determined daily and so was blood pressure. Active plasma renin concentration and some other variables were assessed after seven days under steady state condition.

Based on the final changes in blood pressure the population was divided into tertiles with tertile 1 displaying the greatest fall in blood pressure from day 1 to day 7 and tertile 3 showing almost no change in blood pressure. The data from this study show that cumulative sodium losses were similar between the tertiles and that changes in blood pressure are not correlated to the amount of sodium lost by the body. However, levels of renin appeared to be significantly higher in tertile 3 as compared to tertile 1 which was the most sodium sensitive one. Therefore, the data suggest that sodium sensitivity of blood pressure in essential hypertensive subjects is not determined by sodium status, but rather by renin. In addition, the results indicate that sodium sensitivity is a gradual phenomenon and that one should not dichotomize patients into a sodium sensitive and a sodium resistant group simply on the basis of an arbitrary cut-off point.

In chapter 4 these observations were stretched a little further. The purpose of the study presented in that chapter was to explore whether the degree of sodium sensitivity of blood pressure depends upon renin activation during steady state or upon initial renin activation during the first days of sodium restriction. This study was carried out in sixty-seven untreated essential hypertensive patients along the same lines as the study presented in chapter 3. Besides measurements in steady state condition (after seven days) active plasma renin concentration and aldosterone were also assessed during the first three days of sodium restriction. The results of this study show that both baseline sodium excretion and the activation of renin during the first three days predict total sodium loss after seven days. Changes in blood pressure were not related to changes in sodium balance, but they were to baseline blood pressure and renin activation during the early phase of sodium restriction. In addition, blood pressure appeared to fall more when the normal relationship between sodium loss and early (but not late) activation of renin was disturbed. It was concluded that sodium sensitivity of blood pressure during sodium restriction is linked to a relative unresponsiveness of the renin system during the early phase of sodium loss rather than to absolute renin levels during steady state. 
Because the importance of the renin-angiotensin system had been amply demonstrated by the foregoing studies, attention was now directed towards the function of this system in normal men. The second part of this thesis, therefore, deals specifically with angiotensin I conversion and tissue effects of angiotensin II.

In chapter 5 the systemic and renal effects of equimolar doses of angiotensin I and angiotensin II were compared in order to determine whether the effects of angiotensin I can be fully explained by conversion of angiotensin I into angiotensin II in the plasma compartment. To this end ten healthy volunteers who were in balance on a sodium-restricted diet were studied on two separate occasions during which, in random order, infusions of either angiotensin I or angiotensin II were given in stepwise increasing doses. Mean arterial pressure heart rate, effective renal plasma flow, glomerular filtration rate, renin, angiotensin I, angiotensin II and aldosterone were assessed at baseline, after each dose of angiotensin I or II and thirty minutes and sixty minutes after discontinuation of these infusions.

The results of these experiments indicate that the rise in angiotensin II was significantly lower during the angiotensin I infusion than during the angiotensin II infusion $(\mathrm{p}<0.05)$. The increments in blood pressure and aldosterone and the decrease in glomerular filtration rate, however, were comparable during both infusion regimens. In the kidney, on the other hand, the fall in renin and renal plasma flow during the angiotensin II infusion exceeded those during infusion of angiotensin $1 \quad(p<0.05)$. After cessation of either infusion, angiotensin II concentrations returned to baseline as did blood pressure, renal plasma flow and aldosterone. Only renin remained significantly inhibited $(p<0.05)$. These data strongly suggest that the effects of angiotensin I on blood pressure and aldosterone release may be brought about by angiotensin II, formed, at least partly, from angiotensin $\mathrm{I}$ at tissue sites. However, due to a low capacity of the kidney to convert angiotensin $\mathrm{I}$, the renal effects of angiotensin $\mathrm{I}$ are less prominent than those of angiotensin II. The longer-lasting inhibition of renin after cessation of the angiotensin infusion points towards accumulation of angiotensin II in the kidney.

In chapter 6 it is examined whether it is possible to discriminate between the effects of tissue and plasma angiotensin II in man. To this end the ACE-inhibitor enalaprilate was either infused alone or together with an infusion of angiotensin II. With the latter manoeuvre plasma angiotensin II levels were maintained at baseline levels. Comparison of both infusion regimens allowed to discriminate between effects that are entirely dependent upon plasma angiotensin If versus those that are related to tissue angiotensin II. This study shows that maintenance of plasma angiotensin II during ACE-inhibition elicits renal vasoconstriction and incompletely suppresses renin, while leaving blood pressure and aldosterone levels unchanged. After cessation of the angiotensin II infusion, renal vasoconstriction persists and the more so when higher doses of angiotensin II had been used. These effects could be 
related to renal uptake of angiotensin II from the circulation.

To explore whether the tissue effects of angiotensin II are modified by alterations in sodium intake, the same study was undertaken in volunteers during both a low and a high sodium diet. Data from this study, described in chapter 7 clearly demonstrate that most effects of ACE-inhibition are sodium-dependent when plasma angiotensin II is allowed to fall. When plasma angiotensin II is maintained, however, the observed effects are similar on both diets. The most likely explanation for these observations is that the infusion of angiotensin II had loaded the tissues (in particular the kidney) with this peptide which was subsequently protected from degradation for some time.

When all the data from this study are taken together, it can be concluded that the renin-angiotensin system plays a key role in determining the degree of sodium sensitivity. Whereas it is still unknown why activation of renin fails in some people, it seems that an unresponsive renin system carries the risk of too great a volume loss during sodium restriction. One can now entertain the hypothesis that under such conditions blood pressure has to fall in order to limit furiher sodium losses. This hypothesis needs to be tested in future experiments.

The renin-angiotensin system exerts its effects both through circulating angiotensin II and through angiotensin II that is present in tissues, notably the kidney. The data in this thesis lend support to the hypothesis that tissue depletion of angiotensin II may make tissue 'hungry' for this peptide. Specifically, this seems to be true in the kidney. It is worthwhile, therefore, to test this hypothesis in more detail and to assess whether ACE-inhibitors with different lipophilicity have different effects on tissue levels of angiotensins. 


\section{Chapter 10}

\section{Samenvatting}




\section{Samenvatting}

Dit proefschrift belicht twee belangrijke aspecten van de bloeddrukregulatie: de zouthuishouding van het lichaam en het renine-angiotensine systeem. Gedurende de laatste eeuw zijn beide aspecten ruimschoots in de literatuur aan bod geweest. Desalniettemin is hun beider rol in het ontstaan en het onderhouden van hypertensie nog steeds onvoldoende bekend.

Onder normale omstandigheden leidt een toename van zoutconsumptie met een gelijktijdige stijging van het lichaams natrium(=zout) tot onderdrukking van het renine-angiotensine-aldosteron systeem. Het tegenovergestelde gebeurt wanneer het zoutgebruik wordt gereduceerd. Het renine-angiotensine-aldosteron systeem is echter niet alleen betrokken bij de homeostase van het lichaamsnatrium en (indirect) het circulerend volume, maar ook beïnvloedt dit systeem de bloeddruk. Een verstoorde balans tussen het circulerend volume en de activiteit van het renineangiotensine systeem kan daarom pathofysiologisch van betekenis zijn, niet alleen in het geval van hypertensie, maar ook bijvoorbeeld bij hartfalen.

Dit proefschrift beoogt enkele fundamentele aspecten van het renine-angiotensine systeem in het kader van de regulatie van zoutbalans en bloeddruk te hestuderen

In hoofdstuk 1 wordt een korte inleiding gegeven over hypertensie, enkele pathofysiologische mechanismen van deze aandoening en de algemene vraagstellingen die leidden tot de in dit proefschrift beschreven studies.

In hoofdstuk 2 wordt de reactie van de nier op een acute vermindering van de zoutconsumptie bestudeerd. Indien, zoals tot nu toe werd verondersteld, de zoutexcretie door de nier afneemit volgens een exponentiële functie, dan zal de snelheidsconstante van deze functie aanzienlijk moeten verschillen tussen individuen, als men tenminste de grote verschillen in het cumulatieve zoutverlies tussen verschillende patiènten wil verklaren. Om mogelijke inter-individuele verschillen in zoutuitscheiding na een acute reductie in het zoutgebruik te onderzoeken, werden negentig patiënten met essentiële hypertensie gedurende zeven dagen opgenomen. Gedurende deze opname nuttigden zij een zoutbeperkt dieet van $55 \mathrm{mmol}$ natrium (=3 gram zout) per dag. In deze patiënten waren de veranderingen in de zoutexcretie zeer variabel en kon het beloop van de 24 uurs natriumexcretie worden beschreven aan de hand van tenminste vier verschillende patronen. Één groep kwam geleidelijk in zoutbalans, volgens een exponentiële functie, terwijl een andere groep initieel een abrupte daling van de zoutexcretie liet zien gevolgd door een zeer fluctuerende excretie. De derde groep kwam in zout balans op de vierde dag, maar liet een duidelijke stijging zien in natriumexcretie gedurende de 
daaropvolgende dagen, terwijl de vierde groep slechts zeer langzaam of geheel niet in balans kwam. Vergeleken met de andere groepen, verloor deze laatste groep dan ook het meeste zout en vertoonde daarbij ook een sterkere daling in de bloeddruk. Aan de hand van deze gegevens werd geconcludeerd dat er verschillende patronen zijn waarmee individuen na een plotse vermindering van het zoutgebruik in balans geraken.

In hoofdstuk 3 werd vervolgens onderzocht of een zekere mate van zoutgevoeligheid van de bloeddruk in patiënten met essentiële hypertensie gedurende zoutrestrictie gerelateerd is aan het cumulatieve zoutverlies. Om dit na te gaan kregen honderdenzeventien onbehandelde hypertensieve patiënten gedurende zeven dagen een zoutbeperkt dieet van $55 \mathrm{mmol}$ natrium (=3 gram zout) per dag. Gedurende deze zeven dagen werden zowel de natriumexcretie in de 24 uurs urine als de bloeddrukveranderingen vastgelegd. De actieve plasma renine concentratie en enkele andere variabelen werden gemeten na zeven dagen in de 'steady state' situatie.

Aan de hand van de uiteindelijke veranderingen in bloeddruk werd de onderzochte populatie in tertielen verdeeld, waarbij tertiel 1 de grootste bloeddrukdaling ten toon spreidde van dag één tot dag zeven, terwijl in tertiel 3 vrijwel geen bloeddrukverandering optrad. De resultaten van deze studie lieten zien dat het cumulatieve zoutverlies in de drie tertielen gelijk was en dat de veranderingen in bloeddruk niet gecorreleerd zijn aan het totaie zoutverlies van het lichaam. De steady state renine concentraties, bleken echter in tertiel 3 hoger te zijn dan in tertiel 1 (het meest zoutgevoelige tertiel). Deze uitkomsten pleiten voor de hypothese dat de zoutgevoeligheid van de bloeddruk in essentieel hypertensieve patiënten niet word bepaald door de zoutbalans, maar eerder door het renine. Bovendien tonen deze resultaten nog eens dat zoutgevoeligheid van de bloeddruk een gradueel fenomeen is en dat patiënten niet geclassificeerd kunnen worden als zoutgevoelig of zoutongevoelig op grond van een arbitrair afkappunt.

In hoofdstuk 4 werden deze waarnemingen nog wat verder uitgediept. Het doel van de in dit hoofdstuk beschreven studie was om te ontdekken of de mate van zoutgevoeligheid van de bloeddruk afhankelijk is van de mate van renine-activatie tijdens steady state of van de renine activatie gedurende de eerste paar dagen van de zoutbeperking. Deze studie werd uitgevoerd in zevenenzestig onbehandelde hypertensiepatiënten, grotendeels volgens hetzelfde protocol als dat van de studie in hoofdstuk. 3. Naast bepalingen in steady state (na zeven dagen) werden het renine en het aldosteron ook bepaald gedurende de eerste drie dagen van de zoutbeperking. De resultaten van deze studie laten zien dat zowel de initiële zoutexcretie als de activatie van het renine gedurende de eerste drie dagen een 
voorspellende waarde hebben voor het uiteindelijke zoutverlies na zeven dagen. De veranderingen in bloeddruk waren ook nu niet gerelateerd aan veranderingen in de zoutbalans, maar wel aan de initièle bloeddruk en de mate van renine activatie gedurende de vroege fase van de zoutrestrictie. Bovendien leek de bloeddruk meer te dalen wanneer de normale relatie tussen zoutverlies en de vroege activatie van renine verstoord was. Hieruit werd geconcludeerd dat de zoutgevoeligheid van de bloeddruk tijdens zoutbeperking eerder gekoppeld lijkt aan een relatieve ongevoeligheid van het renine systeem gedurende de vroege fase van het zoutverlies dan aan de absolute renine concentraties gedurende steady state.

Aangezien de betrokkenheid en relevantie van het renine-angiotensine systeem duidelijk was aangetoond in de voorgaande studies, werd de aandacht vervolgens gericht op de functie van dit systeem in de gezonde mens.

Het tweede gedeelte van dit proefschrift gaat dan ook over de conversie van angiotensine İ en de weefseleffecten van angiotensine II.

In hoofdstuk 5 werden de systemische en renale effecten van equimolaire hoeveeiheden van angiotensine I en angiotensine II vergeleken om te kunnen bepalen of de effecten van circulerend angiotensine I geheel kunnen worden verklaard door omzetting van angiotensine I in angiotensine II in het plasma compartiment. Hiervoor werden tien gezonde vrijwilligers, in zoutbalans op een zoutbeperkt dieet, op twee verschillende dagen onderzocht. Gedurende deze experimenten werd in willekeurige volgorde, ofwel angiotensine I ofwel angiotensine II in oplopende doseringen toegediend. De gemiddelde bloeddruk, de effectieve nierdoorbloeding en glomerulaire filtratiesnelheid, alsmede het renine, het angiotensine I en II en het aldosteron werden bepaald bij de start, na iedere dosis angiotensine I of II en respectievelijk dertig en zestig minuten na het stoppen van de infusies.

De resultaten van deze experimenten geven aan dat de stijging van het plasma angiotensine II na angiotensine I infusie significant kleiner was dan na angiotensine II infusie. De stijging in bloeddruk en aldosteron concentratie aan de ene kant en de daling in glomerulaire filtratiesnelheid aan de andere kant waren niet versehillend gedurende beide infusies. Dit in tegenstelling tot de daling van het renine en de nierdoorbloeding welke gedurende de angiotensine Ill infusie duidelijk sterker was dan gedurende de angiotenine I infusie. Na het stoppen van beide infusies daalden de angiotensine II concentraties naar het uitgangs niveau, evenals de bloeddruk, de nierdoorbloeding en het aldosteron. Alleen het renine bleef significant onderdrukt. Deze uitkomsten suggereren dat de effecten van angiotensine ! op de bloeddruk en de aldosteron afgifte kunnen worden verklaard door omzetting van angiotensine I in angiotensine II, waarbij conversie waarschijnlijk ten dele op weefselniveau plaatsvindt. In de nier echter zijn de 
effecten van angiotensine I minder uitgesproken dan die van angiotensine II. Dit hangt mogelijk samen met een lage angiotensine-omzettingscapaciteit in de nier. De nog voortdurende renine-inhibitie na het stoppen van de angiotensine infusies wijst mogelijk op accumulatie van angiotensine in de nier.

In hoofdistuk 6 wordt vervolgens onderzocht of het mogelijk is onderscheid te maken tussen de effecten van weefsel en plasma angiotensine II in de mens. Daartoe werd de ACE-remmer enalaprilaat of wel alleen of wel in combinatie met angiotensine II geïnfundeerd. Met deze angiotensine II infusie werd beoogd de plasma concentraties van angiotensine II op uitgangsniveau te houden. Het vergelijk tussen de twee infusieschema's (enalaprilaat alleen versus de gecombineerde infusie met angiotensine II) maakte het mogelijk om onderscheid te maken tussen effecten welke volledig afhankelijk zijn van het plasma angiotensine II en de effecten gerelateerd aan een extraplasmatisch mechanisme, waarschijnlijk het weefsel angiotensine II. Deze studie laat. zien dat het handhaven van plasma angiotensine II spiegels tijdens ACE-inhibitie gepaard gaat met vasoconstrictie in de nier en een onvolledige suppressie van het renine, terwijl bloeddruk en de aldosteron spiegels onveranderd blijven. Na het beëindigen van de angiotensine infusie blijft de renale vasoconstrictie voortduren. Deze vasoconstrictie is zelfs sterker naarmate voorafgaand een hogere dosis angiotensine II is geïnfundeerd. Dergelijke effecten zouden verklaard kunnen worden doordat de nier angiotensine II vanuit de circulatie opneemt en opslaat.

Om te kunnen bepalen of de weefseleffecten van angiotensine II worden beïnvloed door zout, werd dezelfde studie uitgevoerd bij vrijwilligers tijdens zowel een zoutbeperkt als een zoutverrijkt dieet. De uitkomsten van deze studie, beschreven in hoofdstuk 7 geven duidelijk aan dat de meeste effecten van ACE-inhibitie zoutafhankelijk zijn, als het plasma angiotensine II daalt. Wanneer echter het plasma angiotensine II gelijk wordt gehouden, zijn de effecten van ACE-inhibitie op beide dieten gelijk. De meest aannemelijke verklaring voor deze waarnemingen is dat de angiotensine II infusie de verschillende weefsels (met name de nier) heeft opgeladen met dit peptide dat vervolgens in deze weefsels gedurende enige tijd wordt beschermd tegen afbraak.

Wanneer alle uitkomsten van het in dit proefschrift beschreven onderzoek in ogenschouw worden genomen, kan worden geconcludeerd dat het renineangiotensine systeem een sleutelrol speelt bij het bepalen van de mate van zoutgevoeligheid. Hoewel het nog steeds onbekend is, waatom in sommige mensen het renine niet adequaat reageert, iijkt het erop dat een niet reagerend renine een groter volumeverlies tijdens de fase van zoutbeperking tot gevolg heeft. Men zou zelfs kunnen beredeneren dat onder zulke omstandigheden de bloeddruk wel moet dalen om het. zoutverlies zoveel mogelijk te beperken. Deze hypothese moet in 
toekomstige experimenten getest worden.

Het renine-angiotensine systeem oefent zijn effect uit via enerzijds het circulerende angiotensine II en anderzijds het angiotensine II dat aanwezig is in de weefsels, met name in de nier. De resultaten van de in dit proefschrift beschreven studies onderbouwen de hypothese dat depletie van angiotensine II in de weefsels deze weefsels "hongerig" maakt voor dit peptide. Dit lijkt met name het geval te zijn in de nier. Het is daarom de moeite waard om deze hypothese verder te toetsen en te bezien of bijvoorbeeld ACE-remmers met verschillende lipofiliciteit ook verschillende effecten veroorzaken met betrekking tot de weefsel concentraties van angiotensines. 
Dankwoord 


\section{Dankwoord}

Aan het begin van mijn AIO-schap leefde ik nog in de veronderstelling dat een promotieonderzoek toch wel in twee jaar kon worden afgerond. Dit idee veranderde echter al heel snel. Vlak na het vertrek van mijn toenmalige co-promotor werd alle hoop op een voorspoedig einde de bodem ingeslagen en meende ik dat ik de voorgeschreven termijn van vier jaar zou gaan overschrijden. Dat het uiteindelijk drie jaar geworden is, zegt niet zoveel over mijn inzet en werklust, als wel over die van een aantal belangrijke sleutelfiguren rondom mij. Zonder hen was het nooit gelukt!!!

Allereerst mijn promotor Prof. dr P.W. de Leeuw, met wie dit dankwoord begint, maar ook zal eindigen. Beste Peter, de afgelopen tweeënhalf jaar ben je niet alleen mijn promotor geweest, maar tevens ook een onnavolgbare co-promotor. Daar waar andere promotoren zich alleen bezig houden met de zgn. finishing touch, ben jij bij ieder onderdeel van dit promotie-onderzoek onmisbaar gebleken. Zonder jouw heldere kijk op mijn wetenschappelijke zaak had dit boekje zeker langer op zich laten wachten. Vooral wat betreft de analyse van de onderzoeksresultaten waren jouw invallen (met name die na één uur 's nachts) keer op̣ keer van onschatbare waarde. Ik heb veel van je geleerd en het feit dat het proefschrift nu klaar is, betekent gelukkig niet dat onze samenwerking ten einde is.

Verder wil ik mijn andere promotor Prof. dr H.F.P Hillen bedanken voor zijn bijdrage aan de 'eindspurt'. Beste Harry, zonder jouw aansporing en bovendien jouw vertrouwen dat het me zou lukken was dit boekje niet in 1996 verschenen.

Zonder de steun van de mensen van het hypertensie-lab was het onderzoek niet alleen een onmogelijke maar ook een saaie taak geweest. Één van de juwelen van het hypertensie-lab is ongetwijfeld Monique Fuss. Beste Monique, geruisloos en schijnbaar moeiteloos heb je bergen werk verzet in het kader van mijn promotieonderzoek. Ondanks de smakeloze dieten deden, mede door jouw opgewektheid, veel patiënten en proefpersonen maar wat graag mee aan een angiotensine 'experimentje' op lab 1. Ook nu weer in de hoedanigheid van paranimf kan ik op je rekenen.

Boy Houben, Paul van Es, Claudia de Haan en Arie Lavrijssen hebben mij wegwijs gemaakt wat betreft de bediening van alle apparatuur. Boy, jij hebt mij de kunst van de conjunctiva metingen bijgebracht. Alhoewel de resultaten niet in dit proefschrift zijn beschreven gaan we dat zeker nog een keer doen in de vorm van artikelen. Gusta Frijns en Paul van Es wil ik beide bedanken voor de gezellige samenwerking in het kader van alle klinische trials, die naast het promotieonderzoek ook gewoon doorgingen.

Wie nu denkt dat er alleen gewerkt werd, heeft het mis. Het hypertensie-lab of 
een gedeelte ervan was regelmatig te vinden bij, 'Da Roberto' of bij de Griek.

De afgelopen jaren hebben een aantal studenten zich belangeloos ingezet voor mijn onderzoek. Sergio Rodriguez, Astrid Otten, Wilco Spiering en Jeroen Renzema hebben de werklast aanzienlijk verlicht. Met name Sergio is onlosmakelijk verbonden met het onderzoek. Deze 'regelneef' (en dat is eerbiedig bedoeld) weet alles en iedereen in te zetten voor het goede wetenschappelijke doel.

Dank aan Nicolaas Schaper, Frank Huvers, Bram Kroon, Erik van Beek en Louis Peeters, die naast de vaste hypertensie kern iedere donderdagavond deel uitmaakten van het wetenschappelijke brainstorm groepje en op deze manier bijdroegen aan het bijsturen van mijn onderzoek.

De afdeling diëtetiek en in het bijzonder Lianne Schoorlemmer ben ik erkentelijk voor het verzorgen van de dieten van al die patiënten en proefpersonen die aan het onderzoek meededen.

Verder ben ik het neurohumorale lab dank verschuldigd. Jet Bost, Geertje Swennen en Paul Schiffers hebben de afgelopen jaren niet zelden onder grote werkdruk de ontelbare neurohumorale monsters bepaald.

Toen ik al begonnen was in het Maaslandziekenhuis heeft Tiny Wouters de layout van dit proefschrift geheel op haar schouders genomen, zodat haar wat dit betreft alle eer toekomt.

De leden van de beoordelingscommissie, Prof. dr H.A.J. Struyker Boudier, Prof. dr M.P. van Diejjen-Visser en Prof. dr H.J.J. Wellens wil ik danken voor het kritisch beoordelen van mijn manuscript. I also would like to thank Prof. dr N.K. Hollenberg and Prof. dr H.R. Brunner for their willingness to review my manuscript and to be present at my thesis defense.

Mijn beide ouders wil ik bedanken voor hun nimmer aflatende vertrouwen in mij. Lieve Mam en Pap, zonder jullie steun en liefde was het allemaal niet mogelijk geweest. Ook in deze fase van mijn leven is jullie hulp van vitaal belang gebleken, want in deze laatste maanden hebben jullie heel wat uurtjes op Diederick gelet, zodat ik mij met een gerust hart kon wijden aan het schrijven van dit boekje.

Mijn zus Anne Marie ben ik dankbaar voor het feit dat ze ondanks haar eigen drukke werkzaamheden mijn paranimf wou zijn.

Diederick, lief kereltje, dank je voor de uurtjes die we met z'n drieën hebben doorgebracht, pappa en ik achter de computer en jij in de Maxi Cosi op de grond. $\mathrm{Nu}$ het boekje klaar is gaan we ook eens wat leukere dingen doen.

Lieve Peter, zoals beloofd aan het begin van dit dankwoord ben jij ook degene met wie ik eindig. Zo is de cirkel rond. Niet minder belangrijk dan de rol van promotor was je rol als mijn partner. Afgezien van jouw wetenschappelijke steun had ik jouw emotionele steun niet kunnen ontberen. 


\section{Curriculum Vitae}




\section{Curriculum Vitae}

Marielle Krekels werd geboren op 20 december 1967 te 's-Gravenhage. In 1986 behaalde zij het gymnasium-B diploma aan het Gymnasium Sorghvliet te 's-Gravenhage. Omdat zij werd uitgeloot voor de studie Geneeskunde, startte zij dat jaar met de studie Biologie aan de Rijksuniversiteit Leiden. Het jaar daarop, in 1987, begon zij met de studie Geneeskunde aan de Erasmus Universiteit in Rotterdam. Als $3^{e}$ en $4^{e}$-jaars studente was zij werkzaam als student-assistent op het Endocrinologie laboratorium (Hoofd: Prof. dr J.C. Birkenhäger en Prof. dr G. Hennemann). Gedurende haar doctoraal periode liep zij een stage Interne Geneeskunde in Engeland (Queen Elisabeth Hospital, Birmingham, hoofd: Prof. dr M. Shepard) en een stage Gynaecologie in Italië (Ospedale Università di Bari, Bari, hoofd: Prof. dr L. Selvaggi). In 1993 behaalde zij cum laude het artsexamen waarna zij in datzelfde jaar begon als assistent in opleiding (AIO) bij de werkgroep Nefrologie/Hypertensie/Transplantatie (Hoofd: Prof. dr P.W. de Leeuw), Vakgroep Interne Geneeskunde, AZM/RL en Cardiovascular Research Institute Maastricht (CARIM). Van november 1993 tot en met juni 1996 werkte de auteur aan de in dit proefschrift beschreven experimenten. In april 1996 ontving zij daarvoor de eerste prijs in het kader van de promovendi-competitie ter gelegenheid van tien jaar academisering van het AZM. Vanaf oktober 1996 is zij aangesteld als assistent-geneeskundige niet in opleiding op de afdeling Interne Geneeskunde van het Maaslandziekenhuis alwaar zij per 1 april 1997 zal beginnen met de opleiding tot internist (opleider: Dr. B.J Looij). 


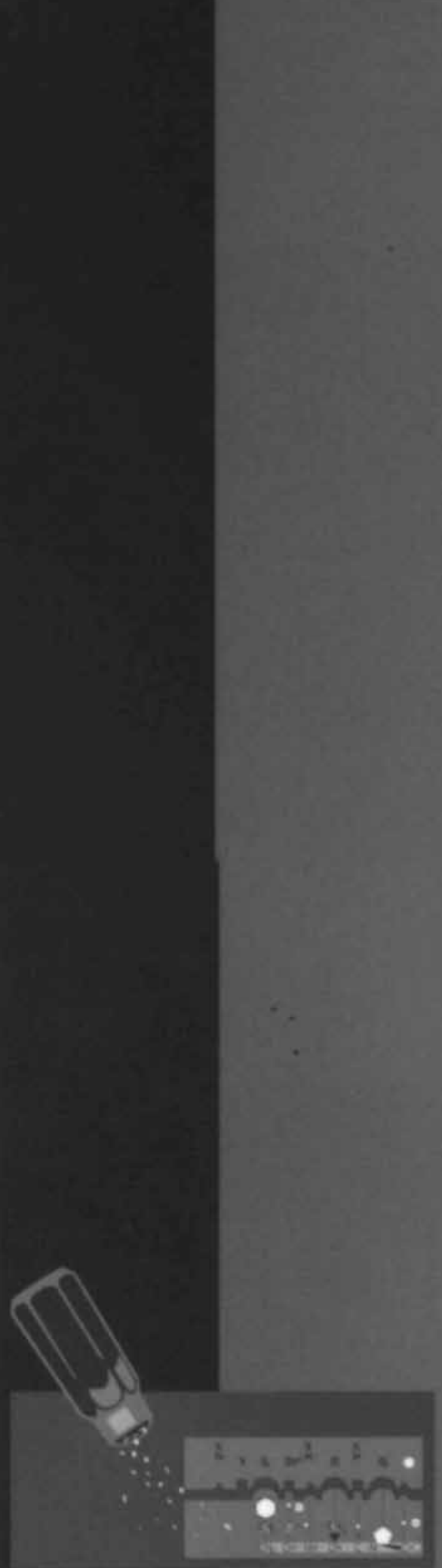

